\title{
LEADERSHIP STYLES - A COMPARATIVE ANALYSIS OF PTD OFFICERS AND DG OFFICERS IN THE MINISTRY OF EDUCATION MALAYSIA
}

\author{
by
}

SHAHRIZAL NORWAWI

A thesis submitted to the Victoria University of Wellington, New Zealand in partial fulfilment of the requirements for the degree of Master of Education

NOVEMBER 2010 
To my darlings Sofea and Sara.

Words can never replace how much I love the both of you. 


\begin{abstract}
The purpose of this study is to explore the leadership styles of middle level managers working in the Ministry of Education Malaysia. The middle level managers in this research are restricted to those from the Administrative and Diplomatic Officers Scheme of service (PTD: Skim Pegawai Tadbir dan Diplomatik) and Education Officers Scheme of service (DG: Skim Pegawai Perkhidmatan Pendidikan Siswazah/Bukan Siswazah). Leadership style, in this study, is defined as the extent to which a leader exhibits transformational, transactional and/or laissez-faire styles of leadership. This study adopts a mixed methods approach in helping to elicit information pertaining to the leadership styles of the PTD and DG middle level managers. A Multifactor Leadership Questionnaire (MLQ) 5x rater form is used in the quantitative strand while the qualitative part of this study utilises a standardised open-ended interview approach. A total of 122 respondents working in ten departments in the Ministry of Education answered the questionnaire while eight middle level managers (four PTD and four DG middle level managers) were interviewed. The results of both of the quantitative and qualitative strands indicate that the PTD and DG middle level managers showed more transformational leadership styles as compared to transactional leadership styles. In addition, the t-test reveals that the two groups of middle level managers do not show any significant differences in terms of their leadership styles. The findings also indicate that there were no significant differences in the perceptions of the overall transformational, transactional and laissez-faire leadership styles of the PTD middle level managers as perceived by their subordinates from different schemes of service. However, the same could not be said of DG middle level managers as their overall transformational as well as laissez-faire leadership styles indicate significant differences as perceived by subordinates from different schemes of service. This study will benefit the Malaysian public sector in understanding the different styles of leadership among middle level managers working in government organization. More specifically, this study is useful for understanding the similarities and differences of leadership styles of the DG and PTD middle level managers working in the Ministry of Education Malaysia.
\end{abstract}




\section{Acknowledgments}

All praise and gratitude be given to God the Merciful for giving me great strength, patience and courage to live life to the fullest every single day.

I was not able to complete this thesis without the guidance of my supervisor Associate Professor Kabini Sanga for whom I owe my highest appreciation and gratitude.

My deepest appreciation and affection goes to my wonderful wife for the never ending support. I could have not done this without you.

I could not have made this journey succesful without the constant support of my parents. Mummy and Abah, thank you from the bottom of my heart.

A big thank you also goes out to my wonderful colleagues at the Examinations Syndicate; Ministry of Education, who have helped me discovered my true potential and ability.

To the Scholarship Division, Ministry of Education, thank you for giving me the opportunity to pursue my Masters degree at Victoria University of Wellington, New Zealand.

Finally, to my family and friends in Wellington and Malaysia, thanks for making my ‘journey’ together with my wife and kids meaningful. 


\section{TABLE OF CONTENTS}

Abstract

Acknowledgement

Table of Contents

iii

List of Tables

vii

List of Figures

ix

List of Appendices

CHAPTER ONE - INTRODUCTION

1.1 Chapter Overview

1.2 The Context: Background of the Ministry of Education Malaysia

1.2.1 The Ministry of Education as an Educational Organization

1.3 Research Problem

1.4 Background of the Research 12

$\begin{array}{lll}1.5 & \text { Purpose of the study } & 15\end{array}$

$\begin{array}{lll}1.6 & \text { Research Questions } & 16\end{array}$

1.6.1 Main Research Question 16

$\begin{array}{lll}\text { 1.6.2 } & \text { Sub-Question } 1 & 16\end{array}$

1.6.3 Sub-Question $2 \quad 16$

1.6.4 Sub-Question $3 \quad 16$

$\begin{array}{lll}1.7 & \text { Significance of the study } & 17\end{array}$

$\begin{array}{lll}1.8 & \text { Organization of the Thesis } & 19\end{array}$

CHAPTER TWO - LITERATURE REVIEW 20

$\begin{array}{lll}2.1 & \text { Chapter Overview } & 20\end{array}$

$\begin{array}{ll}2.2 \text { Leadership Defined } & 20\end{array}$

$\begin{array}{lll}2.3 & \text { Leadership Theories } & 21\end{array}$

2.3.1 Trait Approach 22

2.3.2 Style/Behaviour Approach 23

2.3.3 Transformational and Transactional Approach 25

2.3.3.1 The Early Concept of Transformational Leadership 27

2.3.3.2 The Development of Transformational-Transactional Leadership 28

2.3.3.3 The Expansion of Transformational Leadership 34

2.3.3.3.1 Bennis and Nanus 34

2.3.3.3.2 Tichy and Devanna 35 
2.3.3.3.4 Leithwood 36

$\begin{array}{lll}2.4 & \text { Leadership Styles } & 37\end{array}$

2.4.1 Transformational and Transactional Leadership Styles 38

2.4.2 Review of Some Current Studies 43

2.5 Middle Managers $\quad 45$

$\begin{array}{lll}2.6 & \text { Chapter Summary } & 47\end{array}$

CHAPTER 3 - METHODOLOGY 48

3.1 Chapter Overview $\quad 48$

3.2 Mixed Methods $\quad 48$

3.3 Research Design $\quad 50$

3.4 Research Questions 53

3.5 Sampling Strategy $\quad 54$

3.5.1 Population 56

3.5.2 Sample of the Study $\quad 57$

3.6 Instruments $\quad 58$

3.6.1 Multifactor Leadership Questionnaire (MLQ 5X rater form) 59

$\begin{array}{lll}3.6 .2 & \text { Interview } & 62\end{array}$

$\begin{array}{lll}3.7 & \text { Data Collection Procedure } & 63\end{array}$

$\begin{array}{lll}3.7 .1 & \text { Ethics } & 63\end{array}$

3.7.2 Pilot Study 64

3.7.3 Administration of the Questionnaire 64

3.7.4 Interview Process 66

$\begin{array}{lll}3.8 & \text { Data Analysis Procedure } & 67\end{array}$

3.8.1 Quantitative Analysis $\quad 67$

$\begin{array}{ll}\text { 3.8.2 Qualitative Analysis } & 68\end{array}$

$\begin{array}{lll}3.9 & \text { Chapter Summary } & 69\end{array}$

CHAPTER 4 - DATA DESCRIPTION AND ANALYSIS 70

$\begin{array}{lll}4.1 & \text { Chapter Overview } & 70\end{array}$

$\begin{array}{lll}4.2 & \text { Quantitative Findings } & 70\end{array}$

$\begin{array}{lll}\text { 4.2.1 Respondents Profile } & 70\end{array}$

4.2.1.1 Age Demographics 72

$\begin{array}{lll}\text { 4.2.1.2 Gender Demographics } & 72\end{array}$ 
4.2.1.3 Education Qualification

4.2.1.4 Working Experience 73

4.2.1.5 Grade of the Position $\quad 74$

4.2.2 Reliability Analysis $\quad 75$

4.2.3 Analysis of the Leadership Styles 75

4.2.4 Subordinates' Perceptions of Leadership Styles 79

4.3 Qualitative Findings $\quad 84$

4.3.1 Transformational Leadership $\quad 86$

$\begin{array}{lll}\text { 4.3.1.1 Idealised influence } & 87\end{array}$

4.3.1.2 Inspirational motivation $\quad 88$

4.3.1.3 Intellectual stimulation 90

$\begin{array}{lll}\text { 4.3.1.4 Individualised consideration } & 91\end{array}$

4.3.2 Transactional Leadership 96

$\begin{array}{lll}\text { 4.3.2.1 Contingent reward } & 97\end{array}$

4.3.2.2 Management by Exception (Active and Passive) 98

4.3.3 Other Leadership Styles/Quality 98

4.4 Chapter Summary 99

CHAPTER 5 -DISCUSSION OF THE FINDINGS 100

$\begin{array}{lll}5.1 & \text { Chapter Overview } & 100\end{array}$

$\begin{array}{ll}5.2 & \text { Discussion of the Findings } \\ & 100\end{array}$

5.2.1 Sub-question one: Are there any significant differences of the leadership $\quad 100$ styles practiced by the PTD and DG middle level managers?

5.2.2 Sub-question two: Are there any significant differences in the evaluation of leadership styles of the PTD and DG middle level managers as perceived by subordinates from different scheme of services?

5.2.3 Sub-question three: Are there any significant differences in the evaluation of the leadership styles as perceived by the PTD and DG middle level managers?

5.2.4 Main research question - What are the leadership styles practiced by the PTD and DG middle level managers in the Ministry of Education Malaysia?

5.3 Chapter Summary

CHAPTER 6 - CONCLUSION

$\begin{array}{lll}6.1 & \text { Chapter Overview } & 114\end{array}$

$\begin{array}{lll}6.2 & \text { Summary of Research Findings } & 114\end{array}$ 
6.3 Implications and Recommendations for Practice

6.4 Contribution to the Educational Leadership

6.5 Limitation

119

6.6 Final Thoughts

120

6.7 Chapter Summary

120

APPENDICES

REFERENCES 


\section{LIST OF TABLES}

PAGE

Table 3.1 Matrix crossing purpose of mixed methods research by time orientation

Table 3.2 Sub questions of the research and the proposed methods used to answer the questions

Table 3.3 The components of leadership dimensions in the MLQ 5X questionnaire

Table 3.4 Survey distribution and survey response rate

Table 4.1 Breakdown of the scheme of services of the respondents

Table 4.2 Breakdown of the scheme of services of the respondents and the middle level managers they rated

Table 4.3 Age demographics of the respondents

Table 4.4 Gender demographics of the respondents

Table 4.5 Education qualification of the respondents

Table 4.6 Years of working experience of the respondents

Table 4.7 Respondents grades

Table 4.8 Reliability coefficients of the leadership dimensions of MLQ Form $5 \mathrm{X}$

Table 4.9 Mean ratings of the leadership styles of the middle level managers as rated by their subordinates

Table 4.10 Ranking of leadership styles according to the dimensions of transformational, transactional and avoidance of leadership across groups

Table 4.11 Summary of the comparison of leadership styles according to the dimensions of transformational, transactional and avoidance of leadership between PTD and DG middle level managers

Table 4.12 Mean ratings of the transformational leadership dimension of DG middle level managers as perceived by their subordinates

Table 4.13 Mean ratings of the transformational leadership dimension of PTD middle level managers as perceived by their subordinates 
PAGE

Table 4.14 Mean ratings of the transactional leadership dimension of DG middle level managers as perceived by their subordinates

Table 4.15 Mean ratings of the transactional leadership dimension of PTD middle level managers as perceived by their subordinates

Table 4.16 A comparison of mean ratings of the avoidance of leadership between PTD and DG middle level managers as perceived by their subordinates

Table 4.17 Demographic profiles of interview participants

Table 4.18 A summary of key themes related to transformational, 86 transactional, non-leadership and other relevant leadership styles 


\section{LIST OF FIGURES}

\section{PAGE}

Figure 1.1 Hierarchical structure of the Ministry of Education Malaysia 2

Figure 1.2 Organizational structure of the Ministry of Education Malaysia 5

Figure 2.1 Optimal profile 40

$\begin{array}{lll}\text { Figure 2.2 } & \text { Suboptimal profile } & 41\end{array}$

Figure 3.1 Mixed methods design matrix $\quad 51$

Figure 3.2 Proposed research methodology 52

Figure 3.3 Matrix crossing type of sampling scheme 55 


\section{LIST OF APPENDICES}

\section{Page}

Appendix 1 Classification of the schemes of service in the Malaysian Public

Sector

Appendix 2a Questionnaire

Appendix 2b Questionnaire Participant Information Sheet

Appendix 2c Questionnaire Participant Information Sheet (Malay version)

Appendix 3 Permission to conduct research in Malaysia

Appendix 4 Ethics Approval

Appendix 5a Interview Participant Information Sheet

Appendix 5b Interview Participant Information Sheet (Malay version)

Appendix 6 Consent to Participation in Interview

Appendix 7 One way ANOVA of the components of transformational, transactional and avoidance of leadership of PTD middle level managers as perceived by their subordinates

Appendix 8 One way ANOVA of the components of transformational, transactional and avoidance of leadership of DG middle level managers as perceived by their subordinates

Appendix 9 Detailed Summary of the Transformational Leadership Qualities of the Interview Participants

Appendix 10 Detailed Summary of the Transactional Leadership Qualities of the 


\section{CHAPTER ONE - INTRODUCTION}

\subsection{Chapter Overview}

The purpose of this study is to examine the leadership styles of middle level managers working at the Ministry of Education in Malaysia. This group consist of those from the Administrative and Diplomatic Officers Scheme of service (PTD: Skim Pegawai Tadbir dan Diplomatik) and the Education Officers Scheme of service (DG: Skim Pegawai Perkhidmatan Pendidikan Siswazah/Bukan Siswazah). This chapter begins with an exploration of the context in which the study was conducted. This is followed by descriptions of the study's objective, research problem as well as the statement of the research questions.

\subsection{The Context: Background of the Ministry of Education Malaysia}

The Malaysian education system is governed by the federal government of Malaysia. The Ministry of Education acts as the governing body that oversees and administers the education system in its entirety; hence it practices a centralised administrative system (Kementerian Pendidikan Malaysia, 2001b; N. Lee, 2008; NOOSR, 1996). One of the main aims of centralizing the administration at the ministerial level is to ensure uniformity in the implementation of its policies and procedures (N. Lee, 2008). Another is to avoid regional discrepancies when implementing the education agenda of Malaysia (M. Lee, 1999). Because of the highly centralised system of education, the administration is organised and managed at four hierarchical levels; namely the federal, state, district and finally the school level. The institutions corresponding to each level are the Ministry of Education at the federal (or national) level, the State Education Department at the state level, the District Education Office at the district level and finally schools (EPRD, 2001). Figure 1.1 provides an overview of the hierarchical structure. 


\section{MINISTRY OF EDUCATION}

-35 departments

- Three statutory bodies (Malaysian Examination Council, National Institute of Translation and Dewan Bahasa dan Pustaka)

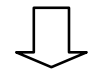

\section{STATE EDUCATION DEPARTMENT}

-15 state education departments

- Each state education department is headed by a State Education Director

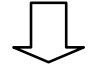

\section{DISTRICT EDUCATION OFFICE}

-135 district education offices

- Each district education office is headed by a District Education Officer

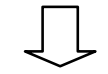

SCHOOLS

- 9,922 schools (primary and secondary schools nationwide)

Figure 1.1: Hierarchical structure of the Ministry of Education Malaysia

Each level and their functions are clearly defined (N. Lee, 2008) and guided by the National Education Philosophy. The hierarchical structure ensures the role of the Ministry of Education in formulating policy guidelines and translating education policies into plans, are carried out effectively (EPRD, 2001). Lee (1999) believes that the highly centralised system allows the Ministry to decide on the allocation of funding to the states and schools, prescribe and standardise the schools' curriculum and formulate a top-down management. Lunenburg and Ornstein (1996) believe that it is beneficial to have an education system that is centralised and governed by the federal government. A federal government's role in education is important because the system's education will influence the future of the nation (Lunenburg \& Ornstein, 1996).

Nonetheless, Lee (2008) believes that the centralised administrative system practiced in Malaysia does not give the individual institutions, such as the schools, much authority; 
especially on policy decisions. Hence, this limits the management and performance of the institutions (schools in particular) towards achieving the objectives of the National Education Philosophy. The Ministry of Education Malaysia (Kementerian Pendidikan Malaysia, 2001a) admits that the management challenge is "to overcome issues and problems due to its structure that is hierarchical, centralised, heavy at the top but small at the bottom, as well as inefficient and ineffective management and resources and personnel" ( $p$. 11).

The three groups of prime movers of the Ministry are the Minister of Education and his two deputies, the Secretary General and his two deputies, and the Director General of Education and his three deputies (Ibrahim, 1995). The Minister is the political head of the Ministry. In this position, he is responsible for the effective implementation of education policy, and is the administrator of the entire education system (EPRD, 2001). The Minister and his deputies are appointed by the Prime Minister as part of the Government's cabinet portfolio holders. They are also members of parliament. The day-to-day running of the Ministry is administered by a Secretary General and a Director General.

Recent changes, particularly at the level of the ministry, in the past six years have had considerable impact on the management and administration of the Ministry. A landmark decision was made by the then Prime Minister Abdullah Badawi in the year 2004 to divide the Ministry of Education into the Ministry of Education and the Ministry of Higher Education. This has allowed the Ministry of Education to focus more on implementing and administrating policies for pre-school, primary school, secondary school, pre-university and teacher education. The Ministry of Higher Education, on the other hand, has the task of administrating and managing the tertiary education system, except for the matriculation (pre-university) level and teachers' education.

\subsubsection{The Ministry of Education as an Educational Organization}

The Ministry of Education Malaysia is an organization that is part of the nation's public sector. Because the Ministry is part of the civil service, all rules and regulations of the civil 
service govern this educational organization (Ibrahim, 1995). Public servants in Malaysia are categorised according to particular schemes of service ${ }^{1}$.

The Ministry of Education has a total of 469,424 personnel (Kementerian Pelajaran Malaysia, 2010). It is responsible for the management and deployment of personnel under the education scheme of service. The personnel classified under this scheme are also called education officers and bear the code of service $D G$. A total of 377,693 (or $80.5 \%$ ) of the Ministry's workforce are from the education scheme of service. From those, 78\% are employed in schools nationwide as teachers, $1.3 \%$ are teaching in the teachers' training institute and matriculation centre and only $1.2 \%$ work at the various departments of the Ministry of Education, state education departments and district education offices (Kementerian Pelajaran Malaysia, 2006; Kementerian Pendidikan Malaysia, 2001b).

The Human Resource Management of the Ministry of Education is quite distinct at all levels from the rest of the Ministry. The positions in all departments are offered only to personnel of particular schemes of service. For instance, in addition to those serving under the education scheme of service, the Ministry also employs in a separate category some from other schemes of service such as those from the Administration and Support scheme of service (12\% of the Ministry's workforce), Skilled/Semi-skilled and Unskilled scheme of service (5\% of the Ministry's workforce) and those from the Finance and Accountancy scheme of service ( $0.33 \%$ of the workforce). Personnel from the Administrative and Diplomatic scheme of service, better known as PTD officers, account for 358 (or only $0.07 \%$ ) of the total workforce in the Ministry. But despite the small numbers, the PTD officers occupy most senior management positions in the Ministry, including the highest position available for its civil servants that of the Secretary General. The Ministry of Education hopes that the involvement of personnel from different schemes of service will enable the Ministry to function effectively (Kementerian Pendidikan Malaysia, 2001b). Nonetheless, the majority of the personnel working in the departments under the professional division of the Ministry come from the education scheme of service; and

\footnotetext{
${ }^{1}$ There are 21 schemes of services for public servants in Malaysia. Each scheme is classified according to the overall description of the job. In addition, each scheme is differentiated by a designated code (refer to Appendix 1).
} 
despite their small numbers, the majority of the administrative positions in the departments are held by those from the Administrative and Diplomatic scheme.

There are 35 departments under the administration of the Ministry of Education at the federal level, including three statutory bodies (refer to figure 1.2 for the organizational structure of the Ministry of Education Malaysia).

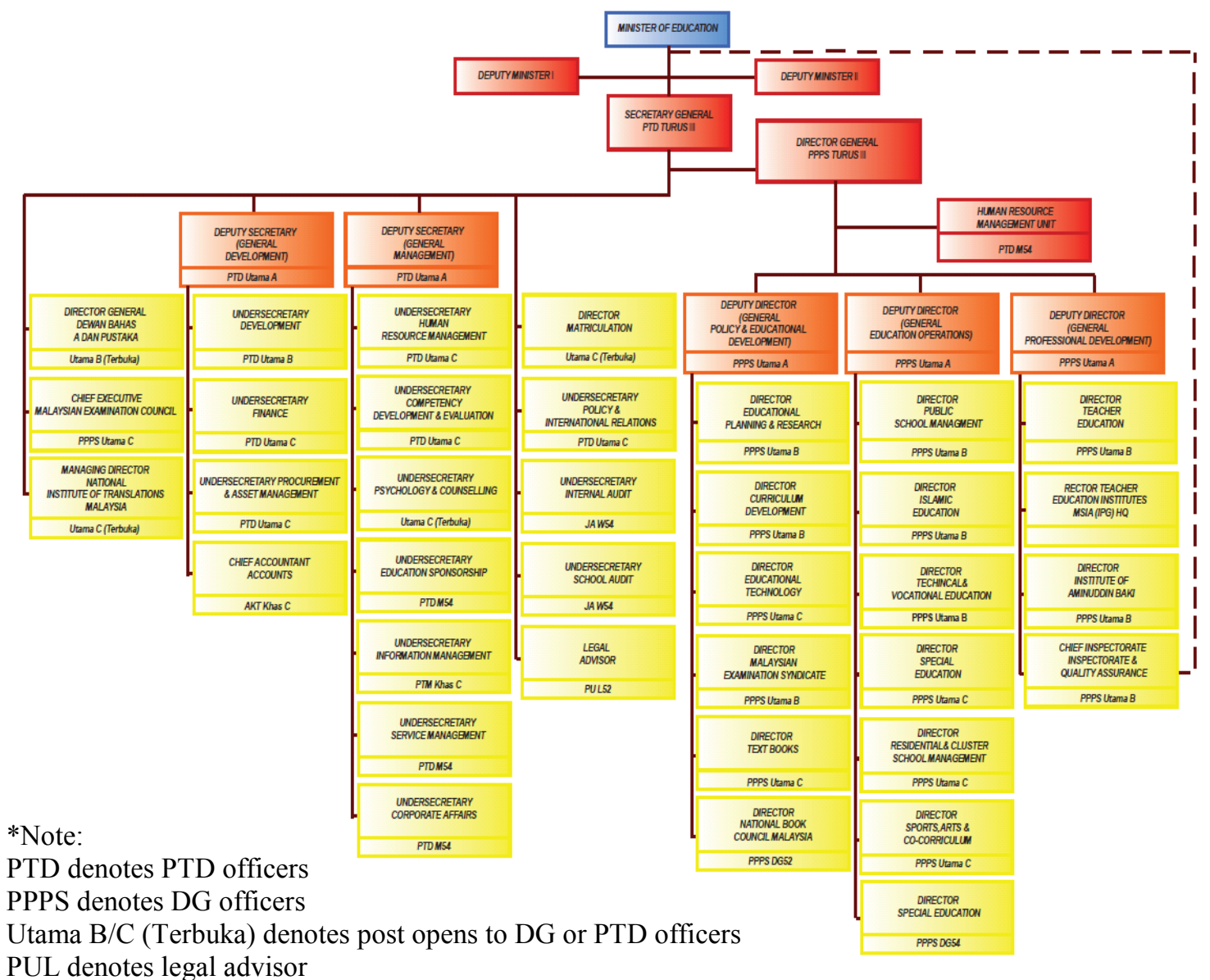

PUL denotes legal advisor

AKT denotes accountants

JW denotes auditors

Figure 1.2: Organizational structure of the Ministry of Education Malaysia (source: www.moe.gov.my/upload/galeri moe/inforasmi/2008 KPM 9 4186.pdf)

The Secretary General of the Ministry is responsible for the administrative matters of the Ministry while the Director General of Education is responsible for matters concerning the education, policy, implementation and professional aspects of education. 
There are 19 departments under the direct control and purview of the Secretary General. Out of these, 14 function executively on the administrative needs of the Ministry. These 14 departments are collectively grouped as the administrative division. This division's departments track all administrative matters of the Ministry including finance, budgeting, infrastructure development of schools and human resource management.

On the other hand, the 16 departments which function directly under the Director General of Education are considered as the professional division (EPRD, 2001). This division consists of departments which essentially formulate the nation's education policy and system.

The eight departments under the administrative division are headed by the PTD officers while the 16 departments of the professional division are headed by DG officers. Three department heads are supposed to be from the finance and accounting scheme of service while the remaining seven department heads are open to those from other schemes. Some departments have personnel consisting of PTD officers only and some may consist of only DG officers. The majority of the personnel working in the departments under the professional division of the Ministry are DG officers, while the majority of positions in the departments under the administrative division are filled by PTD officers. Nonetheless, there are a few departments where PTD and DG officers work together. It is generally understood that the role of PTD officers in the departments under the professional division (which are headed by DG officers) are to assist in the administration and management of services, especially in relation to the departments' financial budgeting and spending as well as other matters concerning human resource management and administration.

The state education departments are established in every state and their role is to ensure that educational policies made by the Ministry are implemented at the school level. These departments are staffed by DG officers. Along with these officers, support staff from the administrative and support scheme of service and the finance and accountancy scheme of service are employed to help with clerical and financial matters.

According to Lim (2007), the PTD officers are considered as the elite corps of the generalist administrators. The former Chief Secretary to the Malaysian Government, Tan Sri Ahmad 
Sarji has reiterated (Ahmad Sarji, 1996) that PTD will remain as the crème-de-la-crème of the country's civil service. The PTD consists of officers who have undergone special training at the renowned National Institute of Public Administration, Malaysia (known as INTAN). These officers are awarded with a Diploma in Public Administration from INTAN after they have completed 9-months of intensive training. A typical job description of the PTD, according to the Public Service Commission website (Suruhanjaya Perkhidmatan Awam, 2010), includes "planning, formulating and implementing public policy on human resource management and organization, financial resources, economy, administration and regional development, / regional / local / land planning and social administration, international relations and foreign affairs (including foreign service ) security/ national resilience and management of information technology".

Having graduated from the INTAN, PTD officers would be employed in various ministries, federal or state departments or could be deployed as foreign diplomatic officers in any of the Malaysian High Commissions or embassies abroad. The PTD officers are to be the standard bearers of administrative excellence. "The pillar of Malaysian Public Service was long established by officers from Administrative and Diplomatic Service which is the core in planning and implementation of public policies. Almost all strategic posts in the government at federal level, overseas, the sates and the district are headed by PTD" (INTAN, 2010, p. 1).

Because the PTD scheme is considered a premier service and leader in public service (INTAN, 2010), the officers are often expected to "display excellent work culture so that their leadership is effective, fulfilling the nation's needs and capable of facing challenges and obstacles" (INTAN, 2010, p. 1). As a requirement, all PTD officers should have a minimum qualification of a bachelor's degree.

The Education Officers (DG officers) working in the Ministry as well as the State education departments are considered to be educational administrators (Ibrahim, 1996). These officers are from the Graduate Education Officers Scheme (Pegawai Perkhidmatan Pendidikan Siswazah or Graduate Education Service Officer) or from the Non-Graduate Education Officers Scheme (Pegawai Perkhidmatan Pendidikan Lepasan Diploma or Non-Graduate Education Service Officer). The DG Officers working in the departments of the Ministry consist of former teachers and school heads that have had at least three years working 
experience in schools. Quite often teachers who have the experience as heads of departments, assistant principals or principals are most likely to be offered a position in one of the departments of the ministry or state education departments. These teachers are considered suitable to the posts available in the Ministry because of their leadership capabilities as well as their management experience in schools. Hence, the notion of teachers as leaders plays a pivotal role for selectors when appointing or offering positions in the ministry.

Unlike PTD officers, DG officers who work in ministry's departments or state education departments do not have a prerequisite requirement to attend a special training programme in administration. Nonetheless, DG officers are encouraged to participate in any professional development programme from time to time. It is assumed that DG officers are deemed to experience a smooth career transition with the work and teaching experience and leadership capabilities they acquired prior to working at the ministry or state education departments.

\subsection{Research Problem}

Grummel, Devine and Lynch (2009) believe that teachers who work as educational administrators in an educational organization apart from schools should have a range of personal criteria that are associated with leadership positions. However, a leading figure in the field of education management, Ibrahim Bajunid, laments that most administrators in the educational organization in Malaysia are not interested in, nor have the education or time to engage in, the science of administration (Ibrahim, 1996). Ibrahim (1996) concedes that the changes facing educational administrators in Malaysia are very significant, broad ranging and affects the organization. Hence, he believes that it is essential for educational administrators to develop confidence in their ability to analyse their needs and the needs for the development of the organization. Ibrahim, Abdul Wahab, Bakhtiar, Maheswari, Yusro, Lim and Macpherson (1996) further argue that educational administrators are expected to be self confident leaders who are highly competent, have a sense of belonging to the organization and have a high sense of self-worth.

The Ministry of Education Malaysia (Kementerian Pendidikan Malaysia, 2001a) recognizes that the challenge of the Ministry in terms of management is "to overcome issues and problems due to its structure that is hierarchical, centralised, heavy at the top but small at the bottom, bureaucratic issues, as well as inefficient and ineffective management and resources 
and personnel" (p. 11). As a result, in the year 2001 the Ministry of Education introduced a ten-year plan to transform the organization into an educational organization that is innovative, creative and continuously improves all aspects of the nation's education system (Ministry of Education, 2001). Part of the ten-year plan includes the need to improve the quality of leadership at all levels of the ministry and develop a group of competent top level managers equipped with the highest professional qualifications and who have expertise in management and education (Kementerian Pendidikan Malaysia, 2001a).

In doing so, the Ministry believes that efficient and effective management at all administrative levels of the organization must first be realized (Ministry of Education, 2001). The ten-year plan outlines several strategies that would hopefully strengthen the administration and management system of the Ministry. Some of the strategies include "creating a pool of highly experienced and qualified professional management executives to ensure the leadership of the Ministry is led by those with expertise in education management; and creating more administrative posts and suitable administrative mechanism to address the shortage of officers" (Ministry of Education, 2001, p. 7-12). This plan has allowed more teachers to be employed as officers in the departments in the Ministry as well as the State Education Departments.

As a follow up to this plan, a National Education Blueprint was launched in 2006. The Blueprint has six areas of focus aimed at pushing the nation forward via education. One of the areas of emphasis includes elevating the teaching profession (Kementerian Pelajaran Malaysia, 2006). This would ensure that more teachers could serve as educational administrators in the Ministry as well as State Education Departments.

Nonetheless, a change introduced by the Ministry of Education in the year 2007 brought a significant impact on the management of the ministry. The change was a major restructuring of the divisions and departments of the ministry. The restructuring did not only involve the departments in the Ministry of Education but also the organizational structure of the state education departments so that it would mirror the functions of the organizational structure at the federal level. The restructuring of the Ministry has allowed the PTD officers to be more actively involved in the human resource and management units of the departments under the professional division of the ministry, including those of the state education departments. 
This led to the human resource and management units of these departments to be managed by PTD officers.

The deployment of PTD officers into the human resource and management units of the departments under the professional division (which were once administered solely by DG officers) was done in phases and did not bring about many problems. However, the decision to deploy PTD officers as senior administrative managers in the state education department's human resource and management units did not go down well with the DG officers who believed that state education departments should remain as part of an education organization for educators and administrators from the education scheme of service (BERNAMA, 2008).

Administrative positions, especially at senior management levels, in the human resource and management units of the state education departments had to be relinquished to PTD officers. The rationale for this move was to allow PTD officers who are well versed with all matters concerning administration, human resource and financing to manage the administrative matters of the departments. This move has drawn nationwide protest from the DG officers (Amir, 2008; Fauziah Arof, 2007).

The National Union of Teaching Profession contested the argument that all senior positions in the state education department, including the head of the human resource and management unit, should remain for DG officers only because they are the ones who are able to carry out the objectives and mission of the Ministry of Education. They argued that because the PTD officers do not have the background in teaching and education, they would not be able to understand the needs of an educational organization (BERNAMA, 2007). A resolution named Resolusi Kota Baharu (Kesatuan Guru Bumiputera Sarawak, 2010) was drafted by DG officers to object to the appointment of PTD officers in the State Education Department. The resolution states that the administration and management style of the PTD does not suit the day-to-day administration of an educational organization. Nonetheless, the resolution agreed that should PTD officers be appointed as personnel in the State Education Department, they could not be appointed as senior managers or middle level managers but only appointed as normal officers assisting senior managers or officers of the education scheme of service. 
The president of the Civil Service Workers Union, the biggest workers' union in Malaysia, supports the education service and agrees that DG officers who are managing the state education department's human resource and management units should remain in their positions. Furthermore, the majority of those serving in the state education department were former teachers, head of departments and principals, and therefore they have enough experience at schools to be able to lead an educational organization such as the state education department (UTUSAN, 2007). Nonetheless, the former Deputy Minister of Education, Noh Omar, felt that DG officers should be open to the idea of having PTD officers managing all administrative and management matters in the departments as they are well trained to do so and they are experts in administration (Hasnurul Mohamed, 2007).

The decision to appoint PTD officers into the human resource and management units in the departments which used to be administered and managed by DG officers has had implications on the organization. First, it signals that educational administrators, who have been serving, particularly in the human resource and management units of the departments for the past 50 years, are incompetent in administrative matters and require professionals such as the PTD officers to take over the positions. Second, by employing PTD officers in those departments, the role of educational administrators has been greatly reduced to those of policy makers while the roles of managing human resources, finance and budgeting have become the exclusive responsibility of the PTD officers. Third, employing PTD officers in those departments serves to the elitist status of the PTD corps in the civil service. Fourth, the appointment of PTD officers has deprived DG officers of jobs that are rightfully theirs, hence making it rather paradoxical for the government to introduce initiative and incentives for teachers who would want to work in the Ministry's departments as outlined in the National Education Blueprint. Finally, the appointment of PTD officers as managers (senior or middle) in those departments represents a high disproportion of the representation of DG officers in the Ministry. PTD officers represent only $0.07 \%$ of the total workforce in the Ministry compared to $80 \%$ of those from the education service scheme; nonetheless, the PTD officers have outnumbered the DG officers in terms of filling in senior management roles in the Ministry. 
The deployment of PTD officers to the administrative, human resource and management units in the Ministry's departments under the professional division and State Education departments was eventually carried out despite the wide protests. Three years on, the effects are not actually better than in the period when those departments were headed by DG officers. PTD officers are deployed on the basis that they are the standard bearers of administrative excellence; hence they can manage all administrative matters effectively. The DG officers, on the other hand, who had been working in those units and departments before, were chosen on the basis of their a) leadership capabilities shown while they were working as teachers or administrators in schools or b) leadership qualities shown as an excellent rank and file officer in those units or departments.

\subsection{Background of the Research}

The current literature highlights the importance of leadership in any organization. Leadership is considered to be a major factor influencing the performance of organizations and their members (Vigoda-Gadot, 2007), and more importantly, contributing significantly to the success and failure of an organisation (Lok \& Crawford, 2004). Fernandez, Cho and Perry (2010) believe that scholars are still trying to understand leadership and its influence on organizations and its subordinates. The importance of leadership in an organization is further echoed by Van Wart (2003), who believes that effective leadership in an organization "provides higher quality and more efficient goods and services; it provides a sense of cohesiveness, personal development, and higher levels of satisfaction among those conducting the work; and it provides an overarching sense of direction and vision" (p. 214). Regardless of their respective organization's size or structure, most leaders strive to maximise the performance of their subordinates in order to achieve organizational goals (McColl-Kennedy \& Anderson, 2002).

A large-scale organization, such as the Ministry of Education Malaysia, has multiple hierarchical levels. Each of the 35 departments in the Ministry is well structured. Every department has its own organizational structure which consists of sub-units, sub-departments or sub-sectors, headed by middle level managers. There are several official titles given to the designated middle level managers. The official titles are Principal Assistant Director, Principal Assistant Secretary, Head of Sector and Head of Unit. Every middle level manager is responsible for managing the personnel and designated sub-units, sub-departments or sub- 
sectors. Although these managers at different levels in the organization have different responsibilities, they are thought to share the same common aims and goals of the Ministry.

Any organization needs effective managers and subordinates to achieve the goals and objectives of the organization (Rad \& Yarmohammadian, 2006). Jago and Vroom (1977) state that all managers, regardless of the level, have subordinates reporting to them, and their effectiveness as managers is to some degree dependent on the extent to which their leadership styles would be able to influence these subordinates towards achieving the goals of the organization. Their argument would lend support to Yukl's (1998) definition of leadership which states that it is a process of interaction between leaders and subordinates in an attempts to influence the behaviour of subordinates to accomplish organizational goals.

Rad and Yarmohammadian (2006) also believe that the leadership styles of managers in an organization contribute to the organization's success in achieving its goals and objectives. Leadership style is thus considered to be a particularly important aspect of leadership, in terms of achieving organizational goals. It is not surprising that many studies endeavour to demonstrate how certain styles of leadership are better or more efficient than others (McColl-Kennedy \& Anderson, 2002; McColl-Kennedy \& Anderson, 2003).

This study is interested in exploring the leadership styles of middle level managers working in the Ministry of Education Malaysia. The middle level managers in this research are restricted to those from the PTD scheme of service and DG scheme of service.

Leadership style, in this study, is thus defined as the extent to which a leader exhibits a transformational and transactional style of leadership. Bass (1998) explains that transformational leaders behave in ways to achieve superior results from their subordinates and for their organization by employing one or more of the four components of transformational leadership.

The late 1970's witnessed the emergence of the concepts of transformational and transactional leadership which was first introduced by Burns (Bass, 2008) and was later refined by Bernard Bass and his colleagues (Bass, 1998). The introduction of these two concepts was seen as the new paradigm in understanding leadership styles and behaviour 
(Bass, 1998). A simple explanation of these two concepts is offered by Bass and Riggio (2006) as follows:

"Transactional leaders are those who lead by exchanging one thing for another (i.e. jobs for votes or subsidies for campaign contributions). In the same way, transactional business leaders offer financial rewards for productivity or deny rewards for productivity. Transformational leaders on the other hand, are those who stimulate and inspire followers to both achieve extraordinary outcomes and in the process develop their own leadership capacity" (p. 3).

Some argue that transformational leaders motivate others to do more than they originally intended and often even more than they thought possible (Bass, 1998; Bass \& Avolio, 1994; Bass \& Riggio, 2006). According to Bass and Avolio (1994), transformational leadership is seen when leaders (1) stimulate interest among colleagues and followers to view their work from new perspectives, (2) generate awareness of the mission or vision of the team and organization, (3) develop colleagues and followers to higher levels of ability and potential, and (4) motivate colleagues and followers to look beyond their own interests toward those that will benefit the group.

Transactional leadership style, on the other hand, is seen as a pattern of leadership that is prevalent in most organizations and organizational situations because it contains the basic mechanism of exchange relations (Popper \& Zakkai, 1994). Transformational leadership and transactional leadership styles are considered well-rounded because they encompass several other dimensions or components of leadership styles. A detailed explanation of transformational and transactional leadership is given in the literature review.

In the study of educational organization, many of the concepts of transformational leadership have become a feature of the leadership styles of educators worldwide (Crowther $\&$ Olsen, 1997). The practice of educational leadership is not confined to the school setting but extends to a wider organizational level (Bowman, 2004; Whitsett, 2007). Foster (as cited by Crowther \& Olsen, 1997) believes that leadership, at its heart, is a critical practice involving educational leaders in any educational organization. Educational leadership has quite often been associated with ascribed authority and positions most relevant to principals 
or assistant principals (Crowther \& Olsen, 1997). Danielson (2006) adds that the current literature on educational leadership focuses much on school principals' forms of leadership. Crowther and Olsen (1997), Danielson (2006) and Bowman (2004) believe that educational leadership should not be restricted to the leadership of principals but should be extended to others working within the educational sphere as well. That is why Gunter (2001) feels transformational leadership works well with educators regardless of where they are working because "transformational leadership is more about leadership in educational setting rather than educational leadership"(p. 73) per se.

Stewart (2006) points out that the distinction between transformational and transactional leadership is very close to the distinction made between management and leadership. According to Dubinsky, Yammarino and Jolson (1995), administrators who practice transformational leadership could be considered as leaders rather than merely managers. Zaleznik $(1990,1992)$ states that managers are likely to show transactional leadership qualities. Stewart (2006) adds that one might argue that a transactional leader might be better termed as a transactional manager. Leithwood and Jantzi (2000) also share the same view in interpreting transactional leadership styles as managerial in nature. Leaders view their job, work environment and subordinates and execute their assignments and responsibilities differently from managers (Dubinsky, et al., 1995).

The relevance of comparing leadership styles of both the PTD and DG middle level managers lies in the fact that PTD officers are known for their administrative and management capabilities while DG officers are promoted on the basis of their leadership capabilities and years of relevant experience. Therefore it is assumed that the DG officers, as educational leaders, are more likely to exhibit a more transformational style of leadership compared to PTD officers. Transformational superiors could conceivably be regarded as leader managers in contrast to routine managers (Dubinsky, et al., 1995).

\subsection{Purpose of the Study}

The focus of this study is to examine the leadership styles of middle level managers, paying particular attention to the departments where there is a mix of PTD and DG officers and the administrative and management departments or units that were once managed solely by DG officers. This study aims to comparatively analyse the leadership styles of the two groups of 
middle level managers from two different schemes of services and identify any differences/similarities of leadership styles. In addition, this study examines the leadership styles of the middle level managers as perceived by their subordinates from different schemes of services. The subordinates in this study refer to the employees of the Ministry who directly report to the middle level managers. The aims of the study are summarised as follows:

i) To examine the leadership styles of PTD and DG middle level managers working in the departments of the Ministry of Education Malaysia.

ii) To investigate whether differences of leadership styles exist between middle level managers of two different schemes of services.

iii) To investigate whether the leadership styles of the PTD and DG middle level managers are perceived differently by their subordinates of different schemes of services.

iv) To investigate whether the PTD and DG middle level managers perceive their leadership styles differently.

\subsection{Research Questions}

This research is guided by the following main question and three sub-questions.

\subsubsection{Main Research Question}

What are the leadership styles practiced by the PTD and DG middle level managers in the Ministry of Education Malaysia?

\subsubsection{Sub-Question1}

Are there any significant differences in the leadership styles practiced by the PTD and DG middle level managers?

\subsubsection{Sub-Question 2}

Are there any significant differences in the evaluation of leadership styles of the PTD and DG middle level managers as perceived by subordinates from different scheme of services?

\subsubsection{Sub-Question 3}

Are there any significant differences in the evaluation of leadership styles as perceived by the PTD and DG middle level managers? 


\subsection{Significance of the Study}

Leadership is thought to occur at different levels throughout an organization (Riches, 1997), and can be practiced by any individual, regardless of one's hierarchical position in the organization (Bass \& Riggio, 2006). Currently, there is insufficient information or literature relating to the leadership styles of middle level managers in the public sector. Oshagbemi and Gill (2004) report that extensive research on leadership styles has focused on leaders in upper organizational levels alone, such as those of managers or directors. Perhaps this is due to the fact that it is generally assumed that middle level managers have significantly smaller roles to play in contributing to organisational success (Oshagbemi and Gill, 2004).Therefore, this study hopes to shed some valuable insights on the leadership styles practiced by the middle level managers in a public organization.

Secondly, this study is also significant in providing valuable insights on different leadership styles shown by middle level managers from two different schemes of service in the Ministry. The leadership styles in this research refer to the transformational and transactional styles. The differences of leadership styles might be significant as the two groups of middle level managers have two different career advancement backgrounds. Prior to working in the Ministry or the state education departments, DG officers work as teachers, head of departments or principals. Their experience of working in primary or secondary schools varies from three to 15 years.

One of the qualities needed for those teachers to be able to work in the Ministry is the exhibition of leadership to some degree. Therefore recommendation letters are required from their principals or the Head District Education officer verifying them as possessing a considerable, if not huge, degree of leadership. It could be established that the DG officers working in the Ministry do not receive any formal training prior to being appointed as officers in the organization. Nonetheless, they are encouraged to participate in professional development courses that would help them understand the management of an educational organization. In contrast, PTD officers are specially trained in various aspects of administration and leadership. All PTD officers undergo a minimum of three years as rankand-file officers before they can take up management positions in the various departments and ministries of the government. Some of the PTD officers would not have to wait that long before they could hold significant leadership positions. For example, most of the middle 
level managers or heads of units in the administrative and management units of State Education Departments consist of PTD officers who are barely one year into their service. It is sufficient to say that the PTD officers are trained and expected to lead many of the Government's departments and Ministries. Hence, this research will identify whether such differences in leadership styles exist between these two groups of middle level managers.

Thirdly, although various studies on leadership styles have been well published (as discussed in the literature review), research on leadership styles involving educational leaders or middle level managers in Malaysian public sectors in general, and in an educational organization such as the Ministry of Education Malaysia in particular, is few and far between (EPRD, 2002, 2008). Previous research done regarding leadership styles in educational organizations in Malaysia was confined to the leadership styles of principals in schools (Jazmi, 2009; Nor Shamsuri, 2002; Nursuhaila, 2007; Yahya, 2009). Hence, this study is significant in contributing to the literature on leadership styles among middle level managers in an educational organization in Malaysia. In addition, this study also provides valuable insights to the views, if any, of the significant roles of DG middle level managers in a Malaysian government department. It is hoped that this study will give credence to the role of DG officers in administrating and managing organizations apart from schools.

Fourthly, this study is significant in terms of understanding the leadership styles as perceived by the subordinates of the middle level managers. The subordinates would be a mix of officers from different schemes or services (namely DG, PTD and the also the support staff from the N scheme of service). McColl-Kennedy and Anderson (2002) believe that the style of leadership is considered important in evoking the performance of the subordinates. Nonetheless, McColl-Kennedy and Anderson believe that the leadership styles of the leaders alone cannot be responsible for the performance of the subordinates. The subordinates' perceptions of their leaders' leadership style are equally important. Subordinates might have different conceptions of what might be the best style that would suit their personality, work ethic and work commitment. Jung and Avolio (1999) found that the same leadership style can be perceived differently and can have different effects on motivation and performance for subordinates from different groups. Hence, this study will examine whether subordinates of different schemes of service perceive the leadership styles of their superiors differently. 


\subsection{Organization of the Thesis}

This study is divided into six chapters. The first chapter serves as an overview of the research; the second chapter explores the relevant literature review pertaining to the aspect of leadership and leadership styles. Chapter three deals with the methodology involved with this research. Chapter four analyses all the findings of the research. Chapter five discusses the results of the findings. The final chapter summarises the findings as well as presenting the implications of this study. 


\section{CHAPTER 2 - LITERATURE REVIEW}

\subsection{Chapter Overview}

In this chapter, literature pertaining to the definition of leadership, leadership theories and leadership styles are explored. Particular focus is given to the transformational and transactional leadership styles. Consequently, historical literature on transformational leadership is reviewed, and background research done particularly in the area of transformational leadership styles is examined. This chapter also discusses the manager and leader dichotomy.

\subsection{Leadership Defined}

Leadership is a universal phenomenon in human societies (Bass, 2008). It is a popular subject that has long excited the interest of scholars (Antonakis \& House, 2002; Bass, 2008; Lunenburg \& Ornstein, 1996; Northouse, 2004; Yuk1, 1998). Nonetheless, many scholars continue to search into what precisely constitutes leadership (Ogawa, 2005). Sanga and Walker (2005), for instance, believe that leadership is a complex concept to explain. As a result, different concepts and definitions of leadership have been studied, discussed and presented in many ways by scholars in various fields (Bass, 2008; Northouse, 2004). Yuk1 (1998) argues that the definition of leadership is arbitrary and very subjective. Yukl adds that "some definitions are more useful than others, but there is no single correct definition" (1998, p. 5). Bass (2008) claims that the definitions most commonly used tend to concentrate on the following aspects: the leader as a person, the behaviour of the leader, the effects of the leader and the interaction process between the leader and those who are being led.

Bryman (1992) defines leadership "as a process of social influence whereby a leader steers members of a group towards a goal" (p. 2). Northouse (2004), on the other hand, has taken into account the many aspects and concepts of leadership from the literature and concisely grouped leadership into four different components: leadership is a process, involves influence, occurs within a group process and involves goal attainment. By considering these four components, Northouse (2004) then defines leadership as "a process whereby an individual influences a group of individuals to achieve a common goal" (p. 3). Similar to Northouse, Anderson (2008) grouped leadership into six different categories. The six 
categories are: 1) leadership as function, 2) leadership as process, 3) leadership as behavioural pattern, 4) leadership as role, 5) leadership as work tasks and activities, and 6) leadership as skills.

Luneburg and Ornstein (1996) summarise leadership into two important concepts. First, that leadership is a relationship between two or more people in which influence and power are unevenly distributed. This definition is applicable to the formal leader who has the authority to exert influence on the group; and also to the informal leader who engages in leadership behaviour as a participant of a group (Lunenburg \& Ornstein, 1996). The second concept of leadership, according to Luneburg and Ornstein(1996), is that leaders do not exist in isolation. Leaders need followers in order to impose their influence and authority.

Yukl (1998) proposes the best summary of what constitutes the definition of leadership, stating that "most definitions of leadership reflect the assumption that it involves a process whereby intentional influence is exerted by one person over the other to guide, structure and facilitate activities and relationships in a group or organization" (p. 3). The majority of the definitions described thus far relate leadership as a process, behaviour (traits and personality), function and leader-subordinate relationship.

\subsection{Leadership Theories}

The study of leadership has been characterized by disparate clusters of theories, approaches and models, each focusing on different aspects of leadership (Fernandez, et al., 2010). Researchers who differ in their conception of leadership select different phenomena to investigate and interpret the results in different ways (Yukl, 1998). As a result, leadership scholars have tried over the last few decades to identify and deconstruct leadership into different theories or approaches that can be measured and studied more in depth (Dulewicz \& Higgs, 2005; Horner, 1997; Messick \& Kramer, 2005). Yukl (1998) for instance classifies leadership theory in terms of different levels of analysis. The levels are intra individual processes, dyadic processes, group processes and organizational processes. Horner (1997) argues that most theories on leadership look at the person in order to gain better understanding. 
Some of the theories or approaches studied and measured by scholars include the trait approach, behaviour approach, situational or contingency approach. According to Bryman (1992), these approaches are widely studied by scholars prior to the 1980's. Later, new leadership approaches or theories had been discovered by leadership scholars. These approaches include neo-charisma approach, psycho dynamic leadership approach, transformational approach and Leader-Member Exchange approach (Winkler, 2010). Mosley (1998) finds that the most widely recognized leadership theories have emphasised the importance of situation, interpersonal or transformational influences and the relationship between leaders and their subordinates.

Given the limited scope of this Master's study, it is not plausible to review all of the leadership approaches mentioned. Therefore, only a review of three major leadership approaches, which are relevant to this research, shall be carried out. This will possibly lead to an understanding of what leadership style is and its relevancy to this research.

\subsubsection{Trait Approach}

One of the earliest approaches for studying leadership is the trait approach (Yukl, 1998). Most research on leadership before the 1940's focused on the leaders and their individual traits (Bass, 2008). Underlying this approach is the assumption that some are people are natural leaders who possess certain traits that make them different from others (Yukl, 1998). In addition, the trait approach emphasizes that individuals have certain qualities that make them leaders (Northouse, 2004). In essence, this approach implies that leaders are born rather than made (Bryman, 1992). Some of the major traits that were found to be essential for leaders include stature, physique, energy, health, appearance, fluency of speech, intelligence, knowledge, ambition, cognitive ability, personal adjustment and emotional control (Bass, 2008; Bryman, 1992; Levine, 2008; Northouse, 2004).

The trait approach recognises that leadership will only be effective when the position is held by people with these traits (Levine, 2008; Northouse, 2004). Northouse (2004) believes that the trait approach is more straightforward than other leadership approaches as it focuses exclusively on the leader and not on the followers or the situation. While there is not one set of traits that guarantees an individual's ascension to leadership in any given situation, the possession of some traits will grant or assign that individual to a leadership position (Levine, 2008). 
The trait approach has drawn major criticism, especially from the renowned researcher of leadership Ralph Stogdill (Bass, 2008; Bryman, 1992; Levine, 2008; Yukl \& Lepsinger, 2004). Stogdill failed to find any consistent evidence or relations to suggest that personal traits of an individual plays a part in leadership (Bryman, 1992). "At best, he [Stogdill] was able to conclude that the personal factors associated with leadership are substantially affected by the requirements of the situation from which the leader emerges" (Bryman, 1992, p. 2). Therefore, this suggests that traits alone could not be accepted as the single factor that guarantees effective leadership as other factors such as situations, settings, environments and leader-subordinate relationships also play a role for a successful leader. Another criticism is that this approach has resulted in highly subjective determinations and classification of what constitutes the most important leadership traits (Northouse, 2004). For example, a leader with certain traits might be effective in a particular situation but ineffective in another, or two leaders with different patterns of traits might be successful in the same situation (Yukl, 1998). Another criticism of the trait theory is that the traits are often described in masculine terms (Jogulu \& Wood, 2006).

\subsubsection{Style/Behaviour Approach}

From the late 1940's onwards, studies on leadership approaches had shifted gradually from the trait approach towards the understanding of the behaviour of leaders (Bryman, 1992). According to Bryman (1992) and Northouse (2004), the behavioural approach is sometimes referred as the style approach as these two terms are often used interchangeably to describe the leaders' behaviours, what leaders do, and their actions toward subordinates in various contexts.

The philosophy underpinning the birth of the behavioural approach in leadership began to move from the belief in the importance of the inborn traits or characteristics of leaders to a focus on behaviour which could be acquired or learned (Jogulu \& Wood, 2006). Mengel (2008) explains that the shift from the trait approach towards the style approach was because of the failure of the former theory to identify a clear and unique set of personal characteristics that would identify great leaders. Because the style approach emphasizes the behaviour of the leader, this distinguishes it from the trait approach (Northouse, 2004).The trait approach emphasises that leaders with the proper leadership qualities or traits should be selected because the traits of good leaders are largely innate and not subjected to substantial 
change (Bryman, 1992). By contrast, Bryman (1992) argues that most leadership style researchers believe that once the behaviour that makes for effective leadership is known, leaders can then be trained to exhibit that behaviour so that they can become better leaders. Hence, a behavioural definition of leadership incorporates the view that leaders can manage their behaviour which enables their followers to achieve organizational goals (Mosley, 1998).

Northouse (2004), Hollander (1978) and Bryman (1992) point out that some of the early research on the behaviour/style theory of leadership was conducted at Ohio State University and the University of Michigan. The studies conducted by researchers from these two universities were carried out to determine how leaders could best combine their task and relationship behaviours so that the impact could maximise the satisfaction and performance of subordinates (Northouse, 2004). Much of the research that followed has taken precedence of the patterns and findings set by these two universities (Yukl, 1998).

Another well known research in the leadership behaviour approach is the Managerial Grid proposed by Robert Blake and Jane Mouton (1964). The grid which is better known as the Leadership Grid, is considered a more practical approach in understanding the behaviours of leaders or managers (Mengel, 2008). The grid was designed to explain how leaders help organizations reach their purposes through two factors: concern for production and concern for people (Northouse, 2004). "Concern for production refers to how a leader is concerned with achieving organizational tasks [while] concern for people refers to how a leader attends to the people within the organization who are trying to achieve its goals" (Northouse, 2004, p. 69). These two factors are also found to bear resemblance to task-oriented behaviour and relationship-oriented behaviour.

The behavioural approach has had some positive contribution in the understanding of leadership. Firstly, this approach has broadened the scope of leadership research to include the behaviours of leaders and what they do in various situations (Northouse, 2004). Secondly, the behavioural approach has introduced concepts which are paramount in the behaviours of leaders: the focus on task and the focus on relationship (Mengel, 2008). 
Nevertheless, the behaviour approach has drawn some criticism. Yukl (1998), for instance, believes that most of the research done on understanding the behaviour of the leaders "have been mostly contradictory and inconclusive" (p. 64). Many studies have failed to identify a sufficiently consistent pattern between the task and relationship behaviours of the leaders with the outcomes such as performance, morale and job productivity (Bryman, 1992; Mengel, 2008; Northouse, 2004).

\subsubsection{Transformational and Transactional Approach}

One of the current approaches to leadership that has been the focus of much research since the early 1980s is the transformational approach (Bass \& Avolio, 1993; Miner, 2005; Northouse, 2004; Yukl, 1998, 1999a). Lowe and Gardner (as cited by Northouse, 2004) found that one third of the research on leadership prior to the year 2001 was about transformational leadership. The transformational leadership approach represents a seminal shift in the field of leadership (Bass, 2008). Many writers and researchers have described the positive aspect of this new leadership approach (Yukl, 1999a). As the name implies, transformational leadership is a process that changes and transforms individuals (Northouse, 2004). According to Yukl (1999a), several versions of this approach have been proposed by other leadership theorists including Burns (see Burns, 1978); Bass (Bass, 1985, 1998, 2008; Bass \& Avolio, 1994); Bennis and Nanus (see Bennis \& Nanus, 1985); Tichy and Devanna (Tichy \& Devanna, 1986); and Leithwood (Leithwood \& Janzti, 2005; Leithwood, Tomlinson, \& Genge, 1996).

The transformational approach in leadership was first mentioned by Downton in 1973 (as cited by Bass, 2008). Downton's study on rebel leadership is often cited as the beginning of academic interest and systematic enquiry about transformational leadership (Leithwood \& Janzti, 2005). The transformational approach was later developed by Burns in his book titled Leadership (see Burns, 1978). The early conception of the transformational approach accepts and incorporates Maslow's hierarchy of needs (Miner, 2005). The transformational approach later evolved and incorporated the Model of Charismatic leadership (Bryman, 1992; Miner, 2005). Bass and Riggio (2006) agree that transformational leadership has much in common with charismatic leadership, but maintains that charismatic leadership is only part of the transformational leadership approach. Bass and Riggio (2006) add that early social science approaches on leadership focused on the dichotomy of directive (task-oriented) 
versus participative (people-oriented) leadership, however, transformational leadership can either be directive or participative and is not an either-or proposition.

Unlike the traditional approaches or theories in leadership which focus on "rational processes", the transformational approach emphasizes emotions and values (Yukl, 1999a, 1999b). In addition, the transformational approach emphasises the necessity to understand the role of the leader and how the leader is able to influence followers to achieve greater heights (Yukl, 1999b). The transformational approach "also recognize the importance of symbolic behaviour and the role of the new leader in making events meaningful for followers" (Yukl, 1999b, p. 33). In addition, the transformational approach has helped us understand how a leader is able to influence followers to make self-sacrifices, commit to objectives and achieve more than what was initially expected (Yukl, 1999a).

According to Yukl (1998, 1999a, 1999b), the transformational approach appears to make an important contribution to the understanding of leadership. Kouzes and Posner believe (2007) transformational leadership is "the kind of leadership that gets people to infuse their energy into strategies"(p. 122). Transformational leadership focuses on intangible qualities such as vision, shared values, and ideas in order to build relationships, give larger meaning to separate activities, and provide common grounds in order to enlist followers in the change process (Zagorsek, Dimovski, \& Skerlavaj, 2009).

Transactional approach is often treated as the opposite of the transformational approach. The distinction between transformational and transactional leadership is commonly emphasised in leadership studies (Tavanti, 2008). Transactional leadership has been the traditional model of leadership (Jones, 2008). It is considered a process-oriented model of leadership that was developed largely from a social exchange perspective, often emphasizing the implicit relational qualities of the transaction that exists between leaders and followers (Hollander, 1993). Transactional leadership stems from more traditional views of workers and organizations, and it involves the power of the leader to use followers for task completion (Horner, 1997). Bennis and Nanus (1985) believe that "leadership is also a transaction between leaders and followers. Neither could exist without the other" (p. 32). 


\subsubsection{The Early Concept of Transformational Leadership}

According to Burns, "leadership must be aligned with a collective purpose and effective leaders must be judged by their ability to make social changes" (Stewart, 2006, p. 8). Burns explains that the leadership process can be conceived as transformational and transactional (Bass, 1998).

Burns (1978) suggests transformational leadership "occurs when one or more persons engage with others in such a way that leaders and followers raise one another to higher levels of motivation and morality [and as a result] transforming leadership becomes moral in that it raises the level of human conduct and ethical aspiration of both leader and led, and thus it has transforming effect on both"(p. 20). Burns claims that leaders must do more than to cater to the needs and desires of the people, thus transformational leadership aims to move beyond this by raising both leaders and followers to a greater level of motivation and morality (Price, 2008). For Burns, transformational leadership is a process and not a set of discrete acts (Yukl, 1998). Burns proposes that transformational leaders shape, alter and elevate the motives, values and goals of their followers into achieving significant changes in the process (Bolden, Gosling, Marturano, \& Dennison, 2003).

Burns (as cited by Bass, 2008) defines transformational leaders as those who (1) raise the followers' level of consciousness about the importance and value of designated outcomes and ways of reaching them; (2) get the followers to transcend their own self-interests for the sake of the team and organization; and (3) raises the followers' level of need from lowerlevel concerns for safety and security to higher level needs for achievement and selfactualization.

Transactional leadership for Burns, on the other hand, is considered as the opposite of transformational leadership (Bass, 2008; Yukl, 1998). The introduction of transactional leadership by Burns is seen as a way to differentiate ordinary (transactional) from extraordinary (transformational) leaderships (Kirby, Paradise, \& King, 1992). According to Burns (1978), "leaders [who] approach followers with an eye toward exchanging" (p. 4) are considered as transactional leaders. Transactional leadership therefore refers to the exchange between leaders and their followers (Bass, 2008; Kuhnert \& Lewis, 1987; Leithwood, et al., 1996; Northouse, 2004; Yukl, 1998). Burns defines this exchange as economic, political or 
psychological in nature (Tavanti, 2008). In addition, Burns believes that the relationship between the leader and the follower revolves around the bargaining process and the maintenance of it (Tavanti, 2008). Burns (as cited by Tavanti, 2008) also argues that as a result, this puts a limit on this leadership approach which does not attempt to push the leader-subordinate relationship beyond bargaining, contracts and exchange.

Burns (as cited by Bass, 2008) adds that the exchange between leaders and followers is aimed at satisfying their (leaders and followers) own self-interests. The notion of exchange as characterised by Burns "could be economic or political or psychological in nature: a swap of goods or of one good for money; a trading of votes between candidate and citizen or between legislators; hospitality to another person in exchange for willingness to listen to one's trouble" (1978, p. 19). Therefore, the exchange dimension of transactional leadership is very common and can be observed at many levels throughout all types of organizations and places (Northouse, 2004). Burns argues that this form of leadership is morally weak and unethical (Price, 2008). This is because transactional leaders are motivated simply by people's wants and needs; therefore it fails to foster and maintain genuine relationship between the leader and follower (Price, 2008).

\subsubsection{The Development of Transformational-Transactional Leadership}

Bernard Bass is considered the chief advocate of transformational leadership (Price, 2008). In 1985, Bass conceptualised the transformational-transactional leadership paradigm which is a two-factor model of leadership. This two-factor model was based on an earlier transformational-transactional distinction made by Burns (Yukl, 1999b). Bass (as cited by Avolio \& Bass, 2004) proposed a model for the relationship between transformational and transactional leadership, suggesting that transformational leadership actually augments transactional leadership for the benefit of the leaders, subordinates and organization. In addition, Bass provided a more expanded and refined version of this two-factor model by providing different dimensions that accompany both transformational and transactional leadership (Northouse, 2004; Stewart, 2006; Yukl, 1998). The transformational-transactional paradigm was further refined by Bass, Avolio and colleagues (Bass \& Avolio, 1994).

For Bass, the main agenda was developing a leadership approach that could be applied and practiced by the masses at all levels (Miner, 2005). Bass aimed at advancing the existing 
research by focusing on the crucial aspects of the transformation of followers because he believes the real movers and shakers of the world are transformational leaders (Winkler, 2010). In addition, “Bass extends Burns' work by giving more attention to followers' rather than leaders' needs by suggesting that transformational leadership could apply to situations in which the outcomes were not positive" (Northouse, 2004, p. 173).

The difference between Burns' and Bass's approach was highlighted by Bryman (1992): "Bass seeks to outline the components of the two types of leadership, and as such is concerned to specify their content more precisely than in Burns' somewhat broad-brush account"(p. 98).

Another difference between the approaches of Burns and Bass was noted by Yukl (1998): "Burns limits transforming leadership to enlightened leaders who appeal to positive moral values and higher-order needs of followers. In contrast, Bass classifies as transformational any leader who activates follower motivation and increases follower commitment, regardless of whether the effects ultimately benefit followers"(p. 327).

A further major difference in the approach is that whilst Burns considered the transformational and transactional dimensions as opposite ends of the leadership continuum, Bass offers quite a different understanding of what entails the transformational-transactional forms of leadership (Leithwood, et al., 1996). Bass (2008) points out that transformational and transactional leadership are not on opposite ends of a single continuum, as suggested by Burns, but are two positively correlated dimensions. Antonakis and House (2002) add: “....in contrast to Burns, Bass argued that transactional leadership is an essential prerequisite to effective leadership" (p. 12).

In addition, Bass maintains that transformational leadership and transactional leadership can actually be complementary (Leithwood \& Janzti, 2000). The difference between the two conception is important because there is an implication for Bass that the best leaders are both transformational and transactional (Bryman, 1992; Tavanti, 2008). Avolio and Bass (2004) argue that transformational leadership does not replace transactional leadership, it augments the transactional leadership approach in achieving the goals of the leaders, subordinates and organization. 
Despite some of his different approaches towards the transformational-transactional paradigm, Bass (Bass \& Avolio, 1993) did not see the need to revamp the earlier works done by Burns. Bass and Avolio (1993) explain: “A common problem with leadership research is that one new theory often is substituted for an older theory that has fallen into disfavour. Rather than build on earlier theories, there is a tendency to discount them for the sake of introducing a new way of thinking. We disagree with this strategy...”(p. 51).

The basic tenets of transformational leadership, as defined by Burns, remained as the core approach for Bass. Like Burns, Bass defined transformational leadership in terms of the leaders' effect on followers; that is, they are able to feel trust, admiration, loyalty and respect toward the leader (Yukl, 1998). Transformational leaders motivate their followers to do more than they originally expected and thought possible to do (Bass, 2008).

Transformational leaders set more challenging expectations and achieve higher standards of performance (Bass, 1998, 2008; Bass \& Riggio, 2006).

Essential to the transformational approach, Bass has introduced four core components that encompass the transformational leadership. Bass argues that transformational leaders behave in ways to achieve superior results by employing one or more of the four core components of transformational leadership (Bass, 1998; Bass \& Avolio, 1994; Bass \& Riggio, 2006). The four components, as suggested by Bass (1998, 2008; Bass \& Avolio, 1993; Bass \& Riggio, 2006), are:

i) Idealized Influence or Charismatic Leadership:

Leaders behave in ways that result in them being role models for their followers. Leaders are admired, respected and trusted. They are willing to take risks and are consistent rather than arbitrary. Followers identify with and emulate these leaders; leaders are endowed by their followers as having extraordinary capabilities, persistence and determination. Among the things the leaders do to earn this credit is considering the needs of others over their own personal needs. The leader can be counted on to do the right thing, demonstrating high standards of ethical and moral conduct. The leader also avoids using power for personal gain. There are two sub components of idealized influence: attributed and behaviour, which are 
measured separately using the Multifactor Leadership Questionnaire. However, for this study, the component of idealized influence is treated as one whole component.

ii) Inspirational Motivation:

Leaders behave in ways that motivate and inspire those around them by providing meaning and challenge to their followers' work. Leaders are clear of the expectations that followers want to meet and also demonstrate commitment to goals and shared visions of the organization. As a result, team spirit is aroused and enthusiasm as well as optimism is displayed by both leader and follower. Leaders get followers involved in envisioning the future of the organization. The leaders are clear in communicating expectations that followers should meet. They are committed to the goals and shared vision of the organization.

iii) Intellectual Stimulation:

Leaders stimulate their followers' efforts to be innovative and creative by reframing problems and approaching old situations in new ways. New ideas and creative solutions are solicited from followers who are included in the process of addressing problems. Followers are encouraged to try new approaches and their ideas are not criticised if it differ from their leaders'. In addition, there is no public criticism of individual members' mistakes.

iv) Individualized Consideration:

Leaders pay special attention to each individual follower's needs for achievement and growth by acting as coach or mentor. Followers are developed to successively higher levels of potential. Individualized consideration is practiced when new learning opportunities are created with a supportive climate. The leader's behaviour demonstrates acceptance of individual differences. Followers are treated differently but equitably on an ongoing basis. The leaders are effective listeners and delegate tasks as a means of developing followers. Delegated tasks are monitored to see if the followers need additional direction or support and to assess progress; ideally, followers do not feel they are being checked. 
The transformational approach "is in some ways an expansion of transactional leadership" (Bass \& Riggio, 2006, p. 4). Therefore, Bass believes that leaders could also be transactional (Bass, 2008; Bass \& Riggio, 2006). Bass argues "transformational leadership adds to the effectiveness of transactional leadership; transformational leadership does not substitute for transactional leadership" (Bass, 1999, p. 21). In support of Bass, Jones (2008) believes that both kinds of leadership are necessary.

Transactional leadership occurs when the leader rewards or disciplines the follower depending on the adequacy of the followers' performance (Bass, 1998; Bass \& Avolio, 1994; Bass \& Riggio, 2006). Transactional leadership can help people recognize what needs to be done in order to reach a desired outcome and may also increase confidence and motivation (Leithwood \& Poplin, 1992). Transactional leadership can service the structure of relationship that is already in place while transformational leadership adds to the structure and readiness by helping the followers to transcend their immediate self-interests (Bass, 1998). Transactional leaders work towards recognizing the roles and tasks required of their subordinates in order to achieve the desired outcomes (Avolio \& Bass, 2004).

Like Burns, Bass sees transactional leadership as the exchange that occurs between the leaders and followers (Bass, 2008; Bryman, 1992). Bass (2008) explains further: "This exchange involves direction from the leader or mutual discussion with the followers about requirements to reach desired objectives. Reaching objectives will appear psychologically or materially rewarding...If the transaction occurs and needs of leaders and followers are met, and if the leader has the formal or informal power to do so, he or she reinforces the successful performance" (p. 618). Because the transactional leadership process builds upon the exchange and rewards between the leader and the follower, this type of leadership is likely to result in followers' compliance, but is unlikely to generate enthusiasm for and commitment to task objectives (Zagorsek, et al., 2009).

Transactional leaders exhibit specific leadership skills usually associated with the ability to obtain results, solve problems, plan/organize and work within the structures and boundaries of the organization (Tavanti, 2008). Because of the effectiveness of the exchange notion of leadership, transactional leadership has remained the organizational model for many people and organizations (Jones, 2008). 
Transactional leadership also involves motivating and directing followers primarily through appealing to their own self-interest (Hellrigel \& Slocum, 2007). Hellrigel and Slocum (2007) explain: "The transactional leader tends to focus on a carrot (but sometimes a stick) approach, set performance expectations and goals, and provide feedback to followers. The primary power of transactional leaders comes from their formal authority and responsibilities in the organization. They focus on the basic management processes of controlling, organizing and short term planning” (p. 236).

According to Tavanti (2008), transactional leadership is based on the assumption that subordinates and systems work better under a clear chain of command. Popper and Zakkai (1994) believe that transactional leadership is prevalent in most organizations and organizational situations because it contains the basic mechanism of exchange and reward.

Bass (as cited by Tavanti, 2008) believes that transactional leadership can be as effective as transformational leadership if the leader is able to: clarify what is expected of the employees' performance, explain how to meet these expectations, spell out the criteria of the evaluation of the performance, provide feedback on whether the employee is meeting the objective and allocate rewards that are contingent to meeting the objectives.

Like transformational leadership, transactional leadership also consists of several components. The components as, suggested by Bass (1998, 2008; Bass \& Riggio, 2006), are:

i) Contingent Reward:

This is considered a constructive transaction. This constructive transaction has been found to be reasonably effective although not as much as any of the transformational components in motivating others to achieve higher levels of development and performance. The leader assigns what needs to be done and promises rewards in exchange for satisfactorily carrying out the assignment. Contingent reward is transactional when the reward is a material one, such as bonus or increment. Contingent reward could also be transformational, however, when the reward is psychological, such as praise. 
ii) Management-by-Exception:

Management-by-Exception is considered a corrective transaction. It tends to be more ineffective than contingent reward or the components of transformational leadership. This corrective transaction can either be considered as active (MBEA) or passive (MBE-P). In MBE-A, the leader actively monitors mistakes and errors in the followers' assignments and takes corrective action when necessary. MBE-P, on the other hand, implies the leader as passively waiting for mistakes to occur and only then will the leader take corrective action. MBE-A may be effective and required in some situations such as when safety issues arise. Leaders must sometimes practice passive MBE when required to supervise a large number of subordinates who report directly to them.

\subsubsection{The Expansion of Transformational Leadership}

Apart from Bass' and Burns' seminal work on transformational-transactional leadership approach, other researchers have joined the bandwagon in trying to extend this leadership approach. The mid-eighties and beyond saw the height of transformational leadership theories being expanded by researchers such as Bennis and Nanus (see Bennis \& Nanus, 1985); Tichy and Devanna (1986); Leithwood (Leithwood, Begley, \& Cousins, 1994; Leithwood \& Janzti, 2005; Leithwood, et al., 1996) and Hellriegel and Slocum (2007). Apart from the conceptual understanding of transformational leadership developed by Burns and Bass, transformational leadership has been defined in several ways.

\subsection{Bennis and Nanus}

Bennis and Nanus (as cited by Ercetin \& Duzer, 2008; Yuk1, 1998), for instance, believe that transformational leadership is the ability of the leader to channel the collective energies of the followers in pursuit of a common goal for the organization. They identified four strategies used by leaders in transforming organizations (Northouse, 2004). First, a transformational leader needs to have a clear vision (Northouse, 2004; Yukl, 1998). A clear and appealing vision serves as an inspiration for followers (Yukl, 1998). Northouse (2004) points out that the vision needs not be too complicated and a simple and understandable vision would provide a more realistic future. Second, Bennis and Nanus believe that transformational leaders are social architects for their organizations as they are the ones that could transform their organization's values and norms (Northouse, 2004). The third strategy, 
according to Bennis and Nanus, is the ability for transformational leaders to develop commitment and trust (Yukl, 1998). Commitment to the vision is closely related to the followers' trust towards the leader (Yukl, 1998). Bennis and Nanus found that when leaders establish trust in an organization, it gives the organization a sense of integrity (Northouse, 2004). The final strategy according to Bennis and Nanus is that transformational leaders use positive self-regard in their approach, as this would create a reciprocal impact on followers' confidence and expectations (Northouse, 2004).

Apart from the four strategies, Bennis and Nanus believe that there are other important elements for a transformational leader. These elements include visionary, committed and trustworthy, able to facilitate organizational learning, communication, decisiveness, empowerment and concentration (Ercetin \& Duzer, 2008; Yukl, 1998).

\subsection{Tichy and Devanna}

Tichy and Devanna (1986) approach transformational leadership as a process of change. Based on the study of 12 CEOs in a variety of large corporations, Tichy and Devanna identified a three-act change process. The process can be viewed as a sequence of phases (Yukl, 1998). This sequence of phases is personified as a three-act drama.

Act I of this process involves recognizing the need for revitalization, or change. Tichy and Devanna (1986) believe that the first thing a transformational leader should do is to acknowledge they are the agent of change. Changes are needed so that organizations would not be stuck in doldrums while other organizations progress. As the agent of change, a transformational leader could help trigger the changing process by challenging the leader, building external networks and visiting other organizations.

Act II in the change process is creating a new vision. According to Tichy and Devanna (1986), a transformational leader needs "to create a vision that a critical mass of employees will accept as a desirable change for the organization" (p. 32). The challenge for transformational leaders is both to find and create a vision of an organization that is some way better than the old one and to encourage others to share that dream (ibid, 1986). Tichy and Devanna believe that vision, therefore, should be formulated in such a way that it will make the complication of changing worth the effort. 
Act III of the change process is called institutionalizing change. Leaders at this stage must turn their attention into "designing new organizational structures and processes so that the vision can be achieved" (Tichy \& Devanna, 1986, p. 186). Transformational leaders at this stage need to identify key personnel or followers who will be committed to the new vision of the organization.

\subsection{Hellriegel and Slocum}

According to Hellriegel and Slocum (2007), transformational leadership is about inspiring followers to understand and embrace a new vision of possibilities, anticipating the future, inspiring followers and relevant stakeholders, developing followers to be leaders and guiding the organization or group into a community of challenged and rewarded learners (ibid, 2007).

In addition, transformational leadership involves "influencing followers through a complex and interrelated set of behaviours and abilities"( Hellrigel \& Slocum, 2007, p. 251). The behaviours and abilities include visionary, inspiring, daring, ethical and assertive risk-takers who seize or create new opportunities (ibid, 2007). In addition, Hellriegel and Slocum (2007) consider transformational leaders as "thoughtful thinkers who understand the interaction of technology, culture, stakeholders and external environment forces" (p. 245). Finally, Hellriegel and Slocum believe transformational leadership is able to foster synergy: "Synergy occurs when people together create new alternatives and solutions that are netter than their individual efforts" (ibid, 2007, p. 249).

Hellriegel and Slcoum built upon Bass's transformational dimension and propose four key components of transformational leadership. The key components include inspirational motivation, intellectual stimulation, idealized influence and individualized consideration (Hellrigel \& Slocum, 2007).

\subsection{Leithwood}

Leithwood and his colleagues have been instrumental in bridging the work of Burns and Bass into the field of educational administration and leadership (Stewart, 2006). Leithwood, Begley and Cousins (1994) believe that the term transformational "implies major changes in 
the form, nature, function and/or potential of some phenomenon; applied to leadership, it specifies general ends to be pursued although it is largely mute with respect to means"(p. 7). The central purpose of transformational leadership is the enhancement of the individual and collective problem-solving capacities of organizational members (Leithwood, et al., 1994).

Like Bass, Leithwood proposes six dimensions that encompass transformational leadership. The six dimensions are building school visions and goals, providing intellectual stimulation, offering individualized support, symbolizing professional practices and values, demonstrating high performance expectations and developing structures to foster participation in school decisions (Leithwood, et al., 1994; Leithwood \& Janzti, 2000).

Leithwood, Tomlinson and Genge (Leithwood, et al., 1996) reviewed two studies of transformational leadership in the education world and found that transformational leadership is strongly related to the satisfaction of the leader and positive perceptions of the leader's effectiveness. Transformational leadership is also thought to be strongly related to the willingness of organizational members to engage in extra effort (Leithwood, et al., 1996). Leithwood concludes that transformational leaders are in constant pursuit of three goals: helping staff members develop and maintain a collaborative and professional school culture, fostering teacher development and helping teachers solve problems together more effectively (Stewart, 2006).

\section{$2.4 \quad$ Leadership Styles}

From the late 1940s, the study of leadership has moved increasingly towards the understanding of leadership styles (Bryman, 1992). Adeyemi-Bello (2001) believes that leadership style is a variable that has received significant attention in the literature of leadership. Other more common leadership styles found in the literature include charismatic, situational, autocratic, democratic, directive, coercive, affiliative, consultative and participative (Bass, 2008; Bryman, 1992; Coleman, 2005; Goleman, 2000; Jung \& Avolio, 1999).

Leadership style represents an important aspect of leadership (Nik Maheran, Filzah, Siti Norezam, \& Rosli, 2009). Like the definition of leadership, the problem of defining leadership styles has overwhelmed the literature. Leadership style may be defined as 
patterns of emphases, indexed by the frequency or intensity of specific leadership behaviours or attitudes which a leader places on the different leadership functions (Andersen, 2008; Casimir, 2001). Eagly and Johannesen-Schmidt (2001), on the other hand, defined leadership style as a "relatively stable pattern of behaviour exhibited by leaders" (p.781). Coleman (2005) defines leadership styles in terms of influence: who is exerting it, what it is exerted for and what are its outcomes. Northouse (2004) and Luneburg and Ornstein (1996) share similar views in which they believe leadership styles is roughly equivalent to the manner in which the leader influences subordinates. Hollander (1978) believes that leadership style refers to the characteristics which are most typical across situations.

Yukl (1998) argues that there is no single leadership style that works in every context, organization or situation. A leader might possess not only one but different leadership styles suiting different situations. Kahai, Sosik and Avolio (2003) agree that leaders could influence their followers by altering their leadership style. Goleman (2000) believes that leaders who could exhibit more than one leadership style are more effective in contributing to the success of the organization. Liu et al (2003) recognize that different employee groups are managed differently and may require different leadership styles.

Organizational leaders show a wide variation of leadership styles which they practice at the organization (Oshagbemi \& Ocholi, 2005). Yukl (1998) and Van Fleet (as cited by Ardichvili, 2001) believe that a match between leadership styles and organizational culture and norms is a key prerequisite for successful achievement of organizational goals. McCoolKennedy and Anderson (2002) agree that the style of the leader is considered to be particularly important in achieving organizational goals and also important in being able to evoke performance among subordinates in the organization. Dulewicz \& Higgs (2005) point out that the relationship between the leaders' styles and their organization in which they work is seen to be important. Jung and Avolio (1999), on the other, hand have found that leadership style can have different effects on the motivation and performance of the subordinates in an organization. Wan Faridah Akmal, Noor Azmi and Ishak (2002) believe that the leadership style could determine the success and failure of an organization. 


\subsubsection{Transformational and Transactional Leadership Styles}

Tichy and Devanna (1986) describe the nature of transformational leadership as not necessarily about the presence of charisma but a style of leadership which could be learned (Jones, 2008). In the context of this study, the styles of leadership refer to the extent of how a person exhibits one or more components of leadership styles as suggested by the Model of the Full Range of Leadership (Bass, 1985, 2008) developed by Bass and Avolio (Bass \& Avolio, 1993, 1994). The Model of the Full Range of Leadership or FRL explains or implies that every leader displays a frequency of leadership style that is either transformational or transactional, and this is central to Bass's argument that leaders are both transformational and transactional (Bass, 1999).

FRL comprises of the four components of transformational leadership, being Idealised Influence, Inspirational Motivation, Intellectual Stimulation and Individualized Consideration (the four I's); and two components of transactional leadership, being Contingent Reward and Management by Exception, both Active and Passive (Bass, 2008; Bass \& Avolio, 1994). In addition, the model also incorporates another style of leadership which is called laissez-faire (Bass \& Avolio, 1994). Laissez-faire leadership is "the avoidance or absence of leadership and is, by definition, most inactive, as well as most ineffective according to almost all research on this (leadership) style" (Bass, 1998, p. 7). Fundamental to the FRL, Bass believes that every leader displays each of the styles to some extent (Bass \& Avolio, 1994). FRL attempts to depict the whole range of leadership styles from non-leadership to the more transformational styles (Kirkbride, 2006).

The Optimal Profile as shown in Figure 2.1 was developed by Bass and Avolio (1994) in relation to FRL. This profile illustrates "how frequently an individual displays a particular style of leadership"(Bass \& Avolio, 1994, p. 5). 


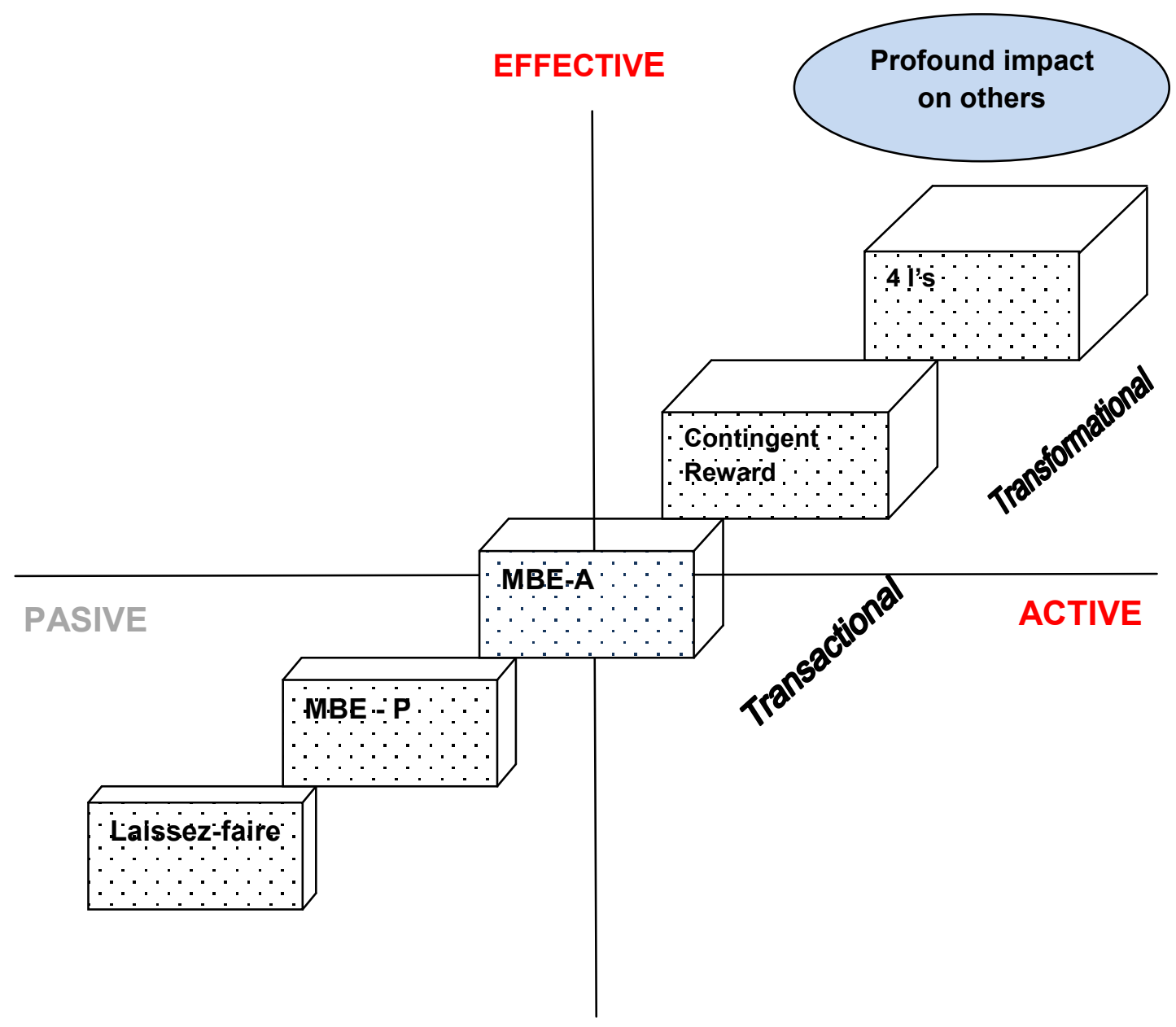

INEFFECTIVE

Figure 2.1: Optimal profile (Bass \& Avolio, 1994; MLQ International, 2008)

The horizontal active dimension helps clarify the style of leadership while the vertical effectiveness dimension represents the impact of the leadership style on the performance of followers (Bass, 1998; Bass \& Avolio, 1994). The boxes represent the dimensions of transformational leadership, transactional leadership and the avoidance of leadership (i.e. laissez faire). The depth of each box represents the degree of leadership style exhibited by the leaders. The optimal profile shows that the depth of the boxes is greater at the top end compared to the depth of the laissez-faire box. This explains that the leader is infrequently displaying a laissez-faire leadership style and increasing the frequencies of the transactional leadership styles of Management by Exception Passive, Management by Exception Active and Contingent Reward (Bass \& Avolio, 1994). The Optimal profile shows the transformational four I's as being most frequently displayed. In contrast, as shown in Figure 
2.2 in the Suboptimal profile, the poorly performing leader tends to be more inactive and ineffective (Bass \& Avolio, 1994), exhibiting more of the transactional and laissez-faire type of leadership style frequently and the transformational components less frequently (Bass, 1998).

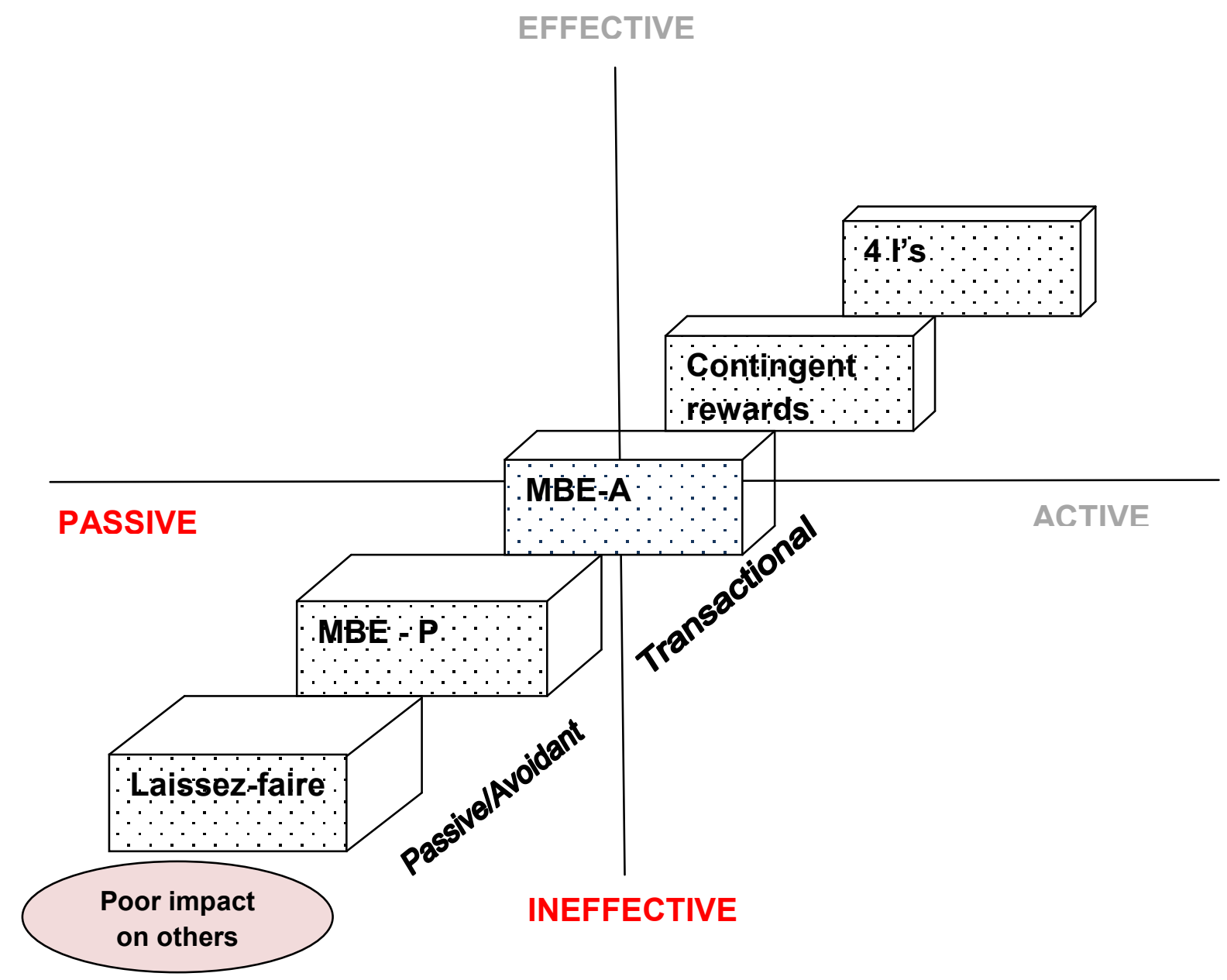

Figure 2.2: Suboptimal profile (Bass \& Avolio, 1994; MLQ International, 2008)

Figure 2.1 and 2.2 represent the full range of leadership styles. The important point about the FRL is "that most leaders display all the styles of leadership in the model but in differing patterns of frequencies"(Bass, 1996). The Optimal and Suboptimal profiles suggest that leaders could be placed on either one of the profiles. Thus, ideally a leader profile should 
show greater depths in the transformational dimensions and less depth on the managementby-exception styles and laissez-faire.

In order for Bass and colleagues to test their model of full range leadership, they have developed a measurement instrument called the Multifactor Leadership Questionnaire (Bass \& Riggio, 2006). The Multifactor Leadership Questionnaire (or MLQ), which actually assesses the Model of Full Range of Leadership, is the most widely accepted instrument to measure the extent of one's leadership style; namely transformational, transactional or laissez-faire (Alimo-Metcalfe \& Alban-Metcalfe, 2001; Bass \& Riggio, 2006). A detailed explanation of MLQ will be given in the next chapter.

Apart from the leadership styles that are relevant to the FRL as proposed by Bass and colleagues, other researchers have also suggested some key components that are essential to the leadership styles of a transformational leader. For instance, Dubinsky, Yammarino and Jolson (1995) suggest leaders possess certain characteristics which are related to transformational leadership, being emotional coping, behavioural coping, abstract orientation, risk taking, innovation, use of humour and experience (Dubinsky, et al., 1995).

Carless, Wearing and Mann (2000) suggest seven leadership styles that "encompass the concept of transformational leadership"(p. 390). These include communicating vision, developing staff, providing support, empowering staff, innovation, leading by example and charisma. Rafferty and Griffin (2004), on the other hand, propose five new sub-dimensions of transformational leadership that adds to the existing components introduced by Bass. The five sub-dimensions act as an extension to the leadership styles that a transformational leader should posses. These include vision, inspirational communication, supportive leadership, intellectual stimulation and personal recognition.

Nonetheless, the core leadership styles that this study is interested in are the transformational, transactional and laissez faire styles as proposed by the FRL. The study, however, will also take into consideration the other components of transformational leadership styles as proposed by other researchers when it comes to identifying the styles of the interview participants of the research. 


\subsubsection{Review of Some Current Studies}

The influence and effects of transformational and transactional leadership styles on job performance, satisfaction, organizational commitment and a multitude of other variables has been well researched (Adeyemi-Bello, 2001; Ardichvili, 2001; Dulewicz \& Higgs, 2005; Dvir, Eden, Avolio, \& Shamir, 2002; Jui-Chen \& Silverthone, 2005; Jung \& Avolio, 1999; Kahai, et al., 2003; Kuchinke, 1999; Lo, Ramayah, \& Wei, 2009; Lok \& Crawford, 2004; Nazatul-Shima, Fatimah, Normaziah, \& Misyer, 2008; Nik Maheran, et al., 2009; Rad \& Yarmohammadian, 2006; Shea, 1999; Viitanen \& Konu, 2009; Whitsett, 2007). These studies reveal that leadership styles play important roles in all aspects of organizational setting.

Jui-Chen and Silverthorne (2005) found that the influence of leadership style on job performance, satisfaction and stress has been well established. By using appropriate leadership styles, managers can affect employee's job satisfaction, commitment and productivity (McColl-Kennedy \& Anderson, 2002; Rad \& Yarmohammadian, 2006). A number of researches have investigated the leadership styles of managers across different organizations. Viitanen and Konu (2009) examined leadership styles of middle-level managers in the social and health care sector in Finland and discovered that they differ in terms of gender, professional background, activity sector, age, work experience and unit size. Rad and Yarmohammadian (2006) conducted a research on the leadership styles of managers in relation to job satisfaction. The participants of the study were senior and middle level managers in Isfahan University Hospital in Iran. Rad and Yarmohammadian (2006) found that the dominant leadership style of the managers was participative. They observed that employee job satisfaction depended on the leadership styles of their managers.

Oshagbemi and Ocholi (2005) conducted a study investigating the extent to which managers from various United Kingdom industries could be meaningfully grouped on the basis of the leadership styles which they exhibit in their jobs. Oshagbemi and Ocholi had utilised the Multifactor Leadership Questionnaire and found that leaders could be grouped into practical leaders, unity leaders and uncaring leaders. The grouping shows a meaningful and alternative classification of managers according to the characteristics of their jobs which is different from the traditional grouping based on rank and position (Oshagbemi \& Ocholi, 2005). 
Ardichvili and Kuchinke (2002) comparatively analysed the leadership styles of managers and subordinates in four countries of the former Soviet Union, Germany and the United States. In this study, Ardichvili and Kuchinke (2002) employed Bass' full range leadership framework which focuses on transformational and transactional leadership styles. The research found that there was no clear preference for one particular leadership style (transformational or transactional), as elements of both styles was shown by the participants of the research.

Keegan and Den Hargtog (2004) conducted a study comparing the relationship between transformational leadership and employee motivation, commitment and stress. Utilizing the Multifactor Leadership Questionnaire, the results of the study show that although project managers and line managers do not differ significantly in terms of their leadership styles, the impact of project managers may be weaker than the impact of line managers in terms of motivation, commitment and stress of their employees. One possible explanation given as to why such outcomes exist is perhaps that the human resource system of that company gives less support to one group of managers as compared to the others (Keegan \& Den Hartog, 2004).

Jung and Avolio (1999) manipulated transformational and transactional leadership style and compared them with individual and group task situations. The reason for this was to determine whether the leadership styles had any impact on individuals and group members when performing a brainstorming task. Results of that study indicated that group members with a transformational leader generated more ideas but individuals who work on their own would generate more ideas if they have a leader who exhibits transactional leadership styles.

In a study of middle level managers in a telecommunications firm, Berson and Avolio (as cited in Bass \& Riggio, 2006) found that transformational leaders were better able to get followers committed to organizational goals, presumably due to their abilities to communicate with followers. Dvir et al.(2002) have found that leaders who exhibit a transformational leadership style have shown positive impacts not only on their immediate subordinates but to other subordinates who do not report directly to them. 
Transformational leadership styles were also examined in educational settings or organizations. Whitsett (2007), for instance, conducted a research on the leadership styles of department heads in a university in the United States of America. Whitsett (2007) found that the department heads were trying to carry out leadership styles accpetable to the members of their faculties. In another study, Bogler (2001) examined the effects of principals' leadership style on teacher job satisfaction. It was found that the principals' transformational leadership style did have a strong effect on the teachers' satisfaction both directly and indirectly. Bogler (2001) also found that teachers prefer to work with principals who exhibit transformational leadership styles compared to transactional leadership styles.

The study of transformational and transactional leadership styles in Malaysia, however, is quite limited. Previous research done in regards to leadership styles in an educational organization in Malaysia was confined to principals in schools (Jazmi, 2009; Nor Shamsuri, 2002; Nursuhaila, 2007; Yahya, 2009). However, notable studies (of transformational and transactional leadership styles which were not conducted in an educational setting in Malaysia) include the comparative analysis of leadership styles among female and male middle managers working in Australia and Malaysia, carried out by Wood and Jogulu (2006). The study concluded that leadership styles in Malaysia were strongly peternalistic due to the nature of hierarchies in the society. Therefore, male managers in Malaysia rated themselves highly on the three dimensions of transformational leadership. Fazli and Khairul Anuar's (2008) study found that transformational leadership was significantly related to the financial performance of organizations. The study implied that an effective management approach emphasises key elements of transformational leadership. Another notable study done on the transformational and transactional paradigm was conducted by Wan Faridah Akmal et al. (2002). The study found that a significant relationship existed between transactional leadership and job identity.

\subsection{Middle Managers}

Floyd and Wooldridge (1994) argue that for much of its history, the academic literature on management and leadership has focused much on the leaders or managers at the upper echelon of organizations. Traditionally, middle managers have never been considered as part of the strategy process in the organization except in providing informational inputs and directing implementation of top management's policy (ibid, 1992). Top managers often fail 
to make distinctions about the variety of contributions made by middle level managers and in particular overlook the possibility that middle managers play strategic roles in the organization (ibid, 1994). Hence, Floyd and Wooldridge (1997) suggest that middle managers do ultimately make important contributions to strategy. In addition, Floyd and Wooldridge (1994) argue that middle managers must be considered as "part of an organization's control system"(p. 48) because they are the ones who "translate strategies defined at higher levels into actions at operating levels" (p. 48).

In short, middle level managers perform a coordinating role where they mediate, negotiate and interpret connections between the organization's strategic level which is the top management and the technical or operational level which consist of the organizations' personnel (Floyd \& Wooldridge, 1997). Floyd and Wooldridge (1997) believe that this role "establishes the potential for significant influence in the organization" (p. 466). Rouleau \& Balogun (2008) add that middle level managers are important because of the way they knowledgeably connect the operational core of what is desired by the top management into the direction that is needed by the organization. In addition, middle managers are considered as "critical mediators that facilitate organizational adaptation by both shaping senior manager strategic thinking and orchestrating the deployment of senior managers' plans" (Rouleau \& Balogun, 2008, p. 2).

According to Rouleau and Balogun (2008), the current literature highlighting the roles of middle managers has helped organizations to understand that the roles of middle managers are more than just "passive linking pins transmitting senior manager's instructions unquestioningly down the organization"(p. 2). Floyd and Wooldridge in particular have been championing the roles of middle level managers. One of the earlier study on middle level managers conducted by Floyd and Wooldridge (1990) have found that the involvement of middle level managers in the organization's strategic planning have resulted in improved organizational performance. Floyd and Wooldridge (1997) have also found that middle managers with formal boundary-spanning sub-units reported higher levels of strategic influence than others. A comprehensive review of middle managers in the literature was conducted by Wooldridge, Schmid and Floyd (2008). Wooldridge, et al (2008) reviewed 37 studies related to middle managers spanning from 1986 to 2008. Wooldridge et al. (2008) summarised that the studies have contributed to the understanding of middle managers in 
three categories: the strategic roles of middle managers and their antecedents, middle managers' involvement in strategy and organizational cognition and the relationship between middle management strategic behaviour and organizational outcomes.

The roles of middle level managers in the education sector are also highlighted by Briggs (2001a, 2001b, 2001c). Briggs (2001c) found that middle managers working in Further Education colleges are respected as experts and facilitators who perform key roles. Nonetheless, Briggs (2001c) believes that these middle managers should receive more support and training. Briggs (Briggs, 2001b) also found that there is evidence of delegated leadership and inclusive leadership environments, both of which support the middle manager's role. Importantly, Briggs' (2001b) research has indicated that the middle manager's role crossed the managerial and professional divide, with the managers showing market awareness, spending time setting targets and measuring against performance indicators, yet also providing academic leadership within their departments.

\subsection{Chapter Summary}

In this chapter, literature pertaining to the definition of leadership, leadership theories and leadership styles were explored. In addition, a section relating to managers vs. leaders was included. Background research, done particularly in the area of transformational leadership styles, was also reviewed. 


\section{CHAPTER 3 - METHODOLOGY}

\subsection{Chapter Overview}

This chapter discusses the methodology of this study. This includes the research design, the location, the samples or participants involved in this study, the research procedure and the data analysis tools. Issues of validity, reliability and rigour are also discussed.

\subsection{Mixed Methods}

This study employed a combination of quantitative and qualitative approaches to obtain both comprehensive and in-depth understandings of leadership styles among PTD and DG middle level managers working in the Ministry of Education Malaysia. According to Onwuegbuzie and Collins (2007), studies that combine qualitative and quantitative research methods "fall into a class of research that are appropriately called mixed methods research" (p. 281). Mixed methods research therefore refers to the use or combination of qualitative and quantitative methods, approaches or concepts in a single study (Johnson \& Christensen, 2008; Morse \& Niehaus, 2009). To be more explicit, Creswell, Plano Clark, Gutmann and Hanson (2003) suggest that "a mixed methods study involves the collection or analysis of both quantitative and/or qualitative data in a single study in which the data are collected concurrently or sequentially... and involve the integration of the data at one or more stages in the process of the research" (p. 212). According to Bergman (2008), mixed methods research has experienced a tremendous rise in popularity in the field of social science. Hence, "research that involves the integration of quantitative and qualitative research has become increasingly common in recent years" (Bryman, 2006, p. 97).

The primary philosophical orientation associated with mixed methods research is pragmatism (Johnson, Onwuegbuzie, \& Turner, 2007; Teddlie, 2005). In the context of research design, pragmatism can be defined as research that utilises both qualitative and quantitative methods and mixing the two methods when beneficial (Leech, Dellinger, Brannagan, \& Tanaka, 2009). According to Hewson (2006), pragmatism is the term given to a particular paradigm (or 'worldview') which has been identified as providing a rationale for mixed methods research. Pragmatism rejects the traditional conception that the paradigms underlying quantitative and qualitative approaches (positivism and constructivism, respectively) are essentially incompatible and in conflict (Hewson, 2006). This either-or 
position is called the incompatibility thesis (Johnson \& Christensen, 2008). Instead, pragmatists argue that both quantitative and qualitative approaches have their own distinctive strengths and weaknesses and can be usefully combined to complement one another (Hewson, 2006). Therefore, pragmatism is very important in mixed methods research because it gives flexibility and practicality to the researcher to integrate the quantitative and qualitative aspects at different stages of the research process (Bryman, 2006). According to Creswell et al. (2003), integration can be defined as the combination of quantitative and qualitative research method within a given stage of inquiry.

There are several justifications as to why mixed methods research was chosen as the research paradigm for this study. First, mixing enhances triangulation (Morrison, 2007). Triangulation is the term given when the researcher seeks convergence and corroboration of results from different methods that are studying the same phenomenon (Johnson \& Christensen, 2008). Johnson and Christensen (2008) add that triangulation can substantially increase the credibility or trustworthiness of the research findings. The second justification as to why this study chooses the mixed methods approach is that the quantitative and qualitative findings are complimentary of each other. According to Bryman (2006), complementarity in mixed methods refers to the notion that the researcher can bring together a more comprehensive account of the area of enquiry when both quantitative and qualitative methods are employed. This is particularly useful in the field of leadership research. Antonakis, Schriesheim, Donovan, Gopalakrishna-Pillai, Pellegrini and Rossomme (2004) argue that leadership researchers combine both quantitative and qualitative methods to better understand and complement the complex nature of leadership. Antonakis et al.(2004) add, "given the contextual and complex nature of leadership, it is important that qualitative methods - as a theory generating approach, complement quantitative methods, whose strengths are in theory testing" (p. 54). Mixed methods research in leadership would also provide the researcher with a broad and in-depth understanding of leadership as agreed by Currie and Lockett (2007).

In examining research methods, Bryman (2004) found that most quantitative methodology was more dominant as compared to qualitative methodology with respect to research in leadership. Nonetheless, Bryman (2004) believes that qualitative researchers on leadership are able to make their findings more credible when merged with the quantitative methods. 
Bryman, Stephens and Campo (1996) add that mixed methods research in leadership "meant that it was possible to compare the findings deriving from the qualitative data with those typically deriving from the quantitative approach that is typically employed in such research" (p. 356). Bryman (2004) argues that despite the small numbers of leadership research which employed the mixed methods approach, every single mixed methods study has enhanced our understanding of the leadership phenomenon from multiple perspectives and methodologies. Bryman et al. (1996) add "through such an exercise, a dialog can be established between quantitative and qualitative research in such a way that the respective contributions of each approach can enhance our overall understanding of a domain like leadership" (p. 356).

\subsection{Research Design}

Mixed methods research offer several research designs or frameworks. Johnson and Christensen (2008), for instance, conceptualize mixed methods research design into two dimensions: time orientation and paradigm emphasis. Johnson and Christensen (2008) explain:

"Time orientation refers to whether the qualitative and quantitative components or phases of the study occur at approximately the same point in time (i.e. concurrently) or whether they are organized into phases over time (i.e. sequentially). Paradigm emphasis refers to whether the qualitative and quantitative parts of the study have approximately equal emphasis (i. e equal status) with regard to answering the research question(s) and interpreting the results or whether one paradigm clearly has more weight than the other (i.e. dominant status)" (p. 446). 
To illustrate the framework clearly, Johnson and Christensen have designed a mixed methods design matrix, shown in Figure 3.1 below:

Time Order Decision

\begin{tabular}{|c|c|c|}
\hline & \multicolumn{2}{|c|}{ 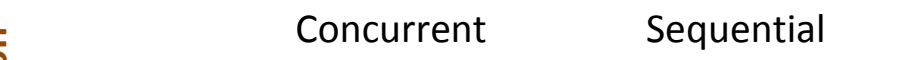 } \\
\hline & QUAL + QUAN & $\begin{array}{l}\text { QUAL } \longrightarrow \text { QUAN } \\
\text { QUAN } \longrightarrow \text { QUAL }\end{array}$ \\
\hline 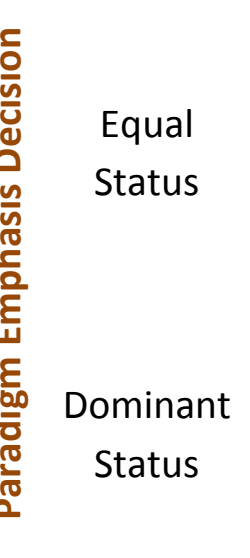 & QUAL + quan & $\begin{array}{l}\text { QUAL } \longrightarrow \text { quan } \\
\text { qual } \longrightarrow \text { QUAN } \\
\text { QUAN } \longrightarrow \text { qual } \\
\text { quan } \longrightarrow \text { QUAL }\end{array}$ \\
\hline
\end{tabular}

Figure 3.1: Mixed methods design matrix (Johnson \& Christensen, 2008)

Creswell and Plano Clark (as cited in Creswell, Plano Clark, \& Garret, 2008) believe that a mixed methods research could be conducted concurrently or sequentially. Concurrent mixed methods design includes triangulation design and concurrent embedded design. Sequential mixed methods on the other hand includes explanatory, exploratory and embedded design.

This study adopts Creswell's triangulation design and also Johnson and Christensen's equal status concurrent design. The triangulation design is a one-phase design in which quantitative and qualitative data are collected and analysed in parallel, and then merged together to develop a more complete understanding or to compare different results (Creswell, et al., 2008). In this triangulation design, the combination of quantitative and qualitative methods is given equal weight and status and most importantly are conducted concurrently (Johnson \& Christensen, 2008). Creswell et al. (2003) believe that this design is advantageous because it is familiar to most researchers and can result in well validated and substantiated findings. Ideally, the priority would be equal between the two methods. But in practical application, the priority may be given to either quantitative or qualitative aspects of the study (Creswell, et al., 2003). A slight modification of the design was made in order to represent the actual conduct of the study. The quantitative and qualitative data obtained from 
the research shall provide the basis of the study's discussion and conclusion. Hence, the design of this study is as illustrated in Figure 3.2:

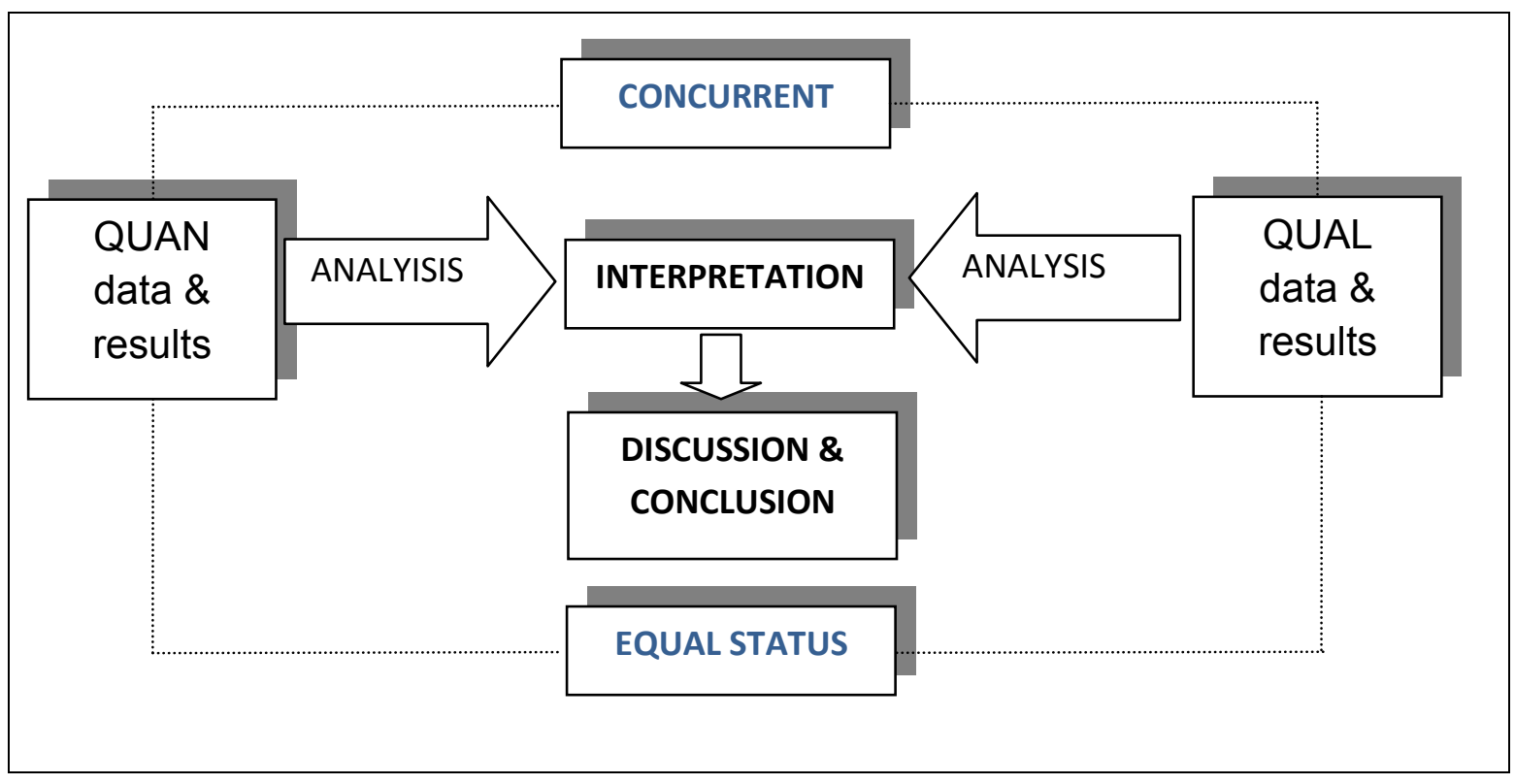

Figure 3.2: Proposed research methodology adapted from Creswell et al (2008) and Johnson and Christensen (2008)

The reason for choosing this design to be employed was partly because this design could be considered time saving compared to other sequential mixed methods designs. The appropriateness of using this design is supported by Onwuegbuzie and Collins's Matrix Crossing Purpose of Mixed Methods Research by Time Orientation, as shown in Table 3.1 below.

\begin{tabular}{|l|c|c|}
\hline \multicolumn{1}{|c|}{$\begin{array}{c}\text { Purpose of Mixed } \\
\text { Methods Research }\end{array}$} & $\begin{array}{c}\text { Concurrent Design } \\
\text { Appropriate? }\end{array}$ & $\begin{array}{c}\text { Sequential Design } \\
\text { Appropriate? }\end{array}$ \\
\hline Triangulation & Yes & No \\
\hline Complementarity & Yes & Yes \\
\hline Development & No & Yes \\
\hline Initiation & Yes & Yes \\
\hline Expansion & No & Yes \\
\hline
\end{tabular}

Table 3.1: Matrix Crossing Purpose of Mixed Methods Research by Time Orientation

The researcher was only able to collect the data within a limited period of time; hence this design was the most practical without compromising the validity of the study. 


\subsection{Research Questions}

A major advantage of mixed methods research is that it enables the researcher to simultaneously answer quantitative and qualitative questions (Teddlie \& Tashakkori, 2003). According to Tashakkori and Creswell (2007), a strong mixed methods study starts with a strong research question or objective. Mixed methods are useful because the combination of quantitative and qualitative designs are able to provide the best opportunity to address the main research question and also specific sub-questions of the study (Morrison, 2007).

Research questions are shaped by the purpose and in turn form the methods and design of the study (Tashakkori \& Creswell, 2007). Johnson and Christensen (2008) add that the research design "should be planned and conducted based on what will best help you answer your research question"(p. 33). The main research question that guided this study was:

What are the leadership styles practiced by the PTD and DG middle level managers in the Ministry of Education Malaysia?

In order for the researcher to answer the main research question, several sub-questions were formulated. The sub questions will be answered by using either a quantitative or a qualitative methodology. Below are the sub questions of the main research question and the methodology used to answer those questions.

\begin{tabular}{|l|l|l|}
\hline Sub-question 1: & $\begin{array}{l}\text { Are there any significant differences in the } \\
\text { leadership styles practiced by the PTD and DG } \\
\text { middle level managers? }\end{array}$ & $\begin{array}{l}\text { Methods used: } \\
\text { Quantitative }\end{array}$ \\
\hline Sub-question 2: & $\begin{array}{l}\text { Are there any significant differences in the } \\
\text { evaluation of leadership styles of the PTD and DG } \\
\text { middle level managers as perceived by } \\
\text { subordinates from different scheme of service? }\end{array}$ & $\begin{array}{l}\text { Methods used: } \\
\text { Quantitative }\end{array}$ \\
\hline Sub-question 3: & $\begin{array}{l}\text { Are there any significant differences in the } \\
\text { evaluation of the leadership styles as perceived by } \\
\text { the PTD and DG middle level managers? }\end{array}$ & $\begin{array}{l}\text { Methods used: } \\
\text { Qualitative }\end{array}$ \\
\hline
\end{tabular}

Table 3.2 Sub questions of the research and the proposed methods used to answer the questions

The formulation of the main research question accompanied by several sub questions originates from Teddlie and Tashakkori's (as cited by Tashakkori \& Creswell, 2007) 
proposition that in a mixed methods research, the researcher could formulate a mixed or hybrid research question which later is broken down into "separate quantitative and qualitative sub questions to answer each strand or phase of this study"(p. 208). Such sub questions "effectively links the components or strands (qualitative and quantitative) and objectives and questions of the study and sets the stage for comprehensive mixed methods inferences and conclusions at the end (Tashakkori \& Creswell, 2007, p. 210). The researcher's ability to creatively combine quantitative and qualitative methods or techniques in answering the study's research question is one of the defining characteristics of mixed methods research (Teddlie \& Fen, 2007). Tashakkori and Creswell (2007) add that "this is more frequent in parallel or concurrent studies than in sequential ones"(p. 207). The formulation of this "hybrid" main research question therefore supports the concurrent mixed methods design employed in the study.

\subsection{Sampling Strategy}

Kemper, Stringfield and Teddlie (2003) and Teddlie and Fen (2007) have provided useful guidelines for sampling in mixed methods research. Some of the guidelines that the researcher has taken into consideration for this study include:

i) The sampling strategy should stem logically from the research questions being addressed

ii) The sampling strategy must be ethical

iii) The sampling plan should be feasible

iv) The sampling scheme should be efficient and practical

In addition, Teddlie and Fen (2007) believe that "creativity and flexibility in the practical design of mixed methods sampling schemes are crucial to the success of the research study" (p. 98).

Choosing a mixed sampling design involves selecting appropriate sampling scheme ${ }^{2}$ and sample size for both the quantitative and qualitative components (Johnson \& Christensen, 2008). In order for a researcher using a mixed methods design to address the research question, the researcher needs to decide which people and research setting can best provide

\footnotetext{
${ }^{2}$ Onwuegbuzie and Collins (2007) define sampling schemes as the techniques used to select samples. Techniques could either be random sampling techniques (sometimes referred to as probability sampling) or non random sampling techniques (commonly referred to as purposive sampling).
} 
the information and data needed for the study (Creswell \& Plano Clark, 2007). Teddlie and Fen (2007) argue that the success of a mixed methods research in answering the research questions, hinges upon the combination of good sampling techniques. Nonetheless, when mixing is concerned, most researchers have fallen into the notion of false dichotomy because they often tend to associate random sampling techniques with the quantitative strand and non random sampling techniques with the qualitative strand when in fact, the most common combination in mixed methods research is that of non-random sampling techniques (Onwuegbuzie \& Collins, 2007). Onwuegbuzie and Collins (2007) have presented a matrix of crossing type of sampling scheme that represents how often mixed methods research and researchers combined both the random sampling techniques with non random sampling techniques. This is shown in Figure 3.3 below.

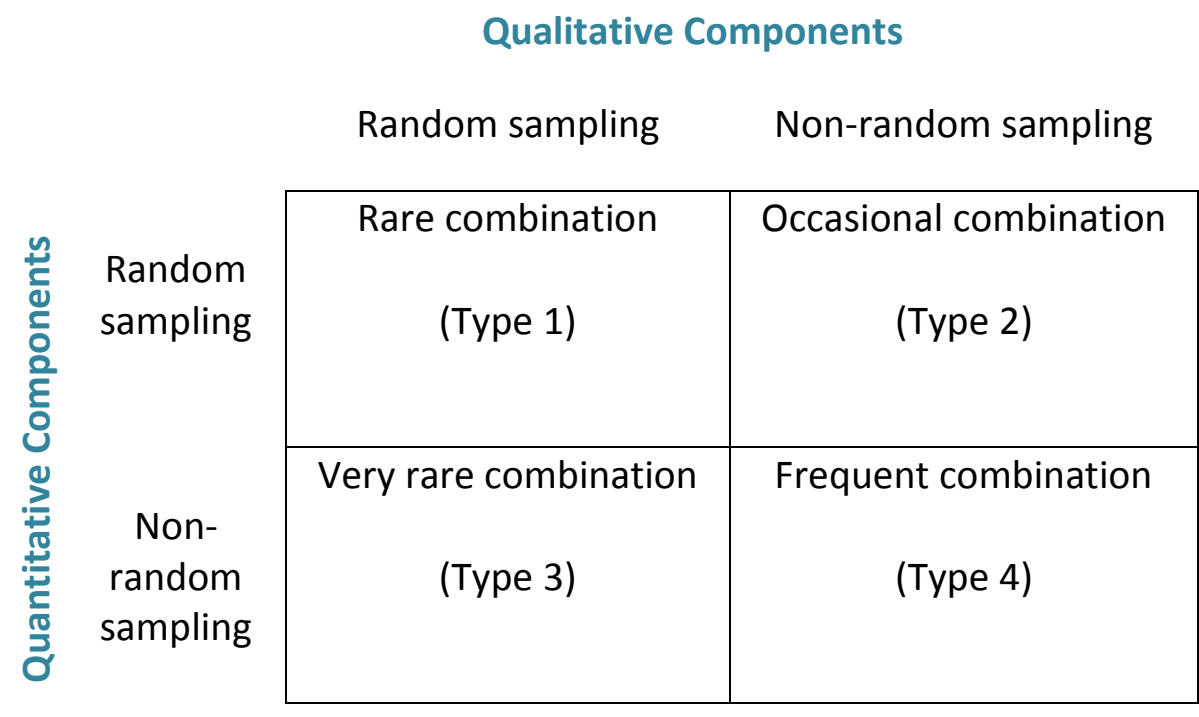

Figure 3.3 Matrix crossing type of sampling scheme (Onwuegbuzie \& Collins, 2007)

Onwuegbuzie and Collins (2007) believed Type 4 is by far the most common combination of sampling schemes used in much of the current mixed methods studies.

The focus of this study is to analyse, study and compare leadership styles of middle level managers from two different schemes of service, PTD and DG, who are working in the Ministry of Education Malaysia. According to Onwuegbuzie and Collins (2007), if the goal of a research is not to generalize a population but to obtain insights into a phenomenon (like in the case of this study: leadership styles), then "the researcher purposefully selects 
individuals, groups and setting ...that maximize understanding of the underlying phenomenon" (p. 287). Thus this mixed method study, like many other mixed methods studies (Onwuegbuzie \& Collins, 2007), utilizes some form of purposive sampling (non random sampling) for both of the quantitative and qualitative strand as shown in Figure 3.3 above.

In order to address the focus of the study comprehensively, an attempt was made by the researcher to make the sample as inclusive and as representative as possible of the middle level managers who are from the two different schemes of service. Therefore, the researcher has chosen the purposive sampling for the quantitative strand as well as the qualitative strand. Purposive sampling is quite common in mixed methods studies (Kemper, et al., 2003). According to Johnson and Christensen (2008), "in purposive sampling, the researcher specifies the characteristics of the a population of interest and then tries to locate individuals who have those characteristics" (p. 239). Kemper et al. (2003) add that researchers who use purposive sampling techniques are able to focus and minimize the sample size so that it might best reflect the purpose of the research. Onwuegbuzie and Collins (2007) have identified 19 different purposive techniques as compared to only five random sampling techniques. Although purposive sampling limits the ability for the study to make generalizations, this problem can be addressed by randomly selecting participants from the target population (Johnson \& Christensen, 2008). The procedure involved in selecting the sample of the study is explained in the next section.

\subsubsection{Population}

The present study was conducted in several selected departments of the Ministry of Education. Before embarking on the data collection process, the researcher had to first identify the target population for the study. The target population had to be specified because the researcher was working on a tight time schedule. The researcher had sent an email to the Human Resource Department of the Ministry of Education Malaysia requesting information on which of the 35 departments had the most number of mixed personnel (PTD and DG) holding the position of middle level managers. However, there was no reply from the Human Resource Department, prompting the researcher to carefully analyse the organizational chart of every department available on the Ministry of Education website (http://www.moe.gov.my/?id=45\&act=division) and from the Ministry of Education 2008 
Annual Report (Kementerian Pelajaran Malaysia, 2008). The organizational charts for most of the departments include information such as the grade of service of the head of the subunits, sub-sectors or sub-departments, hence allowing the researcher to identify and narrow down the target population to only ten departments. The departments include three State Education Departments, four departments of the professional division and three departments under the administration division. For the purpose of confidentiality, all the departments involved in this study will not be named.

\subsubsection{Sample of the Study}

When mixed methods sampling is concerned, the design of the study plays an important role in selecting the samples, as it involved two methodologies or strands. As mentioned earlier, although purposive sampling limits the ability for the study to make generalization but this problem can be addressed by randomly selecting participants from the target population (Johnson \& Christensen, 2008). Therefore, a random purposive sampling technique was employed for the quantitative strand. Random purposive sampling "involves taking a random sample of units in the purposefully selected target population" (Kemper, et al., 2003, p. 282). This particular technique of sampling allows the researcher to specify the characteristics of the target sample and then locate the individuals who have those characteristics before randomly selecting them for the study (Johnson \& Christensen, 2008). The logic behind using random purposive sampling is "to add trustworthiness" (Kemper, et al., 2003, p. 282) to the findings.

Because one of the aims of the research is to identify and compare the leadership styles of middle level managers from the perspectives of their subordinates, the samples identified for the quantitative strand consisted of the subordinates of both DG and PTD middle level managers. The samples (or participants) who were randomly selected from the target population for this study answered a set of questionnaires that describe the styles of leadership of their immediate middle level managers.

As for the qualitative strand, a stratified purposive sampling technique was used. Stratified purposive sampling involves dividing the purposefully selected target population into strata with the goal of discovering elements that are similar or different across sub-groups (Kemper, et al., 2003). Purposive sampling offers researchers a degree of control (Barbour, 
2001). Purposive sampling is also favoured in a qualitative research as compared to other methods of sampling due to the fact that it could improve and ensure rigour (Barbour, 2001; Mays \& Pope, 1995). Although purposive sampling would not be able to statistically represent the general population, this method is theoretically informed and relevant to the research questions (Mays \& Pope, 1995). Mays and Pope (1995) also believe that purposive sampling minimises the possibility of bias arising from selecting samples on the basis of convenience. The samples involved for the qualitative part of this study consisted of four middle level managers from the DG scheme of service and another four middle level managers from the PTD scheme of service. The samples for the interview were drawn from the ten departments targeted for the study. The samples for the qualitative strand were interviewed.

A researcher needs to recognize whether the samples involved for the quantitative strand should also be involved in the qualitative strand. The relationship between the samples involved is called the sample relationship criterion (Johnson \& Christensen, 2008). Onwuegbuzie and Collins (2007) have identified four different relationship criterion between the quantitative and qualitative samples involved in a mixed methods study. The relationship includes identical relationship, parallel relationship, nested relationship and multilevel relationship. The samples involved in this study are that of a multilevel relationship. A multilevel relationship involves the use of quantitative and qualitative samples that are obtained from different levels of the same population (Johnson \& Christensen, 2008; Onwuegbuzie \& Collins, 2007). In addition, since both of the strands are conducted concurrently, the researcher has to take into consideration the availability of the samples.

\subsection{Instruments}

The current mixed methods research design of this study, which utilised the triangulation concurrent design, involves inter-method mixing of the instruments used. Inter-method mixing requires different methods to be employed in a single study (Johnson \& Turner, 2003). According to Johnson and Turner (2003), inter-method mixing is accomplished by concurrently mixing two or more methods (i.e. the research instruments). Johnson and Turner (2003) believe that "the mixing of quantitative and qualitative methods will result in the most accurate and complete depiction of phenomenon under investigation" (p. 299). 
Fundamental to the principle of mixed methods research, "methods should always be mixed in a way that has complementary strengths and non-overlapping weaknesses" (Johnson \& Turner, 2003, p. 299).

In this study, the researcher used two main research instruments. The Multifactor Leadership Questionnaire (MLQ) was used for the quantitative strand with the specific purpose of answering sub-questions one and two of the research. A standardized open-ended interview was utilized for the qualitative strand as this would enable the researcher to answer subquestion three.

\subsubsection{Multifactor Leadership Questionnaire (MLQ 5X rater form)}

Multifactor Leadership Questionnaire (MLQ 5X rater form) was used as the main research instrument for the quantitative strand. As mentioned in the previous chapter, MLQ is the most widely accepted instrument to measure the extent of one's leadership style namely transformational, transactional or laissez-faire (Alimo-Metcalfe \& Alban-Metcalfe, 2001; Bass \& Riggio, 2006; Herman \& Egri, 2002). MLQ 5X contains 45 items that identify and measure key leadership styles and effectiveness behaviours, and prior research has shown strong links with both individual and organizational success (Avolio \& Bass, 2004). The MLQ 5X is the most current version after it was revised several times (Antonakis, Avolio, \& Sivasubramaniam, 2003). According to Avolio and Burns (2004), this latest version has been used in nearly 300 research programs, doctoral dissertations and master's theses around the world between 1995 and 2004.

The MLQ X consists of 45 items that identify and measure key leadership styles and outcomes (Avolio \& Bass, 2004). The 45 items are made up from the components of transformational leadership, transactional leadership and laissez faire leadership. Apart from that, there are also nine items included to measure leadership outcomes. A summary of the items that represent the components of the leadership is shown in Table 3.3 below: 


\begin{tabular}{|l|l|c|}
\hline \multicolumn{2}{|l|}{ LEADERSHIP STYLES/DIMENSIONS } & NUMBER \\
\hline \multirow{5}{*}{ Transformational } & Idealized Influence (attributed \& behaviour) & 8 \\
\cline { 2 - 3 } & Inspirational motivation & 4 \\
\cline { 2 - 3 } & Intellectual stimulation & 4 \\
\cline { 2 - 3 } & Individual consideration & 4 \\
\hline Transactional & Contingent reward & 4 \\
\cline { 2 - 3 } & Management-by-exception (active) & 4 \\
\cline { 2 - 3 } & Management-by-exception (passive) & 4 \\
\hline Non-leadership & Laissez faire & 3 \\
\hline Leadership outcome & Extra effort & 4 \\
\cline { 2 - 3 } & Effectiveness & 2 \\
\cline { 2 - 3 } & Satisfaction & 4 \\
\hline
\end{tabular}

Table 3.3: The components of leadership dimensions in the MLQ 5X rater formquestionnaire

All items are assessed on a five-point rating scale. The anchors used are presented below:

$$
\begin{array}{lll}
0 & = & \text { Not at all } \\
1 & = & \text { Once in a while } \\
2 & = & \text { Sometimes } \\
3 & = & \text { Fairly often } \\
4 & = & \text { Frequently, if not always. }
\end{array}
$$

According to Johnson and Christensen (2008), a key advantage of a questionnaire that uses a rating scale is that it provides more reliable, consistent and stable scores and produces more variability which enables the researcher to make finer distinctions among the respondents.

The MLQ 5X is available in two forms. The first is the self-rating form that asks the leader to rate their leadership behaviour or style. The second is the rater form which is used by subordinates to rate their leader. The leader could be anyone from the immediate superior to the organization's top leader. Bass and Riggio (2006) found that when leaders self-rate their own behaviour on the leader form, it is more likely that the results are prone to bias, "Therefore, the more important version of the MLQ is the rater form... (as)... the rater form is most commonly used in research to measure transformational and transactional 
leadership" (Bass \& Riggio, 2006, p. 20). For the current study, the rater form was chosen as the research instrument.

The researcher has obtained the copyright to reproduce the MLQ 5X (rater form) from Mind Garden Incorporated which holds the licence to distribute the questionnaire. Due to the copyright control over the questionnaire, the researcher was only able to show five sample items in this thesis.

The questionnaire was designed in English; therefore the researcher had to translate a Malay version of the questionnaire. The service of two postgraduate students from Malaysia majoring in linguistics and TESOL was obtained to translate the questionnaire. A comparison of the translated version was made with a Malay MLQ 5X rater form that was used by Jazmi (2009) and Baharudin (2004). Jazmi has utilized the MLQ to comparatively measure leadership styles of principals of the National Secondary Type Schools with principals from the Religious Secondary Schools in Malaysia. Baharudin used MLQ as the instrument to measure the leadership styles of personnel working in the Selangor State Religious Department. After minor adjustments the translated version and the ones used by Jazmi and Baharudin matched. The final version of the questionnaire that was used for this study, however, contains bilingual items.

The researcher also included a participant information sheet as the cover to the questionnaire. This information sheet was used to gauge essential information of the participants while maintaining their anonymity. The information sheet together with five samples of the MLQ 5X rater form questionnaire is attached as Appendix 2a. All participants were also given a Questionnaire Participation Information Sheet. The Questionnaire Participation Information Sheet was essential to explain the aims and objectives of this study to the participants. The Questionnaire Participation Information Sheet is attached as Appendix 2b and the Malay version of the Questionnaire Participation Information Sheet is attached as Appendix 2c.

The MLQ has gone through rigorous reliability and validity scrutiny (Avolio \& Bass, 2004). The latest version of MLQ Form 5X has demonstrated "good to excellent internal consistency with alpha coefficients above .80 using the most recent version of the MLQ across a large sample" (Bass \& Riggio, 2006). However, since the study was using bilingual 
items, the researcher believed that it was imperative to test its internal reliability. In order to measure the internal reliability of the bilingual version of the questionnaire, a pilot test was conducted in one of the departments of the Ministry of Education. 20 questionnaires were distributed to the participants. Cronbach's alpha was used to measure the internal consistency of the items on the questionnaire. The reliability score of .93 meant that the questionnaire was fit and reliable to be used in the study. The results of the reliability test on all the items in the bilingual version of the MLQ Form 5X showed an acceptable range of reliability, hence no revision was made to any of the items of the questionnaire.

\subsubsection{Interview}

Since the researcher was using a triangulation concurrent mixed methods design, careful consideration had to be made so that the data collected in the qualitative strand would be able to complement the data obtained from the quantitative strand.

The researcher utilized a standardized open-ended interview for the qualitative strand of the study. This involved the interviewer engaging in an interview session with a standardized interview protocol (Johnson \& Christensen, 2008). The interview protocol for this study consisted of seven questions. In the standardized open-ended interview, the questions were all written out and the interviewer asked the questions exactly as written to the interviewees (Johnson \& Christensen, 2008). Wilson and Sapsford (2006) and Patton (as cited in Cohen, Manion, \& Morrison, 2000) point out that the strength of standardized open-ended interview lies in the fact that when respondents answer the same questions, it increases the comparability of responses on the topics addressed in the interview. In addition, because respondents answer the same questions, the interviewer would be able to facilitate better data organization and analysis (Cohen, et al., 2000).

Interview participants consisted of four middle level managers from the PTD scheme of service and four middle level managers from the DG scheme of service. The researcher anticipated that the deployment of the qualitative strand in this study will lead to the focus on leadership practices and styles from the perspective of the leaders themselves. Drawing on Herman and Egri's (2002) approach in constructing interview questions in their research, the researcher developed the questions with the focus of eliciting respondents' opinions on what they believe would be the most important leadership styles and skills needed to be 
effective and successful. In addition, questions were developed so that they could draw out respondents' views on their leadership strengths and deficits, how they motivate others and how significant their roles were in the organization. It was hoped that the interview was able to yield important data that could be used to compare the leadership styles as perceived by the middle level managers themselves and as perceived by their subordinates (from the data obtained in the questionnaire).

\subsection{Data Collection Procedure}

This section explains the data collection procedure involved in this study. The researcher travelled to Malaysia for the data collection process. The data collection process took 16 days to complete. Because the research utilised the triangulation concurrent mixed methods research design, the data for both the quantitative strand as well as the qualitative strand were able to be collected within the limited time period.

\subsubsection{Ethics}

Before the data collection process began, the researcher had to seek permission to conduct the research in Malaysia from the Economic Planning Unit, Prime Minister's Department. This is in line with the regulation for conducting research in Malaysia as stipulated in the General Circular Order No. 3 Year 1999 (Prime Minister's Department, 1999). All the necessary information regarding the research was provided to the department. The permission to conduct the research in Malaysia was granted by the Economic Planning Unit, Prime Minister's Department (refer to the attached letter UPE: 42/200/19/2585 dated 18 March 2010 in Appendix 3).

Upon obtaining the permission to conduct the research in Malaysia, the researcher submitted the research proposal, Economic Planning Unit's approval and ethics application to the Victoria University Human Ethics Committee. The ethics approval was received from the Victoria University of Wellington Faculty of Education Ethics Committee (refer to the attached document TKM/2010/19 RM 17471 dated 26 April 2010 in Appendix 4). In undertaking this study, the researcher managed the questionnaire and interviews in ways where ethical consideration was consistently shown. 


\subsubsection{Pilot Study}

The study began by piloting the English version and the Malay version of MLQ Form5X rater form to 20 personnel working in one of the departments of the Ministry of Education. A Pilot test is useful "to find out whether it (the questionnaire) operates properly before using it in a research study" (Johnson \& Christensen, 2008, p. 189). According to Cohen (2000), piloting a questionnaire would increase the reliability, validity and practicability of the questionnaire. A Pilot study would also be able to ensure the clarity of the questionnaire items free from any ambiguity.

The participants of the pilot study consisted of the participants from one of the departments identified for the study. According to Avolio and Bass (2004), MLQ is easily administered takes an average of 15 minutes to complete. Bearing this in mind, the researcher targeted a maximum of three days for the participants to answer the questionnaire. The questionnaire was given to the head of department for random distribution. The pilot study's participants rated their immediate superior. The questionnaire information sheet was distributed together with the questionnaire. As discussed in section 3.6.1 of this chapter, the results of the pilot study demonstrated that the reliability scores for items of the questionnaire were .93 based on Cronbach's coefficient alpha. Since no revision to the questionnaire was made, the data from the pilot study was included in the final sample data of this study.

\subsubsection{Administration of the Questionnaire}

A total of 200 MLQ Form5X rater form questionnaire were distributed to 10 departments of the Ministry of Education Malaysia. This was inclusive of the 20 questionnaires distributed for the pilot study. Participants from those 10 departments were randomly selected. The researcher approached the heads of the respective departments explaining the purpose of this study and how the personnel of those departments were able to contribute significantly to this study by answering the questionnaire. All heads of those departments agreed to allow the researcher to distribute the questionnaire.

Except for the department where the pilot study was conducted, the researcher had requested for a coordinator in the other nine respective departments to distribute and collect the questionnaires. The coordinators were personnel of the departments selected for the study. The reason for requesting a coordinator to distribute the questionnaires randomly was that if 
the raters were selected by the leaders themselves, there might be a chance that the final ratings would be inflated (Avolio \& Bass, 2004). The researcher explained to the coordinators the simplicity of the questionnaire and that it would only take between 10 to 15 minutes to complete. The coordinators were also reminded that the questionnaires would be collected personally by the researcher seven days after the questionnaires were given to the coordinator for distribution. The coordinators were also briefed on the importance of maintaining the anonymity of the raters.

The number of questionnaires distributed and the number of questionnaire received is presented in Table 3.4 below:

\begin{tabular}{|c|c|c|c|}
\hline & $\begin{array}{c}\text { Surveys } \\
\text { distributed }\end{array}$ & $\begin{array}{l}\text { Surveys } \\
\text { received }\end{array}$ & $\begin{array}{c}\text { Response rate } \\
\text { (\%) }\end{array}$ \\
\hline State Education Department A & 20 & 17 & 85 \\
\hline State Education Department B & 10 & 6 & 60 \\
\hline State Education Department C & 10 & - & 0 \\
\hline Department A of the Professional Division* & 20 & 14 & 70 \\
\hline Department B of the Professional Division & 25 & 16 & 64 \\
\hline Department C of the Professional Division & 25 & 12 & 48 \\
\hline Department D of the Professional Division & 30 & 18 & 60 \\
\hline Department $A$ of the Administrative Division & 20 & 16 & 80 \\
\hline Department B of the Administrative Division & 20 & 11 & 55 \\
\hline Department C of the Administrative Division & 20 & 12 & 60 \\
\hline Total & 200 & 122 & 61 \\
\hline
\end{tabular}

Table 3.4: Survey distribution and survey response rate (* denotes the department where the pilot study was conducted)

Avolio and Bass (MLQ International, 2008) suggest that the optimum number of raters evaluating a single leader should be between three to ten or more. As presented in table 3.4 the response rate for all the departments involved in this study ranged from $0 \%$ to $85 \%$ with a total of $61 \%$ overall response rate. Although a response rate of $70 \%$ and higher is considered the acceptable response rate (Johnson \& Christensen, 2008), Baruch (1999) 
examined 175 different studies and has found that on average, most of those studies would yield a response rate of $55.6 \%$ with a standard deviation of 19.7. Baruch suggested that the acceptable response rate for any study directed toward organizational personnel such as rank and file or middle level managers should be $36 \%$ with a standard deviation of 13 . Hence, the response rate for this study can be considered acceptable.

\subsubsection{Interview Process}

The interviews involved eight participants. All the participants hold a middle level managerial role in their respective departments. Because every department has quite a large number of middle level managers, the researcher narrowed down the criteria of the respondents to only those who are managing a unit with mixed numbers of personnel from different schemes of service. The participants for the interview were drawn from the ten departments targeted for the study. Four of the participants were from two departments but heading different sub-units and sub-sectors, while the other four participants were from different departments. The participants were initially approached by the researcher seeking their availability while the researcher was conducting the quantitative strand at their respective departments. Potential participants were provided with the Interview Participation Information Sheet, detailing the names of the people responsible for the study, what the study was about and how the information obtained from the interview would be highly beneficial to the study. A copy of the Interview Participation Information Sheet is included as Appendix 5a. Appendix 5b is the Malay version of the Interview Participation Information Sheet.

The researcher made it clear that the participation was voluntary and that the participants would have a period of time in which to consider the invitation. When the participants agreed to participate, the researcher had to check on the availability of their schedule. All interviews were conducted on different days.

Before each interview session began, the participants were given the reassurance that all information gathered from the interview would be analysed in such a way to reflect the anonymity of the participants. The participants were also told that they could withdraw at any stage of the study without having to give any reasons to the researcher, and that their withdrawal would not have any implications to them, their departments or to this study. The 
participants were given the Consent to Participation in Interview sheet to be signed. A copy of the Consent to Participation in Interview form is attached as Appendix 6.

The interviews were carried out over a ten-day period, and conducted in between the process of distributing and collecting the questionnaires. All interviews were conducted at the participants' offices, and in strict confidentiality. No other person apart from the respective interview participants was present when the interviews were conducted. All interviews were audio taped. Field notes were also taken by the researcher to highlight some of the more important points of the interview. The use of audiotape to record interviews was one of the techniques utilised by the researcher to improve rigour in this study. Mays and Pope (1995) believe that "one of the advantages of audio taping is the opportunity the tapes offer for subsequent analysis by independent observers" (p. 1116).

The interview questions were prepared in both English and Malay. The participants were asked beforehand whether they preferred the interview to be conducted in English or Malay. Seven participants choose to be interviewed in Malay.

Because the interview was a standardized open-ended interview, all questions asked were already pre-determined. This enabled the researcher to control the length of the interview. A standardized open-ended interview was beneficial because the researcher was able to focus on the topic on hand and limits the possibilities that the participants might stray away from the topic. The questions ranged from seeking information on their leadership roles in the department, their career backgrounds, their understanding of leadership, what they might perceive as effective leadership styles and whether they deploy such styles. Nonetheless, when necessary the researcher had to use probes or prompts in order to elicit greater clarity and depth.

\subsection{Data Analysis Procedure}

The data obtained from the questionnaires and interviews were analysed separately. The results of the analysis formed the basis of this study's discussion and conclusion. 


\subsubsection{Quantitative Analysis}

The data obtained from the questionnaires was analysed using the Statistical Package for Social Science (SPSS) version 16 software. The analyses included:

i) Cronbach Alpha - to determine the internal consistency and reliability of the questionnaire.

ii) Descriptive analysis - to analyse the demographics and background of the respondents.

iii) T-test - to determine any significant differences between the leadership styles of the DG middle level managers and PTD middle level managers.

iv) ANOVA test - to determine any significant differences of the leadership styles as perceived by their subordinates.

\subsubsection{Qualitative Analysis}

The standardized open-ended interviews with the eight middle level managers from both the DG and PTD scheme were transcribed verbatim by the researcher. All interviews were transcribed using word-processing software. The transcripts were then translated into English. The service of two postgraduate students majoring in linguistics and TESOL were used to verify the original transcripts with the audio taped interview and translated transcripts. This increases the interpretative validity of the study. Interpretive validity refers to accurately portraying the meaning attached by participants to what is being studied by the researcher (Johnson \& Christensen, 2008). In addition this would also improve rigour in this study.

The transcripts were then analysed using a series of codes. This approach analysis is called concept-driven coding method (Gibbs, 2007). Concept-driven coding refers to a method of coding the transcripts with key concepts, categories or themes which have been predetermined and essential to the study. Concept-driven coding allows the researcher to build upon a series of codes that are relevant to the theme and objectives of the research. This process is called pre-coding (Swift, 2006). According to Swift (2006), one particular advantage of pre-coding is that it cuts the time and costs of data handling. However, Gibbs (2007) points out that the researcher will need to amend the list of the pre-codes in order to accommodate new ideas or themes that are important to the study. 
In concept-driven coding, the researcher is encouraged to build up a list of key concepts and themes before analysing the transcripts (Gibbs, 2007). The key categories, concepts and themes usually derive from the research literature. In the case of this study, the researcher was interested in identifying the leadership styles of middle level managers from two different schemes of service. The core leadership styles that this study is interested in are the transformational, transactional and laissez faire styles, as proposed in the literature review.

In addition, the researcher had also identified other leadership concepts and themes which were relevant to the study and used new codes to identify and differentiate these important points when analysing the transcripts.

When all the transcripts were coded appropriately, a simple count was made of the number of times each leadership style was mentioned by every participant. This allowed the researcher to compare the leadership styles of the DG middle level managers with the styles of the PTD middle level managers. This method was also utilised by Bryman, Stephens and Campo (Bryman, 2004) in their qualitative research on leadership. Although this method was considered as quantitizing qualitative data, the quantitative conversion of qualitative data has enabled the researcher "to extract meaning from the qualitative data and verify the interpretations" (Sandelowski, Voils, \& Knafl, 2009, p. 211) of this study, which was to understand and compare leadership styles of DG and PTD middle level managers.

\subsection{Chapter Summary}

This chapter has outlined the research design and data collection methods. It has also described the data analysis process and the steps taken to ensure the reliability and rigour of this study. The following chapter presents the findings of this analysis. 


\section{CHAPTER 4 - DATA DESCRIPTION AND ANALYSIS}

\subsection{Chapter Overview}

The purpose of this chapter is to discuss, analyse and present the data of this study. The research design relied on a triangulation concurrent approach involving both quantitative and qualitative methodologies to answer this study's questions. The findings of both strands are then converged to answer the study's key research question which is: What are the leadership styles practiced by the PTD and DG middle level managers in the Ministry of Education Malaysia? The analyses of the findings of both methodologies are presented separately.

\subsection{Quantitative Findings}

This section analyses the findings obtained from the Multifactor Leadership Questionnaire (MLQ 5X rater form). This section begins with the demographics profiles of the respondents. The second part of this section analyses the reliability of the MLQ 5X rater form. This is followed with the analyses of t-test to determine any significant differences of leadership styles between the two groups of middle level managers. The final part examines the leadership styles of the middle level managers from the perspectives of their subordinates.

\subsubsection{Respondents Profile}

The sample was made up of 122 participants who returned the MLQ 5X rater form questionnaire to the researcher. The participants consisted of personnel from different schemes of service who were asked to rate the leadership styles of their superiors who were either from the PTD scheme of service or DG scheme of service. The breakdown of the scheme of service of the participants is presented in Table 4.1 below:

\begin{tabular}{|c|c|c|}
\hline Scheme of service of the respondents & Frequency & Percentage (\%) \\
\hline DG & 48 & 39.3 \\
\hline M & 24 & 19.7 \\
\hline $\mathrm{N}$ & 43 & 35.2 \\
\hline Others (J, S and W) & 7 & 5.7 \\
\hline Total & 122 & 100 \\
\hline
\end{tabular}

Table 4.1: Breakdown of the scheme of services of the respondents 
From the total of 122 respondents, 63 or $51.6 \%$ rated their middle level managers who were from the DG scheme of service while 59 or $48.4 \%$ of the respondents rated their superiors who were from the PTD scheme of service. Table 4.2 below shows the breakdown of the scheme of service of the respondents which corresponded to the scheme of service of their superior whom they rated.

\begin{tabular}{|l|l|c|c|c|c|c|}
\hline \multicolumn{2}{|c|}{} & \multicolumn{5}{c|}{ SCHEME OF SERVICE OF THE RESPONDENTS } \\
\cline { 3 - 7 } & & DG & PTD & N & Others & Total \\
\hline $\begin{array}{l}\text { SCHEME OF SERVICE OF THE } \\
\text { RESPONDENTS' MIDDLE LEVEL } \\
\text { MANAGERS WHOM THEY RATED }\end{array}$ & DG & 35 & 8 & 15 & 5 & $\mathbf{6 3}$ \\
\cline { 2 - 8 } & PTD & 13 & 16 & 28 & 2 & $\mathbf{5 9}$ \\
\cline { 2 - 7 } & Total & $\mathbf{4 8}$ & $\mathbf{2 4}$ & $\mathbf{4 3}$ & $\mathbf{7}$ & $\mathbf{1 2 2}$ \\
\hline
\end{tabular}

Table 4.2: Breakdown of the scheme of services of the respondents and the middle level managers they rated

Based on Table 4.2, a total of 35 or $28.6 \%$ of DG respondents rated their superiors who were from the same scheme of service while $10.7 \%$ of the DG respondents rated superiors who were from the PTD scheme of service. Among PTD respondents, 6.5\% rated their superiors who were from the DG scheme of service while another $13.1 \%$ of them rated their superiors who were from the same scheme of service. Out of the 43 respondents who were from the administration and support scheme of service $(\mathrm{N}), 12.3 \%$ rated their superiors whom consisted of DG middle level managers and another $23 \%$ rated their superiors from the PTD scheme of service. Only two personnel or subordinates who were from other schemes of service rated superiors from the PTD scheme of service, while five or $4.1 \%$ rated their superiors who were from the DG scheme of service. 


\subsubsection{Age Demographics}

\begin{tabular}{|l|c|c|c|c|c|c|c|}
\hline \multicolumn{2}{|c|}{} & \multicolumn{2}{|c|}{$\begin{array}{c}\text { DG middle level } \\
\text { managers rated by } \\
\text { their subordinates } \\
\text { (n=63) }\end{array}$} & $\begin{array}{c}\text { PTD middle level } \\
\text { managers rated by } \\
\text { their subordinates } \\
\text { (n=59) }\end{array}$ & \multicolumn{2}{c|}{$\begin{array}{c}\text { TOTAL } \\
\text { (n=122) }\end{array}$} \\
\cline { 3 - 9 } & Freq & $(\%)$ & Freq & (\%) & Freq & (\%) \\
\hline $\begin{array}{l}\text { Age group of the } \\
\text { respondents/ } \\
\text { subordinates }\end{array}$ & $21-24$ & 1 & 0.8 & 5 & 4.1 & 6 & 4.9 \\
\cline { 2 - 9 } & $25-29$ & 9 & 7.4 & 17 & 13.9 & 26 & 21.3 \\
\cline { 2 - 9 } & $30-34$ & 16 & 13.1 & 12 & 9.8 & 28 & 23 \\
\cline { 2 - 9 } & $35-39$ & 8 & 6.6 & 3 & 2.5 & 11 & 9 \\
\cline { 2 - 9 } & $40-44$ & 7 & 5.7 & 8 & 6.6 & 15 & 12.3 \\
\cline { 2 - 9 } & $45-50$ & 14 & 11.5 & 6 & 4.9 & 20 & 16.4 \\
\cline { 2 - 9 } & $51-58$ & 8 & 6.6 & 8 & 6.6 & 16 & 13.1 \\
\hline
\end{tabular}

Table 4.3: Age demographics of the respondents

Table 4.3 outlines the age demographics of the 122 respondents. A total of $58.2 \%$ of the respondents were below the age of 40 while only $16 \%$ of the respondents were between the ages of 51 to 58 .

\subsubsection{Gender Demographics}

\begin{tabular}{|l|l|c|c|c|c|c|c|}
\hline \multicolumn{2}{|c|}{} & \multicolumn{2}{|c|}{$\begin{array}{c}\text { DG middle level managers } \\
\text { rated by their } \\
\text { subordinates } \\
\text { (n=63) }\end{array}$} & \multicolumn{2}{c|}{$\begin{array}{c}\text { PTD middle level } \\
\text { managers rated by their } \\
\text { subordinates } \\
(\mathbf{n = 5 9 )}\end{array}$} & $\begin{array}{c}\text { (\%) } \\
\text { TOTAL } \\
(\mathbf{n}=\mathbf{1 2 2})\end{array}$ \\
\cline { 2 - 8 } & Freq & $(\%)$ & Freq & Freq & $(\%)$ \\
\hline \multirow{2}{*}{$\begin{array}{l}\text { Gender of the } \\
\text { respondents/ } \\
\text { subordinates }\end{array}$} & Male & 28 & 23 & 24 & 19.7 & 52 & 42.6 \\
\cline { 2 - 8 } & Female & 35 & 28.7 & 35 & 28.7 & 70 & 57.4 \\
\hline
\end{tabular}

\section{Table 4.4: Gender demographics of the respondents}

A total of $70 \%$ of the respondents were female. The female respondents were evenly numbered with $28.7 \%$ assessing PTD and DG middle level managers respectively. 


\subsubsection{Education Qualification}

\begin{tabular}{|c|c|c|c|c|c|c|c|}
\hline & \multicolumn{2}{|c|}{$\begin{array}{l}\text { DG middle level } \\
\text { managers rated by } \\
\text { their subordinates } \\
(n=63)\end{array}$} & \multicolumn{2}{|c|}{$\begin{array}{l}\text { PTD middle level } \\
\text { managers rated by } \\
\text { their subordinates } \\
(n=59)\end{array}$} & \multicolumn{2}{|c|}{$\begin{array}{l}\text { TOTAL } \\
(n=122)\end{array}$} \\
\hline & & Freq & (\%) & Freq & (\%) & Freq & (\%) \\
\hline \multirow{4}{*}{$\begin{array}{l}\text { Education } \\
\text { qualification of } \\
\text { the } \\
\text { respondents/ } \\
\text { subordinates }\end{array}$} & $\begin{array}{c}\text { School } \\
\text { certificate }\end{array}$ & 9 & 7.4 & 15 & 12.3 & 24 & 19.7 \\
\hline & Diploma & 9 & 7.4 & 18 & 14.8 & 27 & 22.1 \\
\hline & Degree & 36 & 29.5 & 21 & 17.2 & 57 & 46.7 \\
\hline & $\begin{array}{c}\text { Post graduate } \\
\text { degree }\end{array}$ & 9 & 7.4 & 5 & 4.1 & 14 & 11.5 \\
\hline
\end{tabular}

\section{Table 4.5: Education qualification of the respondents}

Table 4.5 shows that $46.7 \%$ of the respondents hold at least a bachelor's degree with another $14 \%$ hold a postgraduate qualification. Only $19.7 \%$ of the respondents have obtained a minimum of school certificate qualification. The overall demographics indicate that more than $58.2 \%$ of the respondents hold a tertiary level qualification (bachelor's degree and postgraduate degree).

\subsubsection{Working Experience}

\begin{tabular}{|c|c|c|c|c|c|c|c|}
\hline & \multicolumn{2}{|c|}{$\begin{array}{l}\text { DG middle level } \\
\text { managers rated by } \\
\text { their subordinates } \\
\qquad(n=63)\end{array}$} & \multicolumn{2}{|c|}{$\begin{array}{l}\text { PTD middle level } \\
\text { managers rated by } \\
\text { their subordinates } \\
\quad(n=59)\end{array}$} & \multicolumn{2}{|c|}{$\begin{array}{l}\text { TOTAL } \\
(n=122)\end{array}$} \\
\hline & & Freq & $(\%)$ & Freq & $(\%)$ & Freq & $(\%)$ \\
\hline \multirow{4}{*}{$\begin{array}{l}\text { Years of } \\
\text { working } \\
\text { experience of } \\
\text { the } \\
\text { respondents/ } \\
\text { subordinates }\end{array}$} & Less than 1 year & 8 & 6.6 & 14 & 11.5 & 22 & 18 \\
\hline & $\begin{array}{c}\text { Less than } 5 \\
\text { years }\end{array}$ & 33 & 27 & 28 & 23 & 61 & 50 \\
\hline & 5 to 10 years & 13 & 10.7 & 8 & 6.6 & 21 & 17.2 \\
\hline & $\begin{array}{c}\text { More than } 10 \\
\text { years }\end{array}$ & 9 & 7.4 & 9 & 7.4 & 18 & 14.8 \\
\hline
\end{tabular}

\section{Table 4.6: Years of working experience of the respondents}

Table 4.6 shows the number of years the respondents have been working in their current positions. $50 \%$ of the respondents have been working in those positions for a period of one 
to five years. Only $14.8 \%$ of the respondents have been working in the same position for more than 10 years.

\subsubsection{Grade of the Position}

Public servants in Malaysia are categorised according to a particular scheme of services (refer to Appendix 1). Every public servant is also given a numerical grade that denotes their rank or level in that scheme of service. All grades are standardised throughout the system. A higher grade denotes a higher rank or position of that individual. A grade of 41 is the entry level grade for most public servants with a minimum qualification of a degree, while the grade of 11 denotes the entry level for those possessing only a school certificate qualification. The grades of 27 to 34 are given to those with the qualification of a diploma. However, those with only school certificate qualification could be promoted to a higher grade based on good performance or length of service. Most middle level managers working in the Ministry of Education Malaysia comprise of those with the grades of 44 and above. Table 4.7 below represents the grades of the respondents that correspond to the middle managers whom they were rating.

\begin{tabular}{|c|c|c|c|c|c|c|c|}
\hline & \multicolumn{2}{|c|}{$\begin{array}{l}\text { DG middle level managers } \\
\text { rated by their subordinates } \\
\qquad(n=63)\end{array}$} & \multicolumn{2}{|c|}{$\begin{array}{l}\text { PTD middle level managers } \\
\text { rated by their subordinates } \\
\qquad(n=59)\end{array}$} & \multicolumn{2}{|c|}{$\begin{array}{l}\text { TOTAL } \\
(n=122)\end{array}$} \\
\hline & & Freq & (\%) & Freq & (\%) & Freq & (\%) \\
\hline \multirow{7}{*}{$\begin{array}{l}\text { Respondents/ } \\
\text { subordinates } \\
\text { grades of the } \\
\text { position }\end{array}$} & 52 & 2 & 1.6 & 1 & 0.8 & 3 & 2.5 \\
\hline & 48 & 2 & 1.6 & 1 & 0.8 & 3 & 2.5 \\
\hline & 44 & 18 & 14.8 & 9 & 7.4 & 27 & 22.1 \\
\hline & 41 & 23 & 18.9 & 14 & 11.5 & 37 & 30.3 \\
\hline & $32 / 34$ & 5 & 4.1 & 8 & 6.6 & 13 & 10.7 \\
\hline & $22 / 29$ & 2 & 1.6 & 10 & 8.2 & 12 & 9.8 \\
\hline & $11 / 17$ & 11 & 9 & 16 & 13.1 & 27 & 22.1 \\
\hline
\end{tabular}

Table 4.7: Respondents grades

More than $50 \%$ of the total respondents are of the grade 41 or higher. However out of that number, middle managers from the DG scheme of service were rated by $36.9 \%$ subordinates who were of grades 41 and higher as compared to the PTD middle level managers who were rated by only $20.5 \%$ respondents who were of grades 41 and higher. 


\subsubsection{Reliability Analysis}

Cronbach's alpha was used to measure the consistency of the items of the MLQ 5X rater form. "Cronbach's alpha is a commonly used test of internal reliability. It calculates the average of all possible split-half reliability coefficients and a computed alpha coefficient varies between 1, denoting perfect internal reliability, and 0, denoting no internal reliability" (Singh, 2007, p. 78) . As reported in the previous chapter, the reliability analysis of all the questionnaire items in the pilot test was .93 . The researcher has analysed the reliability of the items according to the leadership dimensions and leadership outcomes. The result of the reliability analysis is presented in table 4.8 below:

\begin{tabular}{|l|l|}
\hline Leadership dimension & Cronbach's alpha \\
\hline Transformational leadership & .94 \\
\hline Transactional leadership & .61 \\
\hline Laissez faire & .84 \\
\hline
\end{tabular}

\section{Table 4.8: Reliability coefficients of the leadership dimensions of MLQ Form 5X}

The figure of .70 or more is usually considered as an accepted level of reliability (Muijs, 2004; Singh, 2007). However it is important to point out that the accepted level of reliability could be decreased to .60 in an exploratory research (Hair, Black, Babin, Anderson, \& Tatham, 2006). Avolio and Bass (2004) have validated the MLQ Form 5X based on their various studies and also based on other studies which have used MLQ and summarised that the reliabilities of the leadership dimensions of the questionnaire ranged from .63 to .92 .

\subsubsection{Analysis of the Leadership Styles}

The respondents rated the leadership styles of their superiors according to the dimensions of transformational, transactional and avoidance of leadership; the responses were then averaged to find the mean scores. Avolio and Bass (2004) recommended that the greater mean score on any of the leadership dimensions would most likely represent the groups or individuals preferred leadership styles. Bass and Riggio (2006) suggested that for optimal leadership, a mean of 3.0 or higher should be reflected on all of the four transformational leadership dimensions. The mean rating of contingent reward and active management by exception ideally should be at about 2.5 and passive management by exception and laissezfaire leadership at 1.0 or below on the average (Bass, 1998). Table 4.9 shows the average score of the leadership styles of all middle managers as rated by their subordinates. 


\begin{tabular}{|c|c|c|c|c|}
\hline \multicolumn{2}{|c|}{\begin{tabular}{|l} 
LEADERSHIP DIMENSION/STYLES \\
\end{tabular}} & \multirow{2}{*}{$\begin{array}{c}\mathbf{N} \\
122\end{array}$} & \multirow{2}{*}{$\begin{array}{c}\text { MEAN } \\
2.60\end{array}$} & \multirow{2}{*}{$\begin{array}{c}\text { STANDARD } \\
\text { DEVIATION } \\
0.70\end{array}$} \\
\hline \multirow{4}{*}{ Transformational } & Idealized Influence (attributed \& behaviour) & & & \\
\hline & Inspirational motivation & 122 & 2.72 & 0.78 \\
\hline & Intellectual stimulation & 122 & 2.52 & 0.75 \\
\hline & Individual consideration & 122 & 2.25 & 0.86 \\
\hline \multicolumn{2}{|c|}{ *Total mean rating for transformational leadership styles } & 122 & 2.53 & 0.69 \\
\hline \multirow{3}{*}{ Transactional } & Contingent reward & 122 & 2.46 & 0.83 \\
\hline & Management-by-exception (active) & 122 & 2.43 & 0.67 \\
\hline & Management-by-exception (passive) & 122 & 0.96 & 0.80 \\
\hline \multicolumn{2}{|c|}{ *Total mean rating for transactional leadership styles } & 122 & 1.96 & 0.45 \\
\hline Non leadership & Laissez faire & 122 & 1.03 & 0.91 \\
\hline
\end{tabular}

Table 4.9: Mean ratings of the leadership styles of the middle level managers as rated by their subordinates

The mean ratings of all four components of transformational leadership for the middle managers were between 2.25 to 2.60 . The mean ratings for contingent reward and management by exception active were 2.46 and 2.43 respectively and this was well within the optimum range as suggested by Bass. Management by exception passive and laissezfaire showed mean ratings of 0.96 and 1.03 respectively. The total mean rating of 2.53 for transformational leadership styles suggests that the middle level managers were employing transformational leadership styles more compared to transactional leadership style which reported a mean of only 1.96 and also laissez-faire which was only 1.03 .

The mean value of the leadership dimensions of both groups was translated into a ranking table to determine which of the leadership dimensions were more dominant. Table 4.10 shows the ranking the leadership dimensions of both PTD and DG middle level managers as well as the overall ranking of both groups. 


\begin{tabular}{|c|c|c|c|c|c|c|}
\hline \multirow[t]{2}{*}{ RANKING } & \multicolumn{2}{|l|}{ OVERALL } & \multicolumn{2}{|c|}{$\begin{array}{l}\text { DG MIDDLE LEVEL } \\
\text { MANAGERS }\end{array}$} & \multicolumn{2}{|c|}{$\begin{array}{l}\text { PTD MIDDLE LEVEL } \\
\text { MANAGERS }\end{array}$} \\
\hline & Leadership dimension & Mean & $\begin{array}{l}\text { Leadership } \\
\text { dimension }\end{array}$ & Mean & $\begin{array}{l}\text { Leadership } \\
\text { dimension }\end{array}$ & Mean \\
\hline 1 & Inspirational motivation & 2.72 & $\begin{array}{l}\text { Inspirational } \\
\text { motivation }\end{array}$ & 2.77 & $\begin{array}{l}\text { Inspirational } \\
\text { motivation }\end{array}$ & 2.67 \\
\hline 2 & $\begin{array}{l}\text { Idealized Influence } \\
\text { (attributed \& behaviour) }\end{array}$ & 2.60 & $\begin{array}{l}\text { Idealized } \\
\text { Influence }\end{array}$ & 2.57 & $\begin{array}{l}\text { Idealized } \\
\text { Influence }\end{array}$ & 2.63 \\
\hline 3 & Intellectual stimulation & 2.52 & $\begin{array}{l}\text { Intellectual } \\
\text { stimulation }\end{array}$ & 2.53 & $\begin{array}{l}\text { Intellectual } \\
\text { stimulation }\end{array}$ & 2.51 \\
\hline 4 & Contingent reward & 2.46 & $\begin{array}{l}\text { Contingent } \\
\text { reward }\end{array}$ & 2.47 & M-B-E (active) & 2.48 \\
\hline 5 & M-B-E (active) & 2.43 & M-B-E (active) & 2.40 & $\begin{array}{l}\text { Contingent } \\
\text { reward }\end{array}$ & 2.44 \\
\hline 6 & Individual consideration & 2.25 & $\begin{array}{l}\text { Individualized } \\
\text { consideration }\end{array}$ & 2.24 & $\begin{array}{l}\text { Individualized } \\
\text { consideration }\end{array}$ & 2.26 \\
\hline 7 & Laissez faire & 1.03 & Laissez faire & 1.04 & Laissez faire & 1.03 \\
\hline 8 & M-B-E (passive) & 0.96 & M-B-E (passive) & 1.03 & M-B-E (passive) & 0.89 \\
\hline
\end{tabular}

Table 4.10: Ranking of leadership styles according to the dimensions of transformational, transactional and avoidance of leadership across groups

Overall, the middle level managers showed greater inspirational motivation as compared to other transformational leadership styles with a mean rating of 2.72. This dimension of transformational leadership also ranked first for both PTD and DG middle level managers. This was followed by idealized influence and intellectual stimulation. Idealized influence, which is also known as charismatic leadership, was more dominant in PTD middle level managers with a mean of 2.63 as compared to a mean of 2.57 for DG middle level managers. It was an interesting fact to point that both PTD and DG middle level managers employed greater contingent reward and active management-by-exception leadership styles as compared to the transformational leadership style of individualised consideration. However, the DG middle level managers outranked their PTD counterparts in terms of rewarding their subordinates. PTD middle level managers were most likely preferring to engage in active management by exception style of leadership as compared to rewarding their subordinates. This component reported the highest mean as compared to other transactional leadership components. 
Both groups of middle level managers showed a greater sense of non-avoidance of leadership as compared to practicing a passive style of management by exception. However there was very little to separate between the avoidance of leadership and passive management by exception of the DG middle level managers as the laissez-faire component reported a mean value of 1.04 and the management by exception (passive) component reported a mean value of 1.03 .

A t-test was carried out to further determine any significant difference in terms of the leadership styles between the DG and PTD middle level managers. Table 4.11 shows the results of the t-test which was carried out.

\begin{tabular}{|c|c|c|c|c|c|c|c|c|c|}
\hline & & \multicolumn{3}{|c|}{$\begin{array}{l}\text { DG middle level } \\
\text { managers }\end{array}$} & \multicolumn{3}{|c|}{$\begin{array}{l}\text { PTD middle level } \\
\text { managers }\end{array}$} & \multirow[b]{2}{*}{ t-value } & \multirow[b]{2}{*}{$\begin{array}{l}\text { Sig (two- } \\
\text { tailed) }\end{array}$} \\
\hline & & $\mathbf{N}$ & Mean & SD & $\mathbf{N}$ & Mean & SD & & \\
\hline \multirow{4}{*}{$\begin{array}{l}\text { Transformational } \\
\text { leadership styles } \\
\text { components }\end{array}$} & $\begin{array}{l}\text { Idealized } \\
\text { Influence }\end{array}$ & 63 & 2.57 & 0.76 & 59 & 2.63 & 0.64 & 0.48 & 0.64 \\
\hline & $\begin{array}{l}\text { Inspirational } \\
\text { motivation }\end{array}$ & 63 & 2.77 & 0.81 & 59 & 2.67 & 0.77 & 0.71 & 0.48 \\
\hline & $\begin{array}{l}\text { Intellectual } \\
\text { stimulation }\end{array}$ & 63 & 2.53 & 0.68 & 59 & 2.51 & 0.84 & 0.14 & 0.89 \\
\hline & $\begin{array}{l}\text { Individualized } \\
\text { consideration }\end{array}$ & 63 & 2.24 & 0.89 & 59 & 2.26 & 0.83 & 0.13 & 0.89 \\
\hline \multicolumn{2}{|c|}{ *Overall transformational leadership } & 63 & 2.54 & 0.72 & 59 & 2.54 & 0.66 & 0.34 & 0.97 \\
\hline \multirow{3}{*}{$\begin{array}{l}\text { Transactional } \\
\text { leadership styles } \\
\text { components }\end{array}$} & $\begin{array}{l}\text { Contingent } \\
\text { reward }\end{array}$ & 63 & 2.47 & 0.89 & 59 & 2.44 & 0.77 & 0.21 & 0.84 \\
\hline & M-B-E (active) & 63 & 2.40 & 0.70 & 59 & 2.48 & 0.64 & 0.71 & 0.48 \\
\hline & M-B-E (passive) & 63 & 1.03 & 0.79 & 59 & 0.89 & 0.83 & 0.90 & 0.32 \\
\hline \multicolumn{2}{|c|}{ *Overall transactional leadership } & 63 & 1.97 & 0.48 & 59 & 1.93 & 0.45 & 0.36 & 0.72 \\
\hline $\begin{array}{l}\text { Avoidance of } \\
\text { leadership }\end{array}$ & Laissez faire & 63 & 1.04 & 0.87 & 59 & 1.03 & 0.95 & 0.11 & 0.91 \\
\hline
\end{tabular}

*not significant at 0.05 level, two tailed

Table 4.11: Summary of the comparison of leadership styles according to the dimensions of transformational, transactional and avoidance of leadership between PTD and DG middle level managers 
A comparison of the transformational, transactional and non-leadership components showed that none of the t-tests were significant thus; there was no considerable difference in terms of leadership styles of these two groups of middle level managers.

The two groups of middle level managers provided very similar mean ratings in terms of their leadership styles, and coupled with the fact that the t-test did not return any significant findings, it could be said that the two groups of middle level managers had no significant difference in terms of their leadership styles.

\subsubsection{Subordinates' Perception of Leadership Styles}

In order for the researcher to compare the leadership styles of both DG and PTD middle level managers from the perception of their subordinates, tables depicting the mean values of the leadership styles according to the dimensions of transformational, transactional and avoidance of leadership were produced. Table 4.12 shows the mean rating of the transformational leadership dimension of DG middle level managers as perceived by their subordinates of different schemes.

\begin{tabular}{|c|c|c|c|c|c|c|}
\hline \multirow[b]{3}{*}{$\begin{array}{l}\text { Raters' or } \\
\text { subordinates' } \\
\text { scheme of } \\
\text { service }\end{array}$} & \multicolumn{6}{|c|}{ DG MIDDLE LEVEL MANAGERS } \\
\hline & & \multicolumn{4}{|c|}{ Transformational leadership components } & \multirow[b]{2}{*}{$\begin{array}{c}\text { Overall } \\
\text { transformational }\end{array}$} \\
\hline & (n) & $\begin{array}{l}\text { Idealized } \\
\text { influence }\end{array}$ & $\begin{array}{l}\text { Inspirational } \\
\text { motivation }\end{array}$ & $\begin{array}{l}\text { Intellectual } \\
\text { stimulation }\end{array}$ & $\begin{array}{l}\text { Individualized } \\
\text { consideration }\end{array}$ & \\
\hline DG & 35 & 2.51 & 2.72 & 2.51 & 2.21 & 2.49 \\
\hline PTD & 8 & 3.17 & 3.53 & 3.00 & 2.78 & 3.13 \\
\hline $\mathrm{N}$ & 15 & 2.33 & 2.52 & 2.23 & 2.00 & 2.28 \\
\hline Others & 5 & 2.78 & 2.65 & 2.80 & 2.60 & 2.67 \\
\hline
\end{tabular}

Table 4.12: Mean ratings of the transformational leadership dimension of DG middle level managers as perceived by their subordinates

Table 4.13 on the other hand shows the mean rating of the transformational leadership dimension of PTD middle level managers as perceived by their subordinates of different schemes of services. 


\begin{tabular}{|l|c|r|r|r|r|r|}
\hline & \multicolumn{7}{|c|}{ PTD MIDDLE LEVEL MANAGERS } \\
\cline { 2 - 6 } & & \multicolumn{7}{|c|}{ Transformational leadership components } & \multicolumn{1}{c|}{$\begin{array}{c}\text { Overall } \\
\text { transformational }\end{array}$} \\
\hline $\begin{array}{l}\text { Raters' or } \\
\text { subordinates' } \\
\text { scheme of } \\
\text { service }\end{array}$ & (n) & $\begin{array}{l}\text { Idealized } \\
\text { influence }\end{array}$ & $\begin{array}{c}\text { Inspirational } \\
\text { motivation }\end{array}$ & $\begin{array}{c}\text { Intellectual } \\
\text { stimulation }\end{array}$ & $\begin{array}{c}\text { Individualized } \\
\text { consideration }\end{array}$ & 2.48 \\
\hline DG & 13 & 2.58 & 2.71 & 2.38 & 2.17 & 2.90 \\
\hline PTD & 16 & 2.89 & 3.08 & 3.04 & 2.04 & 2.37 \\
\hline N & 28 & 2.37 & 2.42 & 2.27 & 2.09 & 2.50 \\
\hline Others & 2 & 2.50 & 2.50 & 2.50 & 2.50 & \\
\hline
\end{tabular}

Table 4.13: Mean ratings of the transformational leadership dimension of PTD middle level managers as perceived by their subordinates

The mean ratings of the transformational leadership components showed that the PTD respondents/subordinates rated their DG middle level managers as showing higher transformational leadership styles as compared to the rating of their PTD middle level managers. The DG middle level managers were perceived as showing high transformational leadership with a mean of 3.13 as rated by their PTD subordinates as compared to other subordinates from different scheme of services. This was followed by subordinates from other schemes of services with a mean rating of 2.67. Subordinates from the DG scheme of service came third with the rating of 2.49 of their DG middle level managers' transformational leadership styles. The subordinates from the $\mathrm{N}$ scheme of services rated the DG middle level managers as showing the least transformational leadership styles as compared to the subordinates from other scheme of services with an overall transformational leadership mean rating of 2.28. A close examination at the components of transformational leadership showed that the subordinates from the PTD, DG and N scheme of services rated their DG superiors highly on the component of inspirational motivation while the subordinates from the others' scheme of services considered their managers as showing intellectual stimulation the most. However, all subordinates rated the DG middle level managers as showing the least of individualised consideration.

As for the PTD middle level managers, their subordinates from the same scheme of service rated them the highest in terms of showing transformational leadership with a mean rating of 2.90. This was followed by the subordinates from the other scheme of services albeit the number was only two. The PTD middle level managers were ranked third by subordinates 
from the DG scheme of services with a mean rating of 2.48 while the subordinates from the $\mathrm{N}$ scheme of services rated their managers as the least showing transformational leadership style. Like their DG counterparts, the PTD middle level managers were rated highly on the component of inspirational motivation. The PTD middle level managers were also rated the least on the component of individualised consideration by all of their subordinates as compared to other dimensions of transformational leadership.

\begin{tabular}{|c|c|c|c|c|c|}
\hline \multirow{3}{*}{$\begin{array}{l}\text { Raters' or } \\
\text { subordinates' } \\
\text { scheme of service }\end{array}$} & \multicolumn{5}{|c|}{ DG MIDDLE LEVEL MANAGERS } \\
\hline & & \multicolumn{3}{|c|}{ Transactional leadership components } & \multirow{2}{*}{$\begin{array}{c}\text { Overall } \\
\text { transactional }\end{array}$} \\
\hline & (n) & Contingent reward & M-B-E Active & M-B-E Passive & \\
\hline DG & 35 & 2.44 & 2.40 & 1.01 & 1.95 \\
\hline PTD & 8 & 3.03 & 2.53 & 0.72 & 2.09 \\
\hline $\mathrm{N}$ & 15 & 2.20 & 2.18 & 1.31 & 1.90 \\
\hline Others & 5 & 2.60 & 2.75 & 0.80 & 2.05 \\
\hline
\end{tabular}

Table 4.14: Mean ratings of the transactional leadership dimension of DG middle level managers as perceived by their subordinates

In terms of transactional leadership style, DG middle level managers were rated as more transactional by their subordinates from the PTD scheme of service with a mean rating of 2.09 and this was closely followed by subordinates from the others' scheme of services with a mean rating of 2.05. The mean rating of the subordinates from the DG scheme of service rating their DG middle level managers was 1.95 while the subordinates from the $\mathrm{N}$ scheme of service rated their DG middle level managers as showing the least transactional leadership styles.

The DG middle level managers were seen as possessing higher contingent reward leadership style as compared to other transactional leadership dimension. The PTD subordinates rated the DG managers highly on the dimension contingent reward with a mean rating of 3.03 , followed by subordinates from the others' scheme of services with a mean rating of 2.60 , DG subordinates with mean rating of 2.44 , and lastly the $\mathrm{N}$ subordinates with a mean rating of 2.20. Although the subordinates from the others' scheme of service rated the DG middle level managers quite highly on contingent reward as compared to subordinates from the $\mathrm{N}$ 
and DG scheme of services, they actually rated their superior as possessing active management by exception the highest with a mean rating of 2.75. Passive management by exception was the component of transactional leadership styles that was perceived by the subordinates form the $\mathrm{N}$ scheme of service as the most practiced style of leadershipas compared to the subordinates from other scheme of services.

\begin{tabular}{|c|c|c|c|c|c|}
\hline \multirow{3}{*}{$\begin{array}{l}\text { Raters' or } \\
\text { subordinates' } \\
\text { scheme of service }\end{array}$} & \multicolumn{5}{|c|}{ PTD MIDDLE LEVEL MANAGERS } \\
\hline & \multicolumn{4}{|c|}{ Transactional leadership components } & \multirow{2}{*}{$\begin{array}{c}\text { Overall } \\
\text { transactional }\end{array}$} \\
\hline & (n) & Contingent reward & M-B-E Active & M-B-E Passive & \\
\hline DG & 13 & 2.21 & 2.42 & 0.82 & 1.82 \\
\hline PTD & 16 & 2.77 & 2.60 & 0.69 & 2.01 \\
\hline $\mathrm{N}$ & 28 & 2.38 & 2.50 & 1.03 & 1.96 \\
\hline Others & 2 & 2.13 & 2.37 & 0.75 & 1.75 \\
\hline
\end{tabular}

Table 4.15: Mean ratings of the transactional leadership dimension of PTD middle level managers as perceived by their subordinates

Like the DG middle level managers, the PTD middle level managers were rated as practicing transactional leadership styles most highly by the subordinates from the PTD scheme of services with a mean rating of 2.01 ; this was closely followed by subordinates from the $\mathrm{N}$ scheme of service (1.96) and DG scheme of service (1.82), while the two subordinates from the others' scheme of services rated the PTD middle level managers as having the least transactional leadership styles. The contingent reward component of transactional leadership was also rated the highest by the subordinates of the PTD, N and DG scheme of services with a mean rating of 2.77, 2.38 and 2.21 respectively as compared to other transactional components. 


\begin{tabular}{|l|c|c|c|r|}
\hline & \multicolumn{2}{|c|}{ PTD MIDDLE LEVEL MANAGERS } & \multicolumn{2}{c|}{ DG MIDDLE LEVEL MANAGERS } \\
\hline $\begin{array}{l}\text { Raters' or } \\
\text { subordinates' } \\
\text { scheme of service }\end{array}$ & (n) & \multicolumn{1}{|c|}{$\begin{array}{c}\text { Avoidance of leadership/ } \\
\text { Laissez faire }\end{array}$} & (n) & \multicolumn{2}{|c|}{$\begin{array}{c}\text { Avoidance of leadership/ } \\
\text { Laissez faire }\end{array}$} \\
\hline DG & 13 & 1.33 & 35 & 1.07 \\
\hline PTD & 16 & 0.53 & 8 & 0.09 \\
\hline N & 28 & 1.20 & 15 & 1.50 \\
\hline Others & 2 & 0.63 & 5 & 1.00 \\
\hline
\end{tabular}

Table 4.16: A comparison of mean ratings of the avoidance of leadership between PTD and DG middle level managers as perceived by their subordinates

Based on the table 4.16 above, DG middle managers were rated the highest as showing the avoidance of leadership by their subordinates from the $\mathrm{N}$ scheme of service with a mean rating of 1.50. However, the DG middle level managers were rated as showing the least avoidance of leadership with a low mean rating of 0.09 by their subordinates from the PTD scheme of service. The PTD middle level managers, on the other hand, were rated the highest as showing the avoidance of leadership by their subordinates from the DG scheme of service while the subordinates from the PTD scheme of services rated them as having the least quality of avoiding leadership.

To further validate any difference in the leadership styles as perceived by subordinates from different scheme of services, an analysis of variance (ANOVA) was used by the researcher. Because the subordinates consist of personnel from different schemes of services, the ANOVA test was appropriate to assess whether the differences of leadership styles as perceived by the subordinates or respondents from different schemes of services were statistically significant.

The result of the ANOVA test on the dimensions of transformational leadership, transactional leadership and avoidance of leadership for the PTD middle level managers as perceived by their subordinates is attached as Appendix 7 of this study. The overall transformational and transactional leadership styles were also tested. The results of the ANOVA test has shown that there were no significant differences in the perceptions of the overall transformational leadership styles of the PTD middle level managers as perceived by their subordinates from different scheme of services. Nonetheless two of the dimensions of 
transformational leadership, namely inspirational motivation $(F=2.750, p \leq 0.05)$ and intellectual stimulation $(\mathrm{F}=3.472, \mathrm{p} \leq 0.05)$, yielded significant differences. There was no significant difference in terms of transactional leadership as perceived by the PTD middle level managers' subordinates. The results of the ANOVA also indicated no significant differences in terms of the subordinates' perception towards the avoidance of leadership by their PTD superiors.

The results of the ANOVA test also yielded some significant findings in terms of the leadership styles of DG middle level managers as perceived by their subordinates of different scheme of services. The result of the ANOVA test on the dimensions of transformational leadership, transactional leadership and avoidance of leadership for the DG middle level managers as perceived by their subordinates is attached as Appendix 8 of this study. Unlike their PTD counterparts, the DG middle level managers' overall transformational leadership styles have yielded significant differences as perceived by subordinates from different scheme of services $(F=2.760, p \leq 0.05)$. In addition, one component of the transformational leadership which was inspirational motivation $(\mathrm{F}=3.265$, $\mathrm{p} \leq 0.05)$ also showed significant differences.

The avoidance of leadership of the DG middle level managers too showed significant differences $(\mathrm{F}=5.602, \mathrm{p} \leq 0.05)$ as perceived by their subordinates from different scheme of services. However, there was no significant difference in terms of the transactional leadership styles as perceived by the DG middle level managers' subordinates.

\subsection{Qualitative Findings}

In the following section, the interview responses from the participants are outlined. The qualitative data is presented according to the themes and quotations of the participants. The qualitative findings of this study were utilised to answer sub-question three of this study which is: Are there any significant differences in the evaluation of the leadership styles as perceived by the PTD and DG middle level managers?

The participants of the interview consisted of eight middle level managers from the DG and PTD scheme of services who are working in several departments in the Ministry of Education Malaysia. For the purpose of analysing the findings of this study, all participants 
were categorised according to codes. The demographic profiles of the participants and the codes that represent them are shown in table 4.17. The participants consisted of three female DG middle level managers, one male DG middle level managers and four male PTD middle level managers. Of all the eight middle level managers, only one PTD manager had less than five years of working experience. Five of the middle level managers were of the grade 52 which indicated their seniority.

\begin{tabular}{|c|c|c|c|c|c|c|}
\hline Codes & Sex & $\begin{array}{l}\text { Age } \\
\text { group }\end{array}$ & $\begin{array}{l}\text { Grade of } \\
\text { position }\end{array}$ & $\begin{array}{l}\text { Years in the } \\
\text { scheme of } \\
\text { service }\end{array}$ & $\begin{array}{l}\text { Years in any } \\
\text { leadership position } \\
\text { including the } \\
\text { current position }\end{array}$ & $\begin{array}{l}\text { Department/ } \\
\text { Division of the } \\
\text { Ministry of } \\
\text { Education }\end{array}$ \\
\hline DG1 & Female & $51-58$ & 52 & 20 years ++ & 7 years & $\begin{array}{c}\text { Administrative } \\
\text { division }\end{array}$ \\
\hline DG2 & Male & $51-58$ & 52 & 20 years ++ & 10 years & $\begin{array}{l}\text { Administrative } \\
\text { division }\end{array}$ \\
\hline DG3 & Female & $35-39$ & 44 & 10 years ++ & 1 year & $\begin{array}{l}\text { Professional } \\
\text { division }\end{array}$ \\
\hline DG4 & Female & $51-58$ & 52 & 20 years ++ & 10 years & $\begin{array}{l}\text { Professional } \\
\text { division }\end{array}$ \\
\hline PTD1 & Male & $45-50$ & 52 & 20 years ++ & 12 years & $\begin{array}{l}\text { Professional } \\
\text { division }\end{array}$ \\
\hline PTD2 & Male & $51-58$ & 52 & 20 years ++ & 15 years & $\begin{array}{l}\text { Professional } \\
\text { division }\end{array}$ \\
\hline PTD 3 & Male & $24-30$ & 41 & 4 years & 2 years & $\begin{array}{c}\text { State Education } \\
\text { Department }\end{array}$ \\
\hline PTD 4 & Male & $30-34$ & 48 & 10 years ++ & 5 years & $\begin{array}{l}\text { Professional } \\
\text { division }\end{array}$ \\
\hline
\end{tabular}

Table 4.17: Demographic profiles of interview participants

A set of eight standardized open-ended questions were asked to elicit leadership styles and qualities which they perceived as essential to them and which they felt were representing their leadership styles. The interviews with the eight middle level managers from both the DG and PTD scheme were transcribed verbatim and the analysis was done using the precoded markers. The findings were then summarised according to the dimensions of transformational, transactional, non-leadership qualities and also other relevant leadership styles or qualities. 
In order for the researcher to analyse the respondents' perception of their leadership styles, questions were asked such as 'What is your understanding of the term 'leadership'?', 'What do you think are the most important qualities that leaders should posses?', 'How do you perceive you own leadership style?'. A summary of the qualities or styles which all the middle level managers identified with during the interview is summarised in table 4.18.

\begin{tabular}{|c|c|c|c|c|c|c|c|c|c|}
\hline Leadership & Dimensions & DG 1 & DG2 & DG3 & DG4 & PTD1 & PTD2 & PTD3 & PTD4 \\
\hline \multirow[t]{4}{*}{ Transformational } & $\begin{array}{l}\text { Idealised } \\
\text { influence }\end{array}$ & $\mathbf{v}$ & $\mathbf{v}$ & $\mathbf{v}$ & $\mathbf{v}$ & $\mathbf{v}$ & $\mathbf{v}$ & $\mathbf{v}$ & $\mathbf{v}$ \\
\hline & $\begin{array}{l}\text { Inspirational } \\
\text { motivation }\end{array}$ & $\mathbf{v}$ & $\mathbf{v}$ & & v & $\mathbf{v}$ & $\boldsymbol{v}$ & & $\mathbf{v}$ \\
\hline & $\begin{array}{l}\text { Intellectual } \\
\text { stimulation }\end{array}$ & $\mathbf{v}$ & $\mathbf{v}$ & $\mathbf{v}$ & $\mathbf{v}$ & & $\mathbf{v}$ & & \\
\hline & $\begin{array}{l}\text { Individualized } \\
\text { consideration }\end{array}$ & $\mathbf{v}$ & $\mathbf{v}$ & $\mathbf{v}$ & $\sqrt{ }$ & $\mathbf{v}$ & $\sqrt{ }$ & $\mathbf{v}$ & $\sqrt{ }$ \\
\hline \multirow[t]{3}{*}{ Transactional } & $\begin{array}{l}\text { Contingent } \\
\text { reward }\end{array}$ & & $\mathbf{v}$ & $\mathbf{v}$ & & & & & $\mathbf{v}$ \\
\hline & MBE (Active) & & & & $\mathbf{v}$ & & & & \\
\hline & MBE (Passive) & & & & & & & & \\
\hline Non-leadership & Laissez faire & & & & & & & & \\
\hline $\begin{array}{l}\text { Other leadership } \\
\text { qualities/styles }\end{array}$ & Knowledgeable & $\mathbf{v}$ & $\mathbf{v}$ & $\mathbf{v}$ & & & & & $\mathbf{v}$ \\
\hline
\end{tabular}

Table 4.18: A summary of key themes related to transformational, transactional, nonleadership and other relevant leadership styles

The following sub-sections will explore in detail the important themes emerging from the interview according to three leadership styles: transformational leadership styles; transactional and non-leadership styles; and finally other relevant leadership styles in greater details.

\subsubsection{Transformational Leadership}

Transformational leadership will be discussed in terms of the qualities that represent all four dimensions of transformational leadership which are idealised influence, inspirational 
motivation, intellectual stimulation and individualised consideration. A detailed summary of the transformational qualities exhibited by the participants is attached as Appendix 9 of this study.

\subsubsection{Idealised influence}

Idealised influence as one of the dimension of transformational leadership was identified by all participants. According to Bass and Riggio (2006) there are two aspects of idealised influence: the leaders' behaviour (idealised influence behaviour) and the elements that are attributed to the leader by followers and other associates (idealised influence attributed). There are a number of qualities that could attribute someone as showing or possessing high idealised influence. One of the qualities that four of the participants shared was how they emphasised values and beliefs of themselves and the organization. For instance PTD2 said that as the head of a sector, he always believed in the value of leading by example. DG4 on the hand believed in the virtues of honouring her words and always "adhere to rules and regulations of the organization" (DG4). DG1 believed that knowledge and skills "are the values needed in doing the job now". PTD4 valued the importance of the subordinates placing trust and belief on him as the leader of the sector. PTD4 reaffirmed his beliefs of being a good leader and obedient worker according to the virtues of Islam and this belief was often shared with his subordinates.

Another quality of idealised influence leaders is behaving in ways that allow them to be role models for their followers. PTD2 considered that as a leader, it is important to show and practice good leadership qualities because leaders have the ability to influence others to follow his or her leadership qualities. PTD2 was a strong believer in leading by example because he was taught this exact value by his former superior and that this value has proven to be best method of getting the best out of the leader and subordinates. Apart from PTD2, none other participants mentioned the value of leaders becoming role models for others. Three of the participants agreed that leaders should be admired, respected and trusted which are also qualities of idealised influence. DG2 said that when a leader was appointed to lead a unit/sector, it is important for him get the acceptance and support needed from his subordinates. He continued: "I would not want my subordinates to respect me because of my position as their superior, but importantly they respect me and regard me as someone who could guide them" (DG2). PTD2 shared the same sentiment. PTD2 gave an example of 
being punctual and adhering to the time of work. He said that he would never take an early lunch break or leave the office during office hours to do any personal errands. By showing such qualities, he said that he had gained much respect and admiration from his subordinates by virtue of him showing good discipline as a leader. PTD4 argued that trust and respect played an integral part for such a young middle manager to lead a sector with majority of the subordinates were from the DG and N scheme of services. "So what I did when I first came here was to develop my subordinates' trust in me because if they do not trust me, then it will be difficult. Leadership would not work if subordinates do not trust the leader" (PTD4).

Idealised influence leaders also display a sense of power, are willing to take risks and can be counted on to do the right thing. Three of the participants, who were all from the DG schemes of services, displayed this quality. DG3 for instance believed that a leader should always take charge and must lead her subordinates. DG3 added that leaders must also be confident and committed with all their decisions and most importantly "willing to uphold the principles of the organization" (DG3). DG4 considered that leaders and subordinates should always adhere to the rules and regulations of the organization. DG1 said, “...talking about leadership, to me leaders should be able to make decisions. That is very important". DG1 added that "I accepted the job and responsibility in this organization because I have the experience and capability in curriculum development... and assessment. So for that reasons I can carry out my duties well and I am quite optimistic with whatever I do" (DG1).

The final quality of idealised influence displayed by two of participants is the importance in having a sense of purpose. PTD1 considered that a leader in the organization must be very clear in serving the purpose of ensuring the policies of the organization are followed by subordinates. PTD3 considered that despite of his young age, his deployment as the head of the unit in the state education department was because of the trust the organization has placed on him. Therefore, he regarded that his lack of experience would not hamper his purpose of leading the unit.

\subsubsection{Inspirational motivation}

A leader who is inspirationally motivated will behave in ways that motivate and inspire those around by providing meaning and challenges to their subordinate's work (Bass \& Riggio, 2006). PTD4 believed that "motivation should be the main feature in our daily lives especially when we are leaders in the organization" (PTD4). In doing so, PTD4 would often 
slot in motivational speech during meetings with his subordinates so that indirectly it would develop their confidence and also motivation. DG1 felt that motivation was very important. She gave an example of her subordinate who recently was awarded with the excellent service award by the Government of Malaysia. She sent her subordinate a note thanking and congratulating her on the award. DG1 believed that notes of appreciation would actually increase her subordinates' motivation because in addition to the award received, the subordinates' excellence was being appreciated personally by the immediate superior. This quality of inspirational motivation was also exhibited by DG3. She believed that by putting trust on her subordinate was one form of motivation. She added that by expressing her trust in the capabilities of her subordinates, she was giving her subordinates the motivation needed to accomplish the required job.

Another quality of inspirational motivation is that the leaders are enthusiastic about what needs to be accomplished. As a result, leaders should clearly communicate their expectations to their followers. PTD4 for instance used the annual retreat meeting with his subordinates to restate the yearly key performance index target, reaffirm his desire to lead the organization effectively and to deliver his hopes of what needs to be carried out by his subordinates. PTD1, on the hand, believed that a leader must be very explicit and clear in delivering his expectations across, and subordinates should always be sure and certain of the expectations of the leader in return. PTD2 felt that in order for the subordinates to do what needs to be accomplished, the leader must first be able to deliver what was expected of him by the organization.

Further to the quality of inspirational motivation mentioned previously, a leader should also be visionary. The leader should articulate the vision of the future and gets the subordinates to do so. The leader is committed to the vision and also the goals. As a result the leader is optimistic of the future and confident that the goals can be achieved. DG1, for one, considered that an organization will succeed if a leader has a strong vision and knows the direction the organization is heading. DG1 added that the vision need not have to be the vision statement of the organization, but could be the vision of that particular unit that would directly benefit the whole organization. He gave example of how he has drawn up a vision and mission statement of his unit and set a target period of five years for that mission to be accomplished and for the vision to be realized. DG1 added that "a leader should be visionary 
and possesses a clear indication of how the vision could be recognized and carried out effectively by the subordinates" (DG1). DG1 also pointed out that he was always forward looking and constantly on the alert of the necessary and potential changes and needs of the organization. PTD4 shared the same sentiment. He felt the need to be very clear on his own personal vision and mission as the leader of the organization because he will be held accountable.

\subsubsection{Intellectual stimulation}

One of the qualities that described a leader as showing intellectual stimulation is when the leader seeks different perspectives, especially when solving problems and tasks. The leader would suggest new ways to approach the problems and tasks and encourage their subordinates to be innovative and creative as well in solving the problems and tasks together. DG1 believed that it was essential for a leader to allow her subordinates to be innovative and creative in doing day-to-day tasks. The degree of freedom given to her subordinates in exploring their creativity and innovative was likened to a person flying a kite. DG1 said that a person flying the kite would be really excited watching the kite fly high but sometimes the person needs to pull and control the string of the kite so that it would not be over-blown by the wind. This was the same with the creativity of the subordinates. DG1 believed that the creativity of the subordinates in dealing with problems and solution should be allowed to run free but at the same time there should be some degree of control.

This quality of intellectual stimulation was also exhibited by DG2. DG2 believed that one of the roles of a leader was to solve any problems, including those of their subordinates which were relevant to the organization. In doing so, he encouraged his subordinates to always seek his opinion and at the same time be receptive to other opinions when dealing with those problems. PTD2 gave an example of how he approached a problem or situation from a different angle when he was made the assistant district officer prior to his appointment at his current position. As the assistant district officer, it was required of him to witness the signing of important documents pertaining to land title ownership transfer. Quite often the transfer of ownership involved a person of old age wanting to transfer the land ownership to their next of kin as part of the process of inheritance. Sometimes it would be a struggle for the person of old age to actually make their way to see PTD2 in his office; hence the land title ownership transfer could not be carried out. What PTD2 did was that whenever he faced 
this situation, he would personally approach the land owner at the land owner's convenience and witness the signing of the document instead of asking the land owner to come and see him in the office.

Another quality that a leader with intellectual stimulation exhibit is soliciting new ideas from their subordinates. The subordinates are included in the process of addressing problems and also finding solutions. DG3 would often use the platform of open discussion with her subordinates in order for her to make decisions. She was open to ideas and would accept the ideas, suggestions and solutions of her subordinates for the greater good of the organization. DG1 believed that with years of experience and knowledge, she would still seek advice from her subordinates because she knows that they are experts in their own right. Therefore before DG1 finalises her decision, her subordinates were given the avenue to look at the issue and give their opinions on that matter.

One more quality of intellectual stimulation shown by one of the participants was looking at a problem and situation from another angle. DG1 gave an example of how she approached the task of editing a paper work. DG1 would beam the paper work by using the LCD projector so that everyone could see, give opinion and edit the paper work immediately. By doing so, not only that she was able to get immediate feedback from her subordinates, she was also able to save time in getting the paper work prepared, proof read and edited.

The final quality of intellectual stimulation is that leaders should never publicly criticise their subordinates. DG2 agreed with this quality because he felt that if the subordinates were scolded or criticised in the manner which was not acceptable to them, it will only bring negative effect to the leader and the organization.

\subsubsection{Individualised consideration}

Like idealised influence, individualised consideration, a component of transformational leadership was exhibited by all the participants. One of its qualities, shared by all participants, was that they recognised every subordinate as having different needs, aspirations and abilities, thus treating them as different individuals rather than just mere subordinates. When asked of leading a unit or sector with personnel from different schemes of service, DG1 was very positive. "It's good to me because I am quite positive about 
everybody's own strength, so the strength that the PTD officers have in administration and management could be put into use" (DG1). Similar to DG1, DG2 believed that by having subordinates from the PTD and DG scheme of services was an added advantage because the DG officers are expert in the field of education while PTD officers have expertise in administration and management. DG2 added: "regardless of their scheme of services, there would be no difference for me because they complement each other and they learn from each other". In order for DG2 to understand the strength of his subordinates, he required his subordinates to submit their Curriculum Vitae so that "as a leader, I know would be able to recognize their academic achievement or background, their added skills and knowledge and also something about their family. In doing so, I am able to plan task that suit him and what is the best for him. We must take the initiative to know them personally. To lead them we must understand them". DG4 shared the same sentiment of how different subordinates, especially those from different scheme of services, would complement the strength of the unit, the leader and the organization. DG4 added that if a leader was not able to identify the strengths of their subordinates, it might cause a conflict in the unit and organization.

Having to lead a unit with subordinates from multiple scheme of service was a new experience for PTD1. Prior to his appointment as the head of the current department, he was the head of a unit in a department under the administrative division of the Ministry of Education. His subordinates then consisted only of those from the same scheme of service as well as the support staff who were from the $\mathrm{N}$ scheme of service. However, as the head of the current unit, he has subordinates from different scheme of services to lead. Showing the quality of individualised consideration which is: considering every subordinates as having different abilities and as a result leaders would treat them as individuals; PTD1 acknowledged that DG officers who work in the Ministry of Education were well trained in matters related to education and particularly in teaching. PTD1 came to realise that his subordinates from the DG scheme of services have their own capabilities and were also able to manage and administer an organization besides schools without having to go through a period of intensive diploma course like those required of the PTD scheme of service. Nonetheless, he did feel that having too many DG officers in the Ministry of Education, especially those promoted based on excellent service at school, would actually waste the government's investment in them to become well trained and qualified teachers. 
Like PTD1, PTD2 also would never differentiate between his subordinates just on the basis of their scheme of services. To him, all subordinates were treated with equal respect. The main thing for him was the contribution each subordinate could make to the organization. PTD4 indicated that all of his subordinates were considered as assets to the organization regardless of their service or background, but what mattered most were their different capabilities. PTD3 considered that his inexperience was overcome by the help and guidance of subordinates from different scheme of services who were expert in their own field. For instance, the chief clerk of the unit ( $\mathrm{N}$ scheme of service) was very senior and experienced, hence he sought her help in guiding him with proper writing and editing good minutes of meeting, memos and official letters.

In understanding that subordinates have different needs, the leader would personalise the level of guidance or observation given to their subordinates. This shows that leaders demonstrate acceptance of the differences of their subordinates. PTD4 exhibited this quality: "First of all we have to identify the so-called high performers; those are the people whom I would group as sitting on the first level. Then there is the second level. The third level is occupied by those whose performance and contribution to the unit are very much lacking and minimal. As a leader I would tackle every level differently. I would give least focus for those top performers. I would concentrate more on getting the best from the second level because with proper guidance they could perform excellently. The biggest challenge is to guide those at the third level because they lack severely in motivation and also discipline. As a leader I would not want to use my power to punish them. So I have to really understand what is their problem and what is it that I could help to make them perform better" (PTD4).

As part of the quality of treating subordinates as individuals, the quality of individualised consideration also extends to the manner in which interaction between leaders and subordinates is personalised. For instance, on a general level, DG4 did exhibit this quality to some extent. "I have two kinds of relationship. Number one is professional and number two is personal. As a professional I do not compromise with mediocrity where work performance or rules and regulations are concerned. As for the second relationship, which is on personal level... where personal is concerned, I am friendly with everybody and I do not care about my position or hierarchy. But as subordinates, they must be able to understand 
the situation or instances where I am their leader and other situation where I am their friends".

Another quality of individualised consideration supported by most of the participants was encouraging a two-way exchange in communication. DG1 and PTD3 shared the same avenue for two-way communication which was the concept of mesyuarah. This is the Islamic practice of a meeting or discussion where all voices are heard and the principal of democracy is at its highest standard. DG1 and PTD3 felt that expressing their views should be reciprocated with the views expressed by their subordinates. Therefore both of them felt that mesyuarah was the best platform for the leader and subordinates in the unit to iron matters out which are related to work or interpersonal relationship among members of the unit. In addition, mesyuarah enables the subordinates and leaders to air and resolve any indifferences and dissatisfaction among the members of the unit. PTD4 on the other hand believed that the frequency of formal meetings with his subordinates would encourage in two-way communication between him and his subordinates. PTD1 would use frequent small discussion session with smaller groups for him to air his views and listen to the opinions of his subordinates. Like PTD1, PTD2 would prefer to have frequent discussion session with subordinates. Rather then giving out orders straight away, a discussion beforehand would allow subordinates to ask and clarify any matters so that they understand clearly what is required of them.

In giving support to the effectiveness of two-way communication, DG4 believed that this method was best used in resolving conflicts between leaders and subordinates and also conflicts among subordinates. DG4 believed that leaders should always hear to all sides of every story and never jump into conclusion and believe in hearsay. Furthermore, learning is a two-way process between the leader and their subordinates. Therefore the leader must also take the initiative and opportunity to learn from the subordinates because "they have their own strength" (DG3). As a leader in her unit, DG3 would often encourage dialogues between her and her subordinates as the means of understanding their strength and also ideas.

Leaders who support individualised consideration also show qualities of an effective listener. DG3 believed that as a leader, taking time to listen to any views expressed by her subordinates would indirectly show her support for her subordinates' opinion and as a result 
the subordinates would feel that their views were being heard and appreciated by their leaders. DG2 would not confine his interaction with his subordinates to the limits of the office space and time. He would often invite some of his subordinates for lunch or coffee; by doing this he felt that his subordinates would become more comfortable with him and the barrier of leader-subordinate would be very minimal. In doing so, DG2 was able to maintain an honest and open communication with his subordinates because he felt that his subordinates might feel a bit restricted to have that kind of communication in the office. PTD3, on the other hand, would make time to interact with lower ranked personnel like store keepers or office drivers because he felt they are part of the organization and their opinions and voices should also be heard equally. In return he would reassure them that their opinions were valued and forwarded to the higher management. PTD2 also valued the importance of being an effective listener. "A leader needs to be open and receptive of whatever views and problems of their subordinates because if we do not want to listen, we would certainly be facing a lot of problems in the future" (PTD2). He added: "A leader must be a good listener". PTD2 said that he developed the attribute of listening to people partly because of his prior appointment as the assistant district officer. "I like listening to the people and I feel satisfied if people would come and share their problems with me" (PTD2).

Another quality of individualised consideration, shared by three of the participants, was coaching, mentoring and teaching. DG3, for instance, strongly felt the need for leaders to consistently guide and advise their subordinates. DG2 on the other hand believed that a leader must act as the point of reference for his subordinates. Leaders must not be selective in the knowledge they impart to their subordinates. PTD4 said that as a leader, it was his responsibility to guide and mentor his subordinates. "To give the simplest example is to point out to my subordinates the correct way of writing minutes of a meeting. In the government sector, there is a correct way of writing minutes of a meeting; hence I would take time to correct the minutes together with them so that they would not make the mistakes in the future".

The final quality of individualised consideration endorsed by three of the participants was delegating tasks as means of developing subordinates. Delegated tasks are monitored to see if followers need additional direction or support in such a way that the subordinates do not feel they are being checked upon (Bass \& Riggio, 2006). For instance, PTD2, who was the 
head of the sector in one of the departments under the professional division, has several subsector heads who assist him in the day to day running of the sector. Rather than asking them to report back on the progress of any tasks given, he would rather meet them at their own work space and at ask them of the progress. "Sometimes, a leader might not understand that burden of work that his subordinates are coping with. If a leader takes time and actually goes and sees his subordinate personally, he might find that there are huge piles of files and paperwork on their desk and this shows that the subordinates are under constant pressure to complete the task. Obviously they would not come and see you and complain of the burden they are confronting. Therefore, as a leader, it is upon you to try and ease the burden by perhaps asking another subordinate to help out with the task. You will not be able to see what's actually happening in the office or with your subordinates if you do not take time and have a walk around or look around" (PTD2). PTD4 on the other hand likes to use meetings as the avenue for his subordinates to report back on the delegated tasks. For him, this method has proven to be best in terms of monitoring the progress of the tasks given to his subordinates. DG3 would implement a system whereby all delegated tasks are rotated among her subordinates for the period of one year. This would give the chance for DG3 to allow each of her subordinates to constantly learn new things by carrying out new tasks every now and then. She would not want only one person to specialise in a particular area of the work. She termed this as compartmentalising. If all were given a chance to carry out the same task, there would not be an excuse of the job stalling because the person was away on holiday or on sick leave because another subordinate would be able to take over the task and complete it as required.

\subsubsection{Transactional Leadership}

Transactional leadership is discussed in terms of the qualities that represent all three dimensions of transactional leadership, which are contingent reward, management by exception active, and management by exception passive. A detailed summary of the transactional leadership qualities shown by the managers interviewed is attached as Appendix 10 of this study. 


\subsubsection{Contingent reward}

Contingent reward is transactional when the reward is a material one, such as a bonus; however, contingent reward can also be transformational when the reward is psychological such as praise (Bass \& Riggio, 2006). This was true of DG3 and PTD3. DG3 said that rewarding her subordinates with anything material was never going to be an effective method but when rewarding subordinates with praises, she could see the continuing effort of her subordinates. Likewise, PTD4 and DG2 felt that motivating their subordinates would indirectly affect the performance of his subordinates in a positive manner.

When asked about rewarding their subordinates in exchange for effort, all participants except PTD1 and PTD2, believe that reward is somewhat considered as a motivational factor for their subordinates. The reward referred by the participants however are not material ones but in the form of yearly appraisal marks. One of the qualities of contingent reward, which is making the reward clear if goals are achieved, was shown by four of the participants. In the government sector, yearly appraisal or yearly performance review is necessary. Every subordinate is rated according to performance and contribution to the organization. The yearly appraisal will often be used in the yearly salary increment and also as a basis for promotion. In addition, the annual service excellence award for government employees takes into large consideration one's yearly appraisal marks. It is up to the discretion of the immediate superior to rate and give marks to their immediate subordinate.

DG3 said that if subordinates do perform consistently, there should not be any reason why she would not "reward" her subordinates with the marks which they deserved. PTD4 agreed that the yearly appraisal could be used as a form of reward for his subordinates. DG2 would use the yearly appraisal as a form of promise in return for good performance. The yearly appraisal will also be used as the key performance indicator for his subordinates. He would discuss with them what was expected of them and in return DG2 would not hesitate to award deserving marks in the subordinate's appraisal form. Nonetheless, he would never use this as a form of threat and condemn his subordinates with low marks if they did not perform according to the required standard. Instead he would meet in the middle of the year and advise and also guide the subordinates and tell them that they need to perform better. Another form of reward supported by two of the participants was by nominating them to go for short courses. DG2 and PTD1 believed that occasional short courses or refresher courses 
conducted by other agencies would not only benefit their subordinates, but would indirectly help to hone the strength and ability of the subordinates.

Overall, all participants believed that rewarding subordinates with something material in exchange for effort and work performance was morally and ethically wrong. It is also against the rules and regulations of the General Order of Malaysian public servants.

\subsubsection{Management by Exception (Active and Passive)}

For management by exception (both active and passive), all participants except for DG4 did not endorse this type of leadership. DG4 believed that because of the nature of her job description, mistakes made by subordinates had to be highlighted so that it would not happen in the future. However, she would not focus only on the mistakes but would offer the solution to that mistake. Other participants believed that some of the qualities of management by exception active such as keeping track of mistakes and concentrating on those mistakes are sometimes required; they felt that the onus was actually on them to take responsibility of those mistakes and offer the best possible solution.

\subsubsection{Other Leadership Styles/Quality}

One quality that was not listed as either transformational or transactional but was consistently shown especially by the DG participants is knowledge. DG1 believes that she was appointed as the head of the current position because she has vast knowledge and experience in curriculum development and assessment. Knowledge is essential for a leader as this would be the key values that they want to impart to their subordinates. DG2 said that with good knowledge, a leader would have no problem to guide and be a point of reference to his subordinates. DG3 said that a leader should know more than their subordinates but at the same time value the knowledge of their subordinates. DG3 said that departments in the professional division of the ministry require the leaders and subordinates to be knowledgeable and well-versed in matters related to education and policy; hence for DG3, it was essential that a leader in those departments have the necessary knowledge so that decisions which have to be based on their expertise could be made effectively. DG4, on the other hand, believes that leaders and subordinates should constantly seek knowledge especially among themselves. Leaders, according to DG4, should be receptive to the idea of learning new things despite their vast experience. She pointed out how DG officers should 
equip themselves with knowledge related to managing and administering an organization rather than being content with their knowledge in the area of education alone. PTD4 felt that one quality that defines a good leader is knowledge. "Knowledge is very important. For instance, as a PTD deployed as the head of a unit in the professional department, obviously I would be the one who would give advice on all matters not related to the professional aspect of education. This includes human resource management, proper budgeting and other administrative matters. If I am not knowledgeable enough in those areas, then it would certainly defeat the purpose of deploying a PTD into the professional departments" (PTD4).

\subsection{Chapter Summary}

The findings of the quantitative and qualitative strand of this study have indicated the leadership styles of the middle managers from both the PTD and DG scheme of services working in the Ministry of Education Malaysia. The findings also indicated that subordinates of different scheme of services do perceived the leadership styles of their superiors differently. The interviews have helped the researcher to better understand the leadership styles of the middle managers from their own perspective. 


\section{CHAPTER 5 -DISCUSSION OF THE FINDINGS}

\subsection{Chapter Overview}

In this chapter, the key findings of the quantitative and qualitative strands are highlighted and summarised. As this study employed a triangulation concurrent mixed methods design, the findings obtained from the quantitative and qualitative strands were integrated, compared and discussed so as to provide a complete understanding of the main research question which was: What are the leadership styles practiced by the PTD and DG middle level managers in the Ministry of Education Malaysia? Nonetheless, it is imperative for the researcher to answer the study's sub-questions before discussing the main research question.

\subsection{Discussion of the Findings}

The findings are discussed with specific reference to the study's research questions. To begin with, the three sub-questions were discussed. This was followed by the discussion of the main research questions.

\subsubsection{Sub-question one: Are there any significant differences of the leadership styles practiced by the PTD and DG middle level managers?}

When a t-test was performed to determine whether any significant differences in terms of the leadership styles existed between these two groups of middle level managers, the results indicated that there were no statistical differences between the leadership styles of the PTD and DG middle level managers. Similar result was found by Keegan and Den Hartog (2004) when they conducted a comparative analysis of transformational leadership style between project managers and line managers working for a large technical and logistic-oriented government department in the Netherlands. Bodla and Nawaz (2010) also reported similar findings in their comparative analysis of leadership styles among faculty members in public and private universities in Pakistan. Oshagbemi and Ocholi (2005) conducted a study to compare the leadership styles of managers working in several United Kingdom's key enterprises and found no significant differences in terms of the leadership styles of the managers. Kuchinke (1999) also discovered that there was no significant difference in the leadership styles among managers of a multinational telecommunication organization. Nonetheless, a study conducted by Oshagbemi and Gill (2004) discovered there were 
significant differences in terms of transformational leadership styles between senior managers and middle level managers in UK organizations.

The findings therefore showed that there was no significant difference between the leadership styles of PTD and DG middle level managers working in the Ministry of Education Malaysia.

\subsubsection{Sub-question two: Are there any significant differences in the evaluation of leadership styles of the PTD and DG middle level managers as perceived by subordinates from different scheme of services?}

The ANOVA test was conducted to determine whether any significant differences in terms of the perceived leadership styles of the DG and PTD middle level managers by their respective subordinates who were from different schemes of services. The test has shown that the PTD middle level managers' overall transformational leadership style was not perceived differently by their subordinates of different scheme of services. However, two components of the transformational leadership, namely inspirational motivation and intellectual stimulation, yielded significant differences in terms of perceived leadership styles of the PTD middle level managers by their subordinates of different schemes of services.

The results of the ANOVA test indicated that there was a significant different in the overall transformational leadership style of the DG middle level managers as perceived by their subordinates from different scheme of services. A further significant difference was found in one of the components of transformational leadership which is inspirational motivation. This study suggested that the DG middle level managers were perceived by their subordinates of different scheme of service to show leadership styles that were transformational. McCollKennedy and Anderson (2002) found that employees who perceived their superiors as having high transformational leadership were most likely to experience an increase in optimism and performance.

Subordinates of both groups of middle managers, however, did not perceive their superiors differently in terms of showing transactional leadership styles. But the perception of nonleadership behaviour or laissez-faire of the DG middle level managers by their subordinates 
of different scheme or services was found to be significant. The findings of this study therefore suggested that DG middle level managers were perceived by their subordinates as having both transformational leadership style and nonleadership attributes as well.

In addition to the ANOVA test, the mean ratings of the leadership styles of the PTD and DG middle level managers were used to indicate how the subordinates perceived the leadership styles of their DG or PTD middle level managers. The findings indicated that the subordinates view their superiors as possessing more of the transformational leadership styles than transactional and laissez-faire leadership styles. Similar results were found in studies conducted by Bogler (2001), McColl-Kennedy and Anderson (2002; 2003) and Zaidi (2005).

The mean ratings indicated that the subordinates from the PTD scheme of services perceived their DG middle level managers and PTD middle level managers highly on the dimension of inspirational motivation, followed by idealised influence and intellectual stimulation. The transformational dimension of individualised consideration was rated the least by them. Overall, PTD subordinates rated their superiors, regardless of their scheme of services, highly on all dimensions of transformational leadership as compared to subordinates form the other scheme of services.

On the aspect of transactional leadership styles, subordinates from the PTD scheme of services rated their managers from both scheme of services as showing transactional leadership styles most when compared to subordinates from other scheme of services. The mean ratings of each of the transactional dimension indicated that the subordinates, regardless of their schemes of services, perceived both PTD and DG middle level managers as showing more contingent reward and management by exception active as compared to one of the dimension of transformational leadership which is individualised consideration. Contingent reward and management by exception are ways of looking at reinforcement leadership (Bass, 2008). According to Bass and Avolio (1994), “contingent reward has been found to be reasonably effective, although not as much as the (transformational) four I's, in motivating others to achieve higher levels of development and performance" (p. 4). Such motivation to perform will provide a sense of direction for the subordinates (Avolio \& Bass, 2004). In addition, leaders who exercise transactional leadership styles work toward 
recognising the roles and tasks required by their subordinates to reach the desired outcome (Avolio \& Bass, 2004). The findings of this study therefore supported the argument that effective leaders are both transformational or transactional (Avolio \& Bass, 1995; Bass, 2008; Bass \& Riggio, 2006). In addition this supports the multidimensionality of the Model of Full Range Leadership proposed by Bass.

Finally, the perceptions of the subordinates towards the non-leadership qualities of their superiors are worthy of comment. Only subordinates from the PTD scheme of services rated their DG as showing the least quality in terms of avoiding leadership. With that being the only exception, the DG and PTD middle level managers were rated as showing greater avoidance of leadership than the transactional dimension of management by exception passive. Shea (1999) agrees that leadership styles of managers are expected to affect their subordinates' performance. Casimir (2001) pointed out that subordinates' perceptions of leadership is as important in their own right because perceptions are what subordinates act upon. Casimir also believed that subordinates' perceptions of the leadership styles or behaviour of their superiors are vital for a complete understanding of the effects that leadership styles have on the organization. The majority of the studies reviewed in the literature (Ardichvili, 2001; Ardichvili \& Kuchinke, 2002; Keegan \& Den Hartog, 2004; Oshagbemi \& Gill, 2004) have found that laissez-faire was rated as the least practised leadership quality but this study has indicated otherwise. This study also supports the notion that leadership styles of superiors were perceived differently by subordinates of different groups.

\subsubsection{Sub-question three: Are there any significant differences in the evaluation of the leadership styles as perceived by the PTD and DG middle level managers?}

The interview findings indicated that the transformational leadership styles were practised by both DG and PTD middle level managers. The interview analysis suggested that both groups of middle level managers showed greater preference of individualised consideration. Individualised consideration was also found to be high among the participants of a qualitative study on police leadership conducted by Bryman et al. (1996). Kirby, Paradise and King (1992), in a narrative inquiry of extraordinary leaders in education, too found that individualised consideration was considered as one of the most practiced leadership styles among those holding leadership positions in the educational organization. According to Bass 
(2008), such considerate leaders pay special attention to each followers' needs for achievement and growth. In addition, followers were viewed as unique individuals (Avolio $\&$ Bass, 1995). These qualities were found to be practised by all the middle managers interviewed. Seven of the middle level managers agreed that their interactions with their subordinates were personalised according to their scheme of services, working experience as well as the level of guidance that their subordinates should receive. In addition to that, another quality of individualised consideration which encourages two-way communication was also evident in all eight of the middle level managers.

All of these managers were perceived as showing some of the qualities consistent with the dimension of idealised influence. Idealised influence is often associated with charismatic leadership (Bass, 2008; Bass \& Avolio, 1993; Yukl, 1999b). One of the qualities of idealised influence exhibited by the middle level managers was the importance of the leader to behave in ways that result in their being role models for their followers (Bass \& Riggio, 2006). Again, the findings revealed that there were no significant differences shown by DG and PTD middle level managers in relation to the qualities of idealised influence.

The dimension of inspirational motivation on the other hand was shown by three DG middle level managers and three PTD middle level managers. However, the findings revealed that two PTD middle level managers were showed more qualities of inspirational motivation as compared to the other four middle level managers. An inspirationally motivated leader gets followers involved in envisioning the direction of the organization (Bass \& Riggio, 2006). In addition, inspirational motivation is “a measure of the leader's ability to engender confidence in the leader's vision and values" (Pounder, 2001, p. 282).

The component of intellectual stimulation provided this study with a significant indication on the difference of leadership styles between the two groups of middle level managers. All four DG middle level managers showed qualities of intellectual stimulation, particularly in the need to seek different perspectives from their subordinates when solving problems. These managers also stimulate their subordinates to be innovative and creative. According to Avolio and Bass (2004), such qualities would eventually develop subordinates' capacity and creativity to solve problems on their own. Only one of the PTD middle level managers showed this quality. Another PTD middle level manager was perceived as showing another 
quality of intellectual stimulation, that of looking at problems from different perspectives. The lack of support of this leadership dimension from the PTD middle level managers would lend support to Bass' (2008) argument that intellectual stimulation "is probably the least recognized of the transformational factors" (p. 620). In addition, this would give credibility to Lowe, Kroeck and Subramaniam's (1996) argument that those working in the public sector were often taught to function within a more bureaucratic framework that may serve to suppress the impact of a transformational leadership style such as intellectual stimulation. Bass (2008) pointed out that a majority of managers tend to underutilise the importance of becoming an intellectually stimulated leader.

A further comparison of the transactional component of contingent reward revealed that two PTD and two DG middle level managers were equal in perceiving themselves as having qualities of contingent reward. Contingent reward is transactional when the reward is a material one, such as a bonus or increase in salary. Contingent reward can be transformational, however, when the reward is psychological such as praise or positive feedback (Bass, 2008; Bass \& Riggio, 2006). In the context of this study, two PTD middle managers and one DG middle managers clearly indicated to their subordinates that rewards in the form of high appraisal marks will be given if they meet the organization's targets. They argued that rewarding their subordinates with high appraisal marks was not only a sign of gratitude, but also a form of motivation. Fukushige and Spicer (2007), who conducted an exploratory study of leadership preference in Japan, also found that participants of their study supported contingent reward as a method of motivating subordinates. Apart from contingent reward, management by exception active was only perceived by only one DG middle level manager and one PTD middle level manager as a form of effective leadership. None of the middle level managers described their leadership styles as representing the dimension of management by exception passive or laissez-faire.

The interview findings revealed that both PTD and DG middle level managers were showing more attributes of transformational leadership than transactional leadership. The findings also suggested that managers from the DG scheme of service were showing more qualities intellectual stimulation as compared to the PTD middle level managers. However, no significant differences found between the PTD and DG middle level managers when compared on other dimensions of transformational and transactional leadership. 


\subsubsection{Main research question - What are the leadership styles practiced by the PTD and DG middle level managers in the Ministry of Education Malaysia?}

The leadership styles of the PTD and DG middle level managers were analysed according to the dimensions of transformational, transactional and laissez-faire leadership. This leadership paradigm has helped this study to understand the commonalities of leadership styles shown by the two groups of middle level managers. In addition, the mixed methods design of this study has assisted the researcher to explore and identify leadership styles of middle level managers from the aspects of two strands: quantitative and qualitative. The findings of both quantitative and qualitative strands therefore were utilised to answer the main research question of this study.

The results obtained from this study indicate that the middle level managers of both schemes demonstrated both transformational and transactional leadership. This would confirm Bass' (2008) argument that leaders are both transformational and transactional. However, the transformational leadership attributes were more evident than transactional leadership or avoidance of leadership. Evidence of the middle level managers showing more of transformational leadership styles were also present in the qualitative strand of the study. This finding supports the findings made in previous research in which transformational leadership styles were found to be shown more by leaders as compared to transactional leadership styles (Ardichvili \& Kuchinke, 2002; Berson, Shamir, Avolio, \& Popper, 2001; Bodla \& Nawaz, 2010; Bogler, 2001; Dvir, et al., 2002; Keegan \& Den Hartog, 2004; Kirby, et al., 1992; Kuchinke, 1999; Oshagbemi \& Ocholi, 2005; Podsakoff, MacKenzie, Moorman, \& Fetter, 1990; Wan Faridah Akmal, et al., 2002). In addition, the findings of this study supported the argument brought forth by Lowe et al., (1996) that transformational leadership styles were more frequently observed and applied by leaders working in public organizations than those working in the private sector.

Even though the t-test revealed no significant differences in terms of the leadership styles practiced by the PTD and DG middle level managers, the mean ratings and ranking of the dimensions of transformational and transactional leadership styles were useful to understand the leadership styles of both sets of middle level managers according to the dimensions of transformational and transactional leadership. When the mean ratings of both PTD and DG middle level managers were compared and ranked, the two groups of middle level managers 
displayed very similar mean ratings with one another. The qualitative strand has also allowed this study to analyse the frequency of each qualities of transformational and transactional dimensions displayed by the PTD and DG middle level managers. Therefore both quantitative and qualitative findings of this study revealed no significant difference in terms of leadership styles between DG and PTD middle level managers.

As mentioned in the previous chapter, Bass and Riggio (2006) suggested that for optimal leadership, a mean of 3.0 or higher should be reflected on all four transformational leadership dimensions. The mean rating of contingent reward and active management by exception ideally should be at about 2.5 and passive management by exception and laissezfaire leadership at 1.0 or below on the average (Bass, 1998). The mean ratings of all the transactional components as well as laissez-faire leadership were close to the optimal mean ratings suggested by Bass. However, the mean rating of one of the dimensions of transformational leadership which was individualised consideration was below the expected optimum rating that a transformational leader should possess. Despite that, three of four transformational leadership dimensions had higher mean ratings than the transactional components. The depth of the mean ratings for all transformational, transactional and laissez-faire leadership shown by both PTD and DG middle level managers were indicative of an optimal leadership as suggested by Bass' Model of Full Range Leadership. This shows that the managers were displaying the qualities of laissez-faire leadership style the least and increasing the frequencies of the transactional leadership styles of contingent reward and management by exception active and finally optimizing the styles of transformational leadership (Bass \& Avolio, 1994). The findings would therefore mirror the optimal profile as suggested by Bass' Model of Full Range Leadership. The optimal profile indicated that the transformational four I's as being most frequently displayed. In addition, this also supports Bass' (1998) argument that "every leader displays each style to some amount" (p. 7).

The ranking of all leadership dimensions of transformational, transactional and nonleadership attributes of the middle level managers was useful to indicate inspirational motivation as the most dominant transformational leadership style practised by both PTD and DG middle level managers. A study conducted by Bodla and Nawaz (2010) which analysed leadership styles among faculty members in private and public higher education 
institutes also placed inspirational motivation as the most dominant leadership style as compared to other leadership dimensions. A comparative study of leadership styles of those in managerial roles in four countries conducted by Ardichvili and Kuchinke (2002) also showed that the participants exhibited inspirational motivation the most as compared to other transformational leadership dimensions. Lo, Ramayah and Wei (2009) also found the participants in their study which consisted of 156 executives working in several Malaysian manufacturing industries showed inspirational motivation the most when compared with other transformational and transactional leadership components. In addition, it was found that inspirational motivation was found to have positive relationship with organizational commitment.

Although the findings were not as dominant as the results found in the quantitative strand, six out of the eight middle level managers did exhibit some form of inspirational motivation. Therefore, the qualitative findings presented in this study were indicative of the elements of inspirational motivation as shown by PTD and DG middle level managers. The findings also indicate that inspirational motivation was more strongly portrayed by DG middle level managers than PTD middle level managers. One of the main qualities of inspirational motivation is that the "leader creates clearly communicated expectations that followers want to meet and also demonstrate commitment to goals and the shared vision" (Bass, 1998; Bass \& Riggio, 2006). Perhaps this would support the argument that the goals and vision of the Ministry of Education as an educational organization were better understood by DG middle level managers who were from the education scheme of service as than by the PTD middle level managers. This supports Berson and Avolio's (2004) argument that transformational leaders have the ability to create agreement with their subordinates over the goals and vision of the organization.

Dubinsky, Yammarino and Jolson (1995) add that managers with this dimension communicate their vision with fluency and confidence. Leaders who show a high degree of inspirational motivation often "provide visions of what is possible and how to attain them" (Avolio \& Bass, 2004). Clearly the vision of the organization as well as the vision of the leaders was considered important for all the middle level managers. Inspirational leaders not only strive to point out the importance of any task at hand, they also point out the positive 
qualities of their followers and the ways in which they can complement one another's strength (Bass \& Riggio, 2006).

Another transformational leadership dimension that has yielded an interesting finding was individualised consideration. Individualised consideration is associated with effective leadership (Bryman, et al., 1996; Kirby, et al., 1992). This dimension of transformational leadership was supported by all middle level managers interviewed. However, the findings of the qualitative strand was not consistent with the findings of the quantitative strand which placed individualised consideration lower than the two dimensions of transactional leadership, namely contingent reward and management by exception active. Wright (2007) found similar results in a study conducted on transformational leadership among head teachers in several schools in the United Kingdom. Wright's findings showed that the head teachers rated themselves highly on the aspect of individualised consideration. Nonetheless, they were perceived by their subordinates as having low individualised consideration. Avolio and Bass (2004) suggested that individualised consideration had the highest means when it was self rated by the leaders themselves.

These conflicting findings indicate that although the middle level managers were showing high attributes of individualised consideration, these attributes were not significant from the perspectives of their subordinates. The qualitative findings revealed that all managers agreed that all subordinates should be treated as individuals. One of the reasons why this was considered important was because they felt that their subordinates have different strength and skills that were beneficial to the organization. However, it should be noted that if one of the components of transformational leadership was rated lower than other components of transactional leadership, it could only be associated with unsatisfactory and weak leadership practice (Wright, 2007). In addition, McColl-Kennedy and Anderson (2002) believed that perceptions of low level of transformational leadership can result in high levels of frustration and this can have a negative influence on subordinates' performance.

The low mean rating of individualised consideration among the PTD and DG middle level managers as suggested by the quantitative strand may point to the middle level managers' lack of ability to recognize the needs of their subordinates. In addition, this finding also hints the failure to treat subordinates as individuals. This finding, to some extent, supports 
Mahfooz, Zainal and Rehana's (2004) argument that because leadership in Malaysia is constantly about leading hierarchical levels in organization, managers spend little time or effort in building relationships with their subordinates. In addition, Hofstede (2001) found that in comparison with several other countries Malaysian leaders were placed highest on the power distance index, which contributed to a strict superior-subordinate relationship. Therefore these could be considered as some of the reasons why the middle level managers were perceived as less (individualised) considerate of the needs, abilities and individualism of their subordinates.

The findings also revealed that the middle level managers showed leadership styles that supported the qualities of idealised influence. Idealised influence is considered as charismatic leadership (Bass, 2008). The quantitative strand revealed that idealized influence was ranked as the second highest leadership style for both PTD and DG middle level managers. This finding was concurrent with the qualitative strand of this study which found that all PTD and DG middle level managers exhibited the qualities of idealized influence. Since idealised influence is strongly linked to charismatic leadership (Bass, 2008), this study therefore indicated that PTD and DG middle level managers possessed charismatic leadership qualities. The presence of idealised influence in this study paralleled those exhibited by participants involved in a qualitative study conducted by Bryman et al., (1996). Idealised influence centres upon the qualities of the leaders that enable them to be observed as role models, displaying behaviours that can be admired and respected by their subordinates. To be a good role model, therefore, requires the leader to demonstrate high standards of ethical and moral conduct as well as avoiding the use of power for personal gains.

Intellectual stimulation was another transformational leadership styles that was displayed by middle level managers. The qualitative strand of this study has revealed that this dimension was displayed more by DG middle level managers than their PTD counterparts. Intellectual stimulation is generally associated with encouraging subordinates to think about problems in new ways, which should be important in any organization seeking that competitive edge (Lowe, et al., 1996). Intellectual stimulation was found to be the highest among Malaysian male middle managers according to Wood and Jogulu (2006), who conducted a study to compare the workplace attitudes, aspirations for promotions and leadership styles of female 
and male middle level managers in Malaysia and Australia. Bass (2008) argued that intellectual stimulation "is probably the least recognized of the transformational factors" ( $p$. 620); however this study has revealed otherwise. Kirby et al. (1992), in a mixed method study of educational leaders confirmed the importance of intellectual stimulation especially in problem solving. In addition Kirby et al. (1992) found that intellectual stimulation correlates positively with effectiveness.

The strong presence of contingent reward and management by exception active among the PTD and DG middle level managers confirms the effectiveness of this transactional style of leadership. The quantitative findings of this study indicate that contingent reward and management by exception active were placed higher than the transformational dimension of individualised consideration. Studies conducted by Keegan and Den Hartog (2004), Kuchinke (1999) and Zagorsek, Dimovski and Skerlavaj (2009) also revealed high presence of contingent reward and management by exception active among participants of their study. This finding lends support to Zaleznik's $(1990,1992)$ argument that those who are holding managerial positions are most likely to show transactional leadership qualities. The qualitative strand of this study also indicates that the middle level managers did support the contingent reward dimension of transactional leadership but their leadership style failed to show the qualities of management by exception active or passive.

One possible explanation as to why the transactional component of contingent reward was found to be high among the middle level managers may be attributed to the annual appraisal system which is compulsory for all government servants in Malaysia. Rewarding subordinates with high appraisal marks in return for good performance essentially promotes high contingent reward leadership styles. Podsakoff (as cited by Bass, 2008) found that subordinates were more satisfied if their leaders provided them with rewards contingent on their performance. In this study the middle level managers agreed as to the effectiveness of rewarding their subordinates with the appropriate marks for their annual appraisal. However, the middle level managers felt that rewarding subordinates should not go beyond that. Rewarding subordinates with anything material in return for work performance was never an option for the middle level managers. This finding therefore supported the argument made by Lowe et al. (1996) in which it was found that contingent reward has a general positive association with subordinates' perceptions of work unit effectiveness especially in public 
organizations. Therefore contingent reward style of leadership "may be especially important in public organizations characterised by systematic and political reward granting" (Lowe, et al., 1996, p. 416).

The quantitative strand of this study has indicated that active management by exception was practised more by PTD middle level managers than DG middle level managers. Lowe et al., (1996) noted that leaders in public organizations are most likely to exhibit more management by exception as compared to leaders in other non-government organizations. The high level of this transactional dimension among PTD middle level managers indicated that they constantly monitor the tasks given to their subordinates. The active management by exception leader "remains concerned and will follow up to see if the task has been successfully completed" (Bass, 2008, p. 143). Like contingent reward, management by exception active has its merits and should not be confused with inactive leadership styles (Bass \& Riggio, 2006). The leaders who practice management by exception active allow their subordinates to continue doing tasks that the subordinates and leaders have agreed upon - until the problems could not be solved, at which the leader intervenes to make corrections (Bass, 2008). Nonetheless, it was found that management by exception active do not correlate with effectiveness (Avolio \& Bass, 2004; Lowe, et al., 1996).

Finally, laissez-faire or non-leadership attributes and management by exception passive were less prevalent in the qualitative strand the findings, the quantitative strand indicated laissez-faire leadership was higher than the management by exception passive. Bass (2008) postulated that laissez-faire leadership has been consistently found to be the least satisfying and least effective management style. The perception of this non-leadership style among the DG middle level managers' subordinates which was found to be significant indicated that the DG middle level managers did exhibit characteristics such as avoiding making decisions and constantly being absent when needed. Nonetheless, the low mean ratings of laissez-faire leadership of the DG middle level managers was comparable to the mean ratings of laissezfaire leadership found in other studies (Ardichvili \& Gasparishvili, 2001; Avolio \& Bass, 2004; Bodla \& Nawaz, 2010; Keegan \& Den Hartog, 2004; Wright, 2007) and therefore indicated that the qualities of laissez-faire shown by the middle level managers in this study was not unusual. 


\subsection{Chapter Summary}

This chapter has analysed and discussed the findings of this study. The leadership styles of the PTD and DG middle level managers were analysed and discussed based on the dimensions of transformational and transactional leadership as well as the laissez-faire leadership. The research question and its sub questions were answered. The conclusion of this study is discussed in the final chapter. 


\section{CHAPTER 6 - CONCLUSION}

\subsection{Chapter Overview}

In this final chapter, the research findings are summarised. The implications of the studies are also discussed. This chapter also examines the limitations of this study. The contribution of this study towards educational leadership is also reviewed.

\subsection{Summary of Research Findings}

This study was set out to understand, analyse and compare leadership styles of middle managers from the PTD and DG schemes of services working in the Ministry of Education Malaysia. The leadership styles of the DG and PTD middle level managers indicates the extent to which they exhibit one or more components of the transformational, transactional or non-leadership styles as suggested by Model of the Full Range of Leadership developed by Bass and Avolio (1993, 1994). In addition, this study was conducted to investigate whether differences in leadership styles existed between these two groups of middle level managers. This study was also set out to investigate whether leadership styles of the middle level managers were perceived differently by the subordinates from different scheme of services, and to investigate how the middle level managers perceive their own leadership styles.

Based on the findings, this study concluded that PTD and DG middle level managers displayed both transformational leadership styles as well as transactional leadership. This finding therefore supported Bass' (2008) argument that every leader displays a frequency of leadership styles that is either transformational or transactional; this is central to Bass's argument that both transformational and transactional leadership are significant in promoting growth and effectiveness among leaders as well as subordinates in organizations (Bass, 1999). This conclusion was also consistent with the findings of Berson and Avolio (2004), Bass, (1998, 1999) and Avolio and Bass (2004).

In addition, comparison between the quantitative and qualitative strands yielded two contradictory discoveries: both PTD and DG middle level managers were perceived by their subordinates as showing a high level of inspirational motivation but a low level of individualised consideration; however, both the PTD and DG middle level managers perceived themselves as possessing individualised consideration the most as compared to 
other transformational and transactional leadership dimensions. This finding leads to the conclusion that by envisioning oneself as being highly considerate was by itself not enough to influence what subordinates actually perceived their leadership styles. Perhaps the middle level managers possess leadership styles that were less acceptable to their subordinates.

The findings also indicate that there were no significant differences in the perceptions of the overall transformational leadership styles of the PTD middle level managers as perceived by their subordinates from different scheme of services. Nonetheless, two of the components of transformational leadership, namely inspirational motivation and intellectual stimulation, yielded significant differences. However, the same could not be said of DG middle level managers as their overall transformational leadership styles indicate significant differences as perceived by subordinates from different scheme of services. Additionally, one component of transformational leadership, inspirational motivation, has also shown a significant difference in terms of the perceived leadership styles by subordinates of different scheme of services. However, the avoidance of leadership of the DG middle level managers also showed significant differences as perceived by their subordinates from different scheme of services. The findings suggested that the same leadership style of a manager can be perceived differently by subordinates of different scheme of services. The findings were consistent with the findings of Jung and Avolio (1999).

Finally, the findings of this study reflected that DG and PTD middle level managers are not statistically different in their leadership styles. The exploratory investigation also revealed that they shared similar leadership styles which lead to the conclusion that the PTD and DG middle level managers have more or less the same style of leadership.

\subsection{Implications and Recommendations}

This study will benefit the Malaysian public sector in understanding the different styles of leadership among middle level managers working in government organization. To be more precise, this study is beneficial in understanding the similarities and differences of leadership styles of the DG and PTD middle level managers working in the Ministry of Education Malaysia. The selected implications and recommendations derived from this study are discussed in the following section. 
Although three dimensions of transformational leadership were higher than the transactional dimension, the level of one of the transformational leadership dimensions, which was individualised consideration, indicated that the middle level managers were perceived as low on this dimension. A low level of individualised consideration meant that the managers failed to consider the different needs and abilities of their subordinates. In addition, they neglected their welfare and seldom listened to what their subordinates had to say. Therefore, this study suggests that the middle level managers should recognise the needs, abilities and aspirations of their subordinates. Treating subordinates as equals is good, but the ability to understand and treat each and every subordinate as different individuals with different abilities and needs sets transformational leaders apart from normal managers. Zaleznik (as cited in Avolio \& Bass, 2004) pointed out that individualised interaction between superior and subordinates is of primary importance in differentiating managers from leaders. Therefore, the managers need to be individually considerate in dealing with subordinates from different functional areas and backgrounds and must show sensitivity to these differences (Bass \& Riggio, 2006).

The findings from this study also indicate that DG and PTD middle level managers were perceived significantly as showing some attributes of transformational leadership. The DG middle level managers were even perceived as showing overall transformational leadership style. Nonetheless, the subordinates' perception of the DG middle level managers' laissezfaire leadership style was also found to be significant. This implied that although they were perceived to be showing transformational leadership styles, their non-leadership qualities were also perceptible to their subordinates. The fact that subordinates from different scheme or services perceived DG middle level managers as having laissez-faire attributes should not be taken lightly. Although they were perceived as transformational leaders, they were also characterised significantly as having non-leadership attributes, which would have a negative effect on the organization. Laissez-faire leadership has been connected to low productivity, lack of innovation, more conflict and lack of cohesion among subordinates (Bass \& Riggio, 2006).

Therefore, in order for the DG middle level managers to eliminate or minimize any laissezfaire qualities, they should constantly develop their ability to analyse any negative aspects of their leadership styles which are not suitable or effective when practised in the organization. 
This could be done through attending professional leadership training. Continuous leadership training should be an all-rounded affair that involves everyone in the organization. The Ministry of Education should place extra emphasis on professional leadership development programmes that also cater for middle managers rather than over-emphasising school principals or top level management. The current DG middle managers will be the ones who will lead the organization in the future, and if they are being perceived as having non-leadership qualities while still at the level of middle management, certainly such negative qualities will have negative repercussions for the organization when they are promoted to the top management level in the future. It is now that they need to build the capacity to change their leadership styles for the betterment of the organization.

The transactional dimensions of contingent reward and management by exception active were found to be higher than the transformational dimension of individualised consideration in this study, suggesting that the DG and PTD middle managers were both transformational and transactional. Even though the findings suggest that the middle level managers possessed more transformational attributes than transactional leadership styles, the importance of transactional factors should not be taken lightly. Lowe et al., (1996) believed that transformational leadership is associated with work unit effectiveness; however, the ability to successfully achieve transformational leader outcomes requires building on an effective transactional base. Therefore, this supports Bass' argument that transactional leadership is an essential prerequisite to effective leadership (Antonakis \& House, 2002)

Although transformational leaders can be transactional when appropriate, transactional leadership is often a prescription for lower levels of performance that would not contribute to any significant changes for the organization and the subordinates (Avolio \& Bass, 2004). Transactional leaders who fulfil the expectations of their subordinates would gain a reputation for being able to deliver on their promises and receive the recognition due to them (Avolio \& Bass, 2004). Those who fail to deliver the appropriate rewards tarnish their reputation and therefore no longer can be seen as effective leaders (Avolio \& Bass, 2004). These are the fears for leaders who over rely on the transactional leadership styles. As a result, transactional leadership often fails to work because the leader lacks the necessary resources to deliver the rewards promised to their subordinates. Therefore this study 
suggests that the middle managers should strike a balance between the practice of transformational and transactional leadership styles.

Finally, transformational leadership styles of both DG and PTD middle level managers should be constantly nurtured and maintained for the greater good of the organization. Although both transformational leadership and transactional leadership promote effectiveness in the organization, it is transformational leadership style that actually has positive influence on the leader, subordinate and organization. The effectiveness of transactional leadership may only provide a short term solution to get tasks done. It is transformational leadership styles that actually have the lasting and positive effect that goes beyond getting tasks completed. Bass and Riggio (2006) argued that each of the components of transformational leadership can help leaders to build subordinates' commitment towards the organization in many positive ways. Given the findings of this study and the vast literature which have supported transformational leadership as having positive influence on organization, it is imperative for the Ministry of Education to develop leaders that are attuned to the leadership styles that mirror the qualities of transformational leadership. Bass and Riggio (2006) pointed out that transformational leadership can be taught and learned. This study therefore supports and shares suggestion made by Bass (1999, 2008), Bass and Riggio (2006), Avolio and Bass (2004) as well as McColl-Kennedy and Anderson (2002) that the organization should constantly encourage transformational leadership styles to be practised by their managers. This study adopts Bass and Riggio's (2006) recommendations on how organizations can encourage transformational leadership styles among its member. First, it is vital for the organization to introduce the concept, example and the practicability of transformational leadership to personnel and then provide continuing support for it. Second, its diffusion should flow from top management to down. And finally, the organization should support the development and maintenance of the transformational leadership culture.

\subsection{Contribution to the Educational Leadership}

This study has contributed to the understanding of the leadership styles of educational leaders working in an educational organization apart from school. Previous studies done educational leaders were restricted to principals in schools. Hence this study is significant in 
contributing to the literature on leadership styles among middle level managers in an educational organization in Malaysia.

Another contribution that this study has made is that the comparison of leadership styles between the DG and PTD middle level managers has led to the conclusion that the DG middle level managers have demonstrated that their leadership qualities are as comparable to that of their PTD counterparts. The fact will always remain that PTD officers are viewed the standard bearers for good administrative and management practice. All PTD officers are also expected to "display excellent work culture so that their leadership is effective, fulfilling the nation's needs and capable of facing challenges and obstacles" (INTAN, 2010, p. 1). To meet that expectation, the PTD officers are required to undergo a rigorous nine-month training that covers all aspects of administration, management and leadership. Despite lacking such training, DG middle level managers were perceived to be more transformational by subordinates of different scheme of services when compared with their PTD counterparts. This also has indicated that the management of Ministry of Education was right to select the managers based on their leadership qualities among other things.

\subsection{Limitation}

As with many other studies, this study also has come across several limitations. The first limitation was the sample size of this study, which must be acknowledged, was fairly small. The sample size was limited to ten selected departments of the Ministry of Education Malaysia and if this study had widened its sample size, the generalizability would be greater. Secondly, the researcher did not take into consideration the cultural factor in understanding the leadership styles of the middle level managers. Malaysia is a multicultural society. Aspects of managerial leadership among different races and cultures in Malaysia were highlighted by Gill (1998), Mahfooz et al. (2004) and Pearson and Entrekin (2001). It was found that leaders of different races in Malaysia have different approaches to their leadership styles.

This study also did not take into consideration gender factors in analysing the leadership styles of the middle managers. Malaysia is progressing well in increasing the participation of women in high ranking managerial positions in the public and private sectors (Ministry of Women Family and Community Development, 2007). Bass and Riggio (2006) argue that 
past research points to the greater tendency for women in leadership positions to be somewhat more transformational and display less management by exception and laissezfaire leadership than their male counterparts. Nonetheless, Wood and Jogulu (2006) found that male managers in Malaysia are likely to display three dimensions of transformational leadership more than their female counterpart.

Finally it should be acknowledged that the limitation of time in collecting the data also represented a constraint to the researcher and this study. Nonetheless, the researcher has gone to great lengths to ensure that the data collection process was done according to proper procedure.

\subsection{Final Thoughts}

This study sought to understand the leadership styles of PTD and DG middle level managers working in the Ministry of Education Malaysia. This study was not intended to criticise the leadership styles of the PTD or DG middle level managers, nor was it set to identify which group of middle level manager is better. This study was successful in the sense that it was able to investigate and analyse the leadership styles of two groups of middle level managers which have different career advancement: the PTD managers as being trained administrators and the DG managers as former teachers. The findings revealed that both sets of managers were exhibiting more transformational leadership qualities as compared to transactional leadership styles.

\subsection{Chapter Summary}

This chapter has summarised the main findings of this study. This chapter has also discussed several practical implications this study has brought to the public sector management in Malaysia. Recommendations were made in light to the implication mentioned earlier. The researcher also acknowledged some limitations which have surfaced in this study. 


\section{Appendix 1 \\ Classification of the schemes of service in the Malaysian Public Sector}

Public servants in Malaysia are categorised according to a particular scheme of service.

There are 21 schemes of service for public servants in Malaysia. Each scheme is classified according to the overall description of the job. In addition, each scheme is differentiated by a designated code.

\begin{tabular}{|l|l|}
\hline CLASSIFICATION FOR THE SCHEME OF SERVICES & \\
\hline Transportation & CODE OF SERVICE \\
\hline Talent and Art & B \\
\hline Science & C \\
\hline Education & D (includes DG, DU, DH and DS) \\
\hline Economics & E \\
\hline Information System & F \\
\hline Agriculture & G \\
\hline Engineering & J \\
\hline Security and Civil Defence & K \\
\hline Law and Justice & L \\
\hline Administrative and Diplomatic Service & M \\
\hline Administration and Support & N \\
\hline Enforcement & P \\
\hline Research and Development & Q \\
\hline Skilled/Semi-skilled and Unskilled & R \\
\hline Social Services & S \\
\hline Medical and Health & U \\
\hline Finance and Accountancy & W \\
\hline Maritime Enforcement & X \\
\hline Police & Y \\
\hline Armed Forces & Z \\
\hline (source: Jabatan Perkhidmatan Awam & \\
\hline
\end{tabular}

(source: Jabatan Perkhidmatan Awam, 2010)

In addition to the designated codes, grades are used to denote the rank of the employee. A higher grade means that the person holds a high rank position or has been promoted to that grade based on performance/length of service. A grade of 41 is the entry level grade for positions that require a minimum qualification of a degree. A job that requires a minimum qualification of a diploma will offer a position with an entry level grade of 29. 


\section{Appendix 2a \\ Questionnaire}

MULTIFACTOR LEADERSHIP QUESTIONNAIRE - RATER FORM

(Please do not write your name or the name of your head of sector/unit on the questionnaire sheet/Jangan tuliskan nama anda ataupun nama ketua sektor/unit anda pada borang soal selidik ini)

Sector/Unit:

Sektor/Unit

Your Head of Sector/Unit's scheme or service/Grade:

Skim perkhidmatan ketua sektorlunit tuan/puan (contoh DG48, M48)

Rater's scheme or service and grade:

Skim dan gred perkhidmatan penilai (contoh DG41,M41)

Your Official Designation:

Jawatan rasmi anda

Your Scheme or service/Grade:

Skim perkhidmatan/gred anda

Years in the above position:

Tempoh berkhidmat didalam jawatan yang disandang

Highest academic qualification:

Kelayakan akedemik tertinggi

Gender: Male/Female

Jantina

Age group (please tick):

Umur (sila tanda)

\begin{tabular}{|l|l|}
\hline $21-24$ & \\
\hline $25-29$ & \\
\hline $30-34$ & \\
\hline $35-39$ & \\
\hline
\end{tabular}

\begin{tabular}{|l|l|}
\hline $40-44$ & \\
\hline $45-50$ & \\
\hline $51-58$ & \\
\hline
\end{tabular}


This questionnaire is to describe the leadership style of your Head of Sector/Unit, as you perceive $\mathrm{him} / \mathrm{her}$. Please circle the rating that you perceive is most relevant. If an item is irrelevant, or if you are unsure or do not know the answer, leave it uncircled.

Soal selidik ini adalah untuk mendapatkan gambaran anda mengenai gaya kepimpinan Ketua SektorlUnit anda. Sila bulatkan mana-mana skala yang difikarkan tepat menggambarkan gaya kepimpinan Ketua Sektor/Unit anda. Sekiranya item itu dianggap tidak releven, atau anda tidak pasti jawapannya, sila tinggalkan ia kosong.

Forty-five descriptive statements are listed on the following pages. Judge how frequently each statement fits the person you are describing. Please use the following rating scale:

Terdapat empat puluh lima item deskriptif pada halaman berikut. Sila nyatakan pandangan anda terhadap Ketua Sektor/Unit yang anda nilai. Sila gunakan skala pengelasan berikut:

\begin{tabular}{|c|c|}
\hline $\begin{array}{c}\text { Not at all/ } \\
\text { Langsung tiada }\end{array}$ & 0 \\
\hline $\begin{array}{c}\text { Once in a while/ } \\
\text { Sekali sekala }\end{array}$ & 1 \\
\hline $\begin{array}{c}\text { Sometimes/ } \\
\text { Kadang-kadang }\end{array}$ & 2 \\
\hline $\begin{array}{c}\text { Fairly often/ } \\
\text { Agak Kerap }\end{array}$ & 3 \\
\hline $\begin{array}{c}\text { Frequently, if not always/ } \\
\text { Sentiasa, jika tidak selalu }\end{array}$ & 4 \\
\hline
\end{tabular}

\begin{tabular}{|c|c|c|c|c|}
\hline $\begin{array}{c}\text { Not at all/ } \\
\text { Langsung tiada }\end{array}$ & $\begin{array}{c}\text { Once in a } \\
\text { while/Sekali } \\
\text { sekala }\end{array}$ & $\begin{array}{c}\text { Sometimes/ } \\
\text { Kadang- } \\
\text { kadang }\end{array}$ & $\begin{array}{c}\text { Fairly often/ } \\
\text { Agak Kerap }\end{array}$ & $\begin{array}{c}\text { Frequently, if } \\
\text { not always/ } \\
\text { Sentiasa, jika } \\
\text { tidak selalu }\end{array}$ \\
\hline 0 & 1 & 2 & 3 & 4 \\
\hline
\end{tabular}

MY HEAD OF SECTOR/UNIT:

KETUA SEKTORIUNIT SAYA :

\begin{tabular}{|c|l|c|c|c|c|c|}
\hline 1. & $\begin{array}{l}\text { Provides me with assistance in exchange for my efforts } \\
\text { Memberi saya bimbingan sebagai ganjaran di atas usaha saya }\end{array}$ & 0 & 1 & 2 & 3 & 4 \\
\hline 6. & $\begin{array}{l}\text { Talks about their most important values and beliefs } \\
\text { Sentiasa berbicara tentang nilai-nilai dan kepercayaan yang } \\
\text { penting kepada beliau }\end{array}$ & 0 & 1 & 2 & 3 & 4 \\
\hline 13. & $\begin{array}{l}\text { Talks enthusiastically about what needs to be accomplished } \\
\text { Berbicara dengan penuh semangat tentang apa yang perlu } \\
\text { dicapai }\end{array}$ & 0 & 1 & 2 & 3 & 4 \\
\hline 19. & $\begin{array}{l}\text { Treats me as an individual rather than just a member of the } \\
\text { organization } \\
\text { Menganggap saya sebagai seorang individu dan bukan setakat } \\
\text { ahli organisasi ini }\end{array}$ & 0 & 1 & 2 & 3 & 4 \\
\hline 27. & $\begin{array}{l}\text { Directs my attention toward failures to meet standards } \\
\text { Mengalihkan perhatian saya kepada kegagalan agar ia menjadi } \\
\text { garis panduan untuk mencapai standard }\end{array}$ & 0 & 1 & 2 & 3 & 4 \\
\hline
\end{tabular}




\title{
Appendix 2b
}

Questionnaire Participant Information Sheet

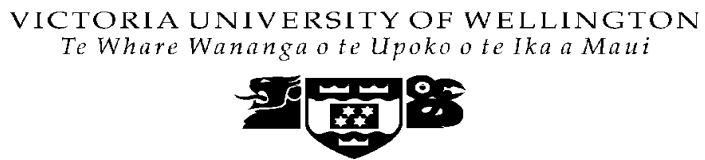

\section{QUESTIONNAIRE PARTICIPANT INFORMATION SHEET}

RESEARCHER: Shahrizal Norwawi

\author{
Faculty of Education \\ Victoria University of Wellington
}

Dear Sir/Madam,

I am a Masters student at the Faculty of Education, Victoria University of Wellington, completing a Master of Education degree. As part of this degree, I am pursuing a research project leading to a thesis. The University requires that ethics approval be obtained for research involving human participants. This research has been reviewed and approved by Victoria University Faculty of Education Ethics Committee, approval number 17471.

The research project is entitled: LEADERSHIP STYLES- A COMPARATIVE ANALSYIS OF PTD OFFICERS AND DG OFFICERS IN THE MINISTRY OF EDUCATION MALAYSIA The focus of the project is examining leadership styles of middle level managers working in the Ministry of Education, Malaysia. This research would comparatively analyse the leadership styles of middle level managers (i.e Head of Unit or Head of Sector) consisting of those from the Administrative and Diplomatic scheme (PTD) and the Graduate Education Service scheme (DG). In addition, it is hopeful that this study would demonstrate any similarities or differences of the middle level managers from the two different scheme of services.

You are invited to participate in this research project. You are invited as a possible participant because you are a personnel of the organization and your opinion:

i) about the leadership styles of your head of unit/sector; OR

ii) about your leadership style as the head of unit/sector

will help me to understand the leadership styles demonstrate by the head of unit/sector. I would like to seek your cooperation by answering the questions on the attached questionnaire. I hope you will agree that this is a worthwhile area of research and cooperate by completing the questionnaire. By returning the questionnaire, you give consent to participate in the research.

Please do not write your name/or the name of your head of unit/sector on the questionnaire. Please complete the questionnaire not spending too much time on any one item. It will take between 10 to 15 minutes to complete. I do seek your honest opinion when completing the questionnaire, therefore, please respond open and truthfully to the questionnaire. 
The responses collected from the questionnaire will form the basis of my research project. I emphasise strongly here that the information obtained will be used in the strictest and confidential manner. You will not be identified at any stage in this study. All material collected will be kept confidential. No other person besides me and my supervisor Associate Professor Dr. Kabini Sanga will be able to see and access the questionnaires. The questionnaires will be destroyed two years after the end of the project.

If you have any questions or would like to receive further information about the research project, please contact my supervisor at:

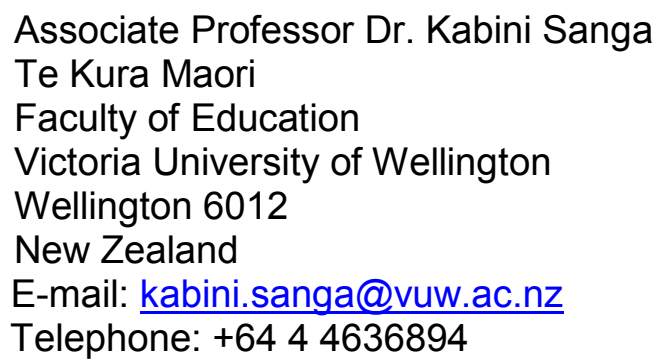

or you could contact me directly at:

Shahrizal Norwawi

31B Campbell Street

Faculty of Education

Victoria University of Wellington

Wellington 6012

New Zealand

E-mail: shahrizal.norwawi@vuw.ac.nz

Telephone: +64 211162682 (mobile)

Yours sincerely,

Shahrizal Norwawi 


\title{
Appendix 2c \\ Questionnaire Participant Information Sheet (Malay version)
}

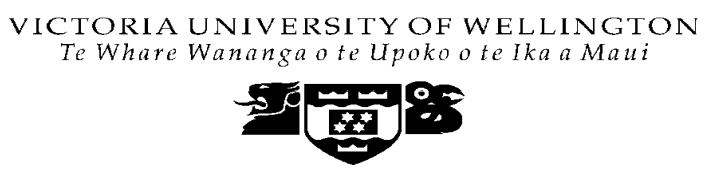

\section{MAKLUMAT PESERTA SOAL SELIDIK}

\author{
PENYELIDIK: Shahrizal Norwawi \\ Faculty of Education \\ Victoria University of Wellington
}

Tuan /Puan,

Saya adalah pelajar Sarjana di Fakulti Pendidikan, Universiti Victoria, Wellington yang sedang dalam proses menyiapkan Sarjana dalam bidang pendidikan. Sebagai sebahagian dari tugasan untuk menyiapkan ijazah ini,saya sedang menjalankan satu kajian projek yang akan dijadikan tesis bagi ijazah saya. Pihak universiti menekankan bahawa kelulusan etika adalah diperlukan sekiranya sesuatu kajian itu melibatkan sekumpulan manusia sebagai responden. Kajian projek ini telah pun mendapat kelulusan Jawatankuasa Etika, Universiti Victoria, Wellington, nombor kelulusan 17471.

Kajian ini bertajuk: GAYA KEMPIMPINAN - SATU ANALISIS PERBANDINGAN DI ANTARA PEGAWAI-PEGAWAI SKIM PEGAWAI TADBIR DIPLOMATIK DAN SKIM PEGAWAI PERKHIDMATAN PELAJARAN DI KEMENTERIAN PELAJARAN MALAYSIA. Fokus kajian ini ialah untuk mengkaji gaya kepimpinan seorang ketua diperingkat pertengahan yang bertugas di Kementerian Pelajaran Malaysia. Kajian ini akan membandingkan gaya kepimpinan ketua di peringkat pertengahan (contohnya Ketua Unit atau Ketua Sektor)yang terdiri dari pegawai-pegawai dari skim Pegawai Tadbir dan Diplomatik dan pegawai-pegawai dari skim Pegawai Perkhidmatan Pendidikan Siswazah. Adalah diharapkan kajian ini akan dapat menjelaskan samada wujudnya perbezaan dari segi gaya kepimpinan di kalangan ketua di peringkat pertengahan yang dilantik dari skim Pegawai Tadbir dan Diplomatik (PTD) dan skim Pegawai Perkhidmatan Pendidikan (DG).

Tuan/puan adalah dialukan untuk menyertai kajian ini sebagai salah seorang responden.Penyertaan tuan/puan dalam kajian ini adalah kerana tuan/puan bertugas di organisasi ini dan pandangan tuan/puan berkaitan:

i) gaya kepimpinan ketua unit/sektor tuan/puan; ATAU

ii) gaya kepimpinan tuan/puan sendiri sebagai seorang ketua unit/sektor

dapat membantu saya memahami dengan lebih mendalam akan gaya kepimpinan yang ditunjukkan oleh ketua unit/sektor. Justeru,saya berharap agar tuan/puan dapat memberi kerjasama dengan menjawab borang kajian selidik yang disertakan bersama. Saya berharap agar tuan/puan mendapati kajian saya ini sebagai sesuatu yang penting dan bermanfaat dan bersetuju untuk bekerjasama dengan menjawab borang kajian selidik 
tersebut. Dengan menjawab serta memulangkan borang kajian selidik ini, tuan/puan adalah bersetuju untuk menyertai kajian ini.

Sila jangan tuliskan nama tuan/puan ataupun nama ketua unit/sektor tuan/puan. Sila jawab soalan-soalan di dalam borang tersebut dan jangan mengambil masa yang terlalu panjang pada satu-satu soalan/item. Kajian ini akan mengambil masa di antara 10 hingga 15 minit. Saya amat berharap agar tuan/puan dapat menjawab soalan-soalan kajian tersebut dengan ikhlas.

Segala respon dari borang soal selidik ini akan menjadi asas kepada kajian yang saya jalankan. Di sini juga saya ingin menekankan bahawa segala maklumat yang diperolehi dari borang soal selidik ini adalah sulit dan terkawal. Maklumat tuan/puan tidak akan didedahkan pada mana-mana bahagian kajian ini. Segala maklumat serta bahan-bahan berkaitan kajian ini adalah sulit dan akan disimpan rapi. Tiada sesiapa boleh melihat atau mempunyai akses kepada borang soal selidik ini selain daripada saya dan penyelia saya iaitu Prof. Madya Dr. Kabini Sanga. Borang soal selidik ini akan dilupuskan dalam tempoh dua tahun selepas kajian projek ini selesai.

Sekiranya anda mempunyai sebarang pertanyaan, atau ingin mengetahui dengan lebih lanjut tentang projek kajian ini, sila hubungi penyelia saya di:

\author{
Associate Professor Dr. Kabini Sanga \\ Te Kura Maori \\ Faculty of Education \\ Victoria University of Wellington \\ Wellington 6012 \\ New Zealand \\ E-mel: kabini.sanga@vuw.ac.nz \\ Telefon: +64 44636894
}

atau anda juga boleh terus menghubungi saya di:

Shahrizal Norwawi

31B Campbell Street

Faculty of Education

Victoria University of Wellington

Wellington 6012

New Zealand

E-mel: shahrizal.norwawi@vuw.ac.nz

Telefon: +64 211162682 (tel. bimbit)

Yang ikhlas,

Shahrizal Norwawi 


\title{
Appendix 3 \\ Permission to conduct research in Malaysia
}

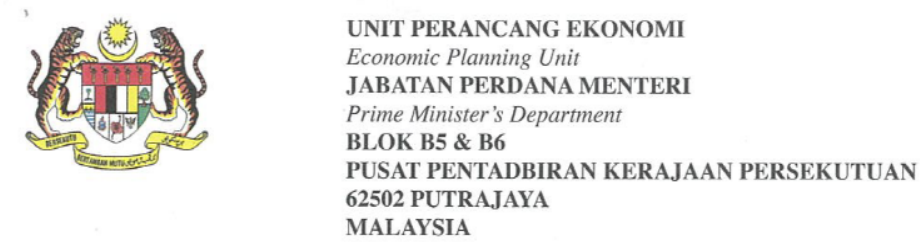

UNIT PERANCANG EKONOMI

2 PUTRAJAYA

MALAYSIA

Shahrizal Bin Norwawi

$\begin{aligned} \text { Ruj. Tuan: } & \\ \text { Your Ref.: } & \text { UPE: 40/200/19/2585 } \\ \text { Ruj. Kami: } & \\ \text { Our Ref:: } & \\ \text { Tarikh: } & \\ \text { Date: } & \end{aligned}$

37A Cooper Street

Karori

Wellington 6012

New Zealand.

Email: sharizal.norwawi@vuw.ac.nz

\section{APPLICATION TO CONDUCT RESEARCH IN MALAYSIA}

With reference to your application, I am pleased to inform you that your application to conduct research in Malaysia has been approved by the Research Promotion and Co-Ordination Committee, Economic Planning Unit, Prime Minister's Department. The details of the approval are as follows:

\author{
Researcher's name : $\quad$ SHAHRIZAL BIN NORWAWI \\ Passport No. / I. C No: $\quad$ 780404-06-5039 \\ Nationality : MALAYSIAN \\ Title of Research \\ "LEADERSHIP STYLES - A COMPARATIVE \\ ANALYSIS OF PTD OFFICERS AND DG OFFICERS \\ IN MINISTRY OF EDUCATION MALAYSIA"
}

Period of Research Approved: 1 YEAR

2. Please collect your Research Pass in person from the Economic Planning Unit, Prime Minister's Department, Parcel B, Level 1 Block B5, Federal Government Administrative Centre, 62502 Putrajaya and bring along two (2) passport size photographs. You are also required to comply with the rules and regulations stipulated from time to time by the agencies with which you have dealings in the conduct of your research. 
3. I would like to draw your attention to the undertaking signed by you that you will submit without cost to the Economic Planning Unit the following documents:

a) A brief summary of your research findings on completion of your research and before you leave Malaysia; and

b) Three (3) copies of your final dissertation/publication.

4. Lastly, please submit a copy of your preliminary and final report directly to the State Government where you carried out your research. Thank you.

Yours sincerely,

Wintimbi

(MUNIRAH ABD. MANAN)

For Director General,

Economic Planning Unit.

E-mail: munirah@epu.gov.my

Tel: 88725281

Fax: 88883961

\section{ATTENTION}

This letter is only to inform you the status of your application and cannot be used as a research pass.

Cc:

Ketua Sektor

Sektor Penyelidikan Dan Penilaian,

Bahagian Perancangan dan Penyelidikan Dasar Pendidikan

Kementerian Pelajaran Malaysia

Aras 1-4, Blok E-8

Kompleks Kerajaan Parcel E

Pusat Pentadbiran Kerajaan Persekutuan

62604 Putrajaya. 


\section{Appendix 4 Ethics approval}

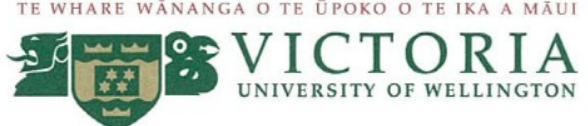

26 April 2010

Shahrizal Norwawi

M.Ed Student

Victoria University of Wellington Faculty of Education

C/- School of Te Kura Māori

Donald Street

Wellington

\section{Dear Shahrizal}

\section{RE: Ethics Application: TKM/2010/19 RM 17471}

I am pleased to advise you that your ethics application 'Leadership Styles - a comparative analysis of PTD officers and DG officers in the Ministry of

Education Malaysia' with the requested amendments, has been approved by the Victoria University of Wellington Faculty of Education Ethics Committee. Please note that the approval for your research to commence is from the date of this letter.

Best wishes for your research.

Yours Sincerely
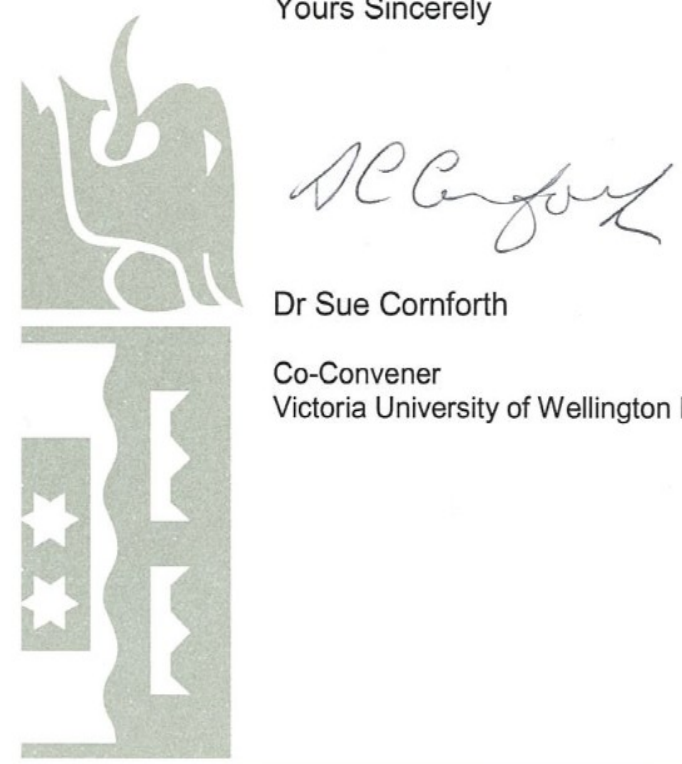

Dr Sue Cornforth

\section{Co-Convener}

Victoria University of Wellington Faculty of Education Ethics Committee 


\title{
Appendix 5a \\ Interview Participant Information Sheet
}

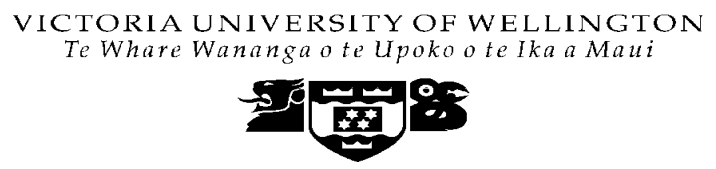

\section{INTERVIEW PARTICIPANT INFORMATION SHEET}

\author{
RESEARCHER: Shahrizal Norwawi \\ Faculty of Education \\ Victoria University of Wellington
}

Dear Sir/Madam,

I am a Masters student at the Faculty of Education, Victoria University of Wellington, completing a Master of Education degree. As part of this degree, I am pursuing a research project leading to a thesis. The University requires that ethics approval be obtained for research involving human participants. This research has been reviewed and approved by Victoria University Faculty of Education Ethics Committee, approval number 17471.

The research project is entitled: LEADERSHIP STYLES- A COMPARATIVE ANALSYIS OF PTD OFFICERS AND DG OFFICERS IN THE MINISTRY OF EDUCATION MALAYSIA. The focus of the project is examining leadership styles of middle level managers working in the Ministry of Education, Malaysia. This research would comparatively analyse the leadership styles of middle level managers (i.e Head of Unit or Head of Sector) consisting of those from the Administrative and Diplomatic scheme (PTD) and the Graduate Education Service scheme (DG). In addition, it is hopeful that this study would demonstrate any similarities or differences of the middle level managers from the two different schemes of services.

You are invited to participate in this research project. You are invited as a possible participant because you are a personnel of the organization and your opinion about your leadership style as the head of unit/sector will help me to understand the leadership styles demonstrated by you as the head of unit/sector. I would like to seek your cooperation by participating in a one-to-one interview. I hope you will find that this is a worthwhile area of research and agree to cooperate in the interview.

The responses collected from the interview will form the basis of my research project. The interview will be audio taped and I would endeavour to maintain anonymity of your contribution in the interview. The interview would take about 30 to 45 minutes and would be at a time suitable to you. I would tape the interview to allow for correct transcribing following the interview and I would send you a transcript of the interviews before the process of analysing the transcripts in order for you to check and verify the information of the interview.

I emphasise strongly here that the information obtained will be used in the strictest and confidential manner. All documentation relating to this study would have pseudonyms used in order to protect the identities of the participants. You will not be identified at any stage in 
this study. All material collected will be kept confidential. No other person besides me and my supervisor Associate Professor Dr. Kabini Sanga will be able to see and access the audio copy and transcript of the interview. The audio copy and transcript of the interview will be destroyed two years after the end of the project.

If you would wish or agree to participate in the interview, kindly fill in the attached consent form. You have the right to decline and doing so will not affect the research or your position in your organization. I thank you for taking time in to read the information sheet.

If you have any questions or would like to receive further information about the research project, please contact my supervisor at:

Associate Professor Dr. Kabini Sanga

Te Kura Maori

Faculty of Education

Victoria University of Wellington

Wellington 6012

New Zealand

E-mail: kabini.sanga@vuw.ac.nz

Telephone: +64 44636894

or you could contact me directly at:

Shahrizal Norwawi

31B Campbell Street

Faculty of Education

Victoria University of Wellington

Wellington 6012

New Zealand

E-mail: shahrizal.norwawi@vuw.ac.nz

Telephone: +64 211162682 (mobile)

Yours sincerely,

Shahrizal Norwawi 


\title{
Appendix 5b
}

Interview Participant Information Sheet (Malay Version)

\author{
VICTORIA UNIVERSITY OF WELLINGTON \\ Te Whare Wananga o te Upoko o te Ika a Maui \\ 59 \\ MAKLUMAT PESERTA TEMURAMAH KAJIAN
}

\author{
PENYELIDIK: Shahrizal Norwawi \\ Faculty of Education \\ Victoria University of Wellington
}

Tuan /Puan,

Saya adalah pelajar Sarjana di Fakulti Pendidikan, Universiti Victoria, Wellington yang sedang dalam proses menyiapkan Sarjana dalam bidang pendidikan. Sebagai sebahagian dari tugasan untuk menyiapkan ijazah ini,saya sedang menjalankan satu kajian projek yang akan dijadikan tesis bagi ijazah saya. Pihak universiti menekankan bahawa kelulusan etika adalah diperlukan sekiranya sesuatu kajian itu melibatkan sekumpulan manusia sebagai responden. Kajian projek ini telah pun mendapat kelulusan Jawatankuasa Etika, Universiti Victoria, Wellington, nombor kelulusan 17471.

Kajian ini bertajuk: GAYA KEMPIMPINAN - SATU ANALISIS PERBANDINGAN DI ANTARA PEGAWAI-PEGAWAI SKIM PEGAWAI TADBIR DIPLOMATIK DAN SKIM PEGAWAI PERKHIDMATAN PELAJARAN DI KEMENTERIAN PELAJARAN MALAYSIA.

Fokus kajian ini ialah untuk mengkaji gaya kepimpinan seorang ketua diperingkat pertengahan yang bertugas di Kementerian Pelajaran Malaysia. Kajian ini akan membandingkan gaya kepimpinan ketua di peringkat pertengahan (contohnya Ketua Unit atau Ketua Sektor)yang terdiri dari pegawai-pegawai dari skim Pegawai Tadbir dan Diplomatik dan pegawai-pegawai dari skim Pegawai Perkhidmatan Pendidikan Siswazah. Adalah diharapkan kajian ini akan dapat menjelaskan samada wujudnya perbezaan dari segi gaya kepimpinan di kalangan ketua di peringkat pertengahan yang dilantik dari skim Pegawai Tadbir dan Diplomatik (PTD) dan skim Pegawai Perkhidmatan Pendidikan (DG).

Tuan/puan adalah dialukan untuk menyertai kajian ini sebagai salah seorang responden.Penyertaan tuan/puan dalam kajian ini adalah kerana tuan/puan bertugas sebagai seorang ketua unit/sektor dalam organisasi ini. Pandangan serta pendapat tuan/puan berkaitan gaya kepimpinan tuan/puan sebagai seorang ketua unit/sektor dapat membantu saya memahami dengan lebih mendalam akan gaya kepimpinan yang ditunjukkan oleh tuan/puan. Justeru,saya berharap agar tuan/puan dapat memberi persetujuan dan kerjasama untuk ditemuramah secara individu. Saya juga berharap agar tuan/puan mendapati kajian saya ini sebagai sesuatu yang penting dan bermanfaat dan bersetuju untuk bekerjasama dengan saya di dalam temuramah ini nanti.

Segala respon dari temuramah ini akan menjadi asas kepada kajian yang saya jalankan. Sesi temuramah tersebut akan dirakamkan dan saya akan berusaha agar apa jua maklumat yang diberikan oleh tuan/puan semasa sesi temuramah tersebut akan 
dirahsiakan. Setiap satu sesi temuramah ini dijangka akan mengambil masa diantara $30 \mathrm{ke}$ 45 minit, dan akan dijalankan mengikut kesesuaian atau kelapangan masa tuan/puan. Temuramah tersebut akan dirakam agar ia boleh ditranskripkan setepat yang mungkin. Saya akan menghantar salinan transkrip temuramah tersebut kepada tuan/puan sebelum proses analis transkrip temuramah tersebut bermula. Ini adalah perlu agar tuan/puan dapat menyemak serta mengesahkan maklumat yang diberikan dalam sesi temuramah yang dijalankan.

Di sini juga saya ingin menekankan bahawa segala maklumat dan keterangan yang diperolehi adalah sulit dan terkawal. Segala dokumentasi yang berkaitan dengan kajian ini akan diberikan nama samaran bagi memelihara identiti tuan/puan. Nama sebenar tuan/puan tidak akan didedahkan pada mana-mana bahagian kajian ini. Segala maklumat serta bahan-bahan berkaitan kajian ini dianggap sulit dan akan disimpan rapi. Tiada sesiapa boleh melihat atau mempunyai akses kepada segala salinan audio dan transkrip kajian ini selain daripada saya dan penyelia saya iaitu Prof. Madya Dr. Kabini Sanga. Salinan audio dan transkrip ini akan dilupuskan dalam tempoh dua tahun selepas kajian projek ini selesai.

Sekiranya tuan/puan bersetuju untuk mengambil bahagian didalam temuramah ini, sila isikan borang persetujuan yang disertakan. Tuan/puan berhak untuk menolak pelawaan ini dan ianya sama sekali tidak akan menjejaskan kajian ini ataupun menjesajskan kedudukan tuan/puan di dalam organisasi tuan/puan. Saya dengan ini mengucapkan ribuan terima kasih kerana sudi membaca maklumat yang disertakan ini.

Sekiranya anda mempunyai sebarang pertanyaan, atau ingin mengetahui dengan lebih lanjut tentang projek kajian ini, sila hubungi penyelia saya di:

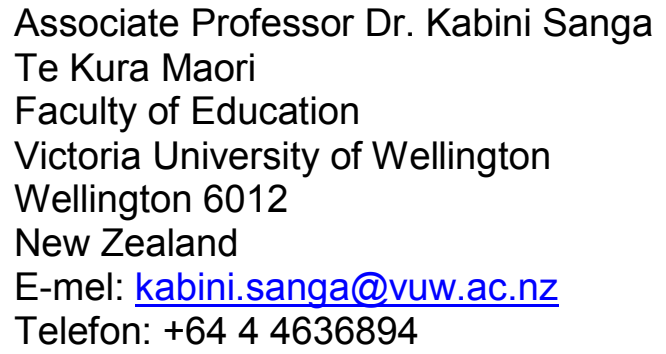

atau anda juga boleh terus menghubungi saya di:

Shahrizal Norwawi

31B Campbell Street

Faculty of Education

Victoria University of Wellington

Wellington 6012

New Zealand

E-mel: shahrizal.norwawi@vuw.ac.nz

Telefon: +64 211162682 (tel. bimbit)

Yang ikhlas,

Shahrizal Norwawi 


\title{
Appendix 6: \\ Consent to Participation in Interview
}

\author{
VICTORIA UNIVERSITY OF WELLINGTON \\ Te Whare Wananga o te Upoko o te Ika a Maui

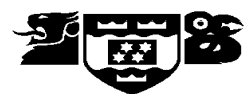 \\ CONSENT TO PARTICIPATION IN INTERVIEW \\ KEBENARAN UNTUK DITEMURAMAH BAGI TUJUAN KAJIAN

\section{LEADERSHIP STYLES: A COMPARATIVE ANALSYIS OF PTD OFFICERS AND DG OFFICERS IN THE MINISTRY OF EDUCATION MALAYSIA \\ GAYA KEMPIMPINAN: SATU ANALISIS PERBANDINGAN DI ANTARA PEGAWAI- PEGAWAI SKIM PEGAWAI TADBIR DIPLOMATIK DAN SKIM PEGAWAI PERKHIDMATAN PELAJARAN DI KEMENTERIAN PELAJARAN MALAYSIA}

I have been given and have understood an explanation of this research project. I understand that I have the opportunity to ask questions and have them answered to my satisfaction. I understand that I may withdraw myself (or any information I have provided) from this project (before interview and transcription is complete) without having to give reasons or without penalty of any sort.

Saya telah diberi penerangan dan faham akan keperluan kajian projek ini. Saya faham bahawa saya akan diberi peluang untuk mengaju sebarang soalan dan mengharapkan jawapan yang memuaskan. Saya faham bahawa saya boleh menarik diri (atau apa jua maklumat yang telah saya berikan) dari kajian projek ini (sekalipun sebelum temuramah dan proses transkipsi temuramah tamat) tanpa perlu memberi apa jua sebab atau dikenakan sebarang tindakan.

I also understand that any information I provide in the interview will be kept confidential to the researcher and the supervisor. I am aware that the published results will not use my name and that no opinions will be attributed to me in any way that will identify me as participant of this study. I also understand that the tape recording of interviews and also the full transcription of the interview will be kept secure at all times. I understand that the data I provide will not be used for any other purpose or released to others.

Saya juga faham bahawa apa jua maklumat yang saya berikan didalam temuramah ini adalah sulit. Saya sedar bahawa dapatan kajian ini tidak akan menggunakan nama saya dan apa jua pandangan yang saya berikan didalam temuramah ini tidak akan merujuk kepada saya dalam apa jua bentuk sekalipun. Saya juga faham bahawa rakaman temuramah dan juga transkip temuramah tersebut akan disimpan di tempat yang selamat sepanjang masa. Saya faham maklumat yang saya berikan tidak akan digunakan untuk tujuan lain atau disebarkan kepada mana-mana pihak yang lain.

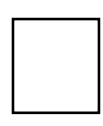

I have been given and have understood an explanation of this research project.

Saya telah diberi penerangan yang menyeluruh dan juga faham tentang kajian projek ini.

Signed/Tandatangan:

Name/Nama penuh: 


\section{Appendix 7:}

One way ANOVA of the components of transformational, transactional and avoidance of leadership of PTD middle level managers as perceived by their subordinates

\begin{tabular}{|c|c|c|c|c|c|c|}
\hline & & \begin{tabular}{c|} 
SUM OF \\
SQUARES
\end{tabular} & DF & \begin{tabular}{|c|} 
MEAN \\
SQUARE
\end{tabular} & $\mathbf{F}$ & SIG. \\
\hline \multirow[t]{3}{*}{ Idealized Influence } & Between Groups & 1.228 & 3 & \multirow{3}{*}{$\begin{array}{l}.409 \\
.408\end{array}$} & \multirow[t]{3}{*}{1.003} & \multirow[t]{3}{*}{.399} \\
\hline & Within Groups & 22.442 & 55 & & & \\
\hline & Total & 23.669 & 58 & & & \\
\hline \multirow[t]{3}{*}{ Inspirational motivation } & Between Groups & 4.377 & 3 & \multirow{3}{*}{$\begin{array}{r}1.459 \\
.531\end{array}$} & \multirow[t]{3}{*}{2.750} & \multirow[t]{3}{*}{$.050^{*}$} \\
\hline & Within Groups & 29.178 & 55 & & & \\
\hline & Total & 33.555 & 58 & & & \\
\hline \multirow[t]{3}{*}{ Intellectual stimulation } & Between Groups & 6.458 & 3 & \multirow{3}{*}{$\begin{array}{r}2.153 \\
.620\end{array}$} & \multirow[t]{3}{*}{3.472} & \multirow[t]{3}{*}{$.022 *$} \\
\hline & Within Groups & 34.095 & 55 & & & \\
\hline & Total & 40.553 & 58 & & & \\
\hline \multirow[t]{3}{*}{ Individualized consideration } & Between Groups & 2.982 & 3 & \multirow{3}{*}{$\begin{array}{l}.994 \\
.676\end{array}$} & \multirow[t]{3}{*}{1.470} & \multirow[t]{3}{*}{.233} \\
\hline & Within Groups & 37.196 & 55 & & & \\
\hline & Total & 40.178 & 58 & & & \\
\hline \multirow{3}{*}{$\begin{array}{l}\text { *OVERALL } \\
\text { TRANSFORMATIONAL }\end{array}$} & Between Groups & 2.836 & 3 & \multirow{3}{*}{$\begin{array}{l}.945 \\
.414\end{array}$} & \multirow[t]{3}{*}{2.283} & \multirow[t]{3}{*}{.089} \\
\hline & Within Groups & 22.775 & 55 & & & \\
\hline & Total & 25.611 & 58 & & & \\
\hline \multirow[t]{3}{*}{ Contingent Reward } & Between Groups & 2.661 & 3 & \multirow{3}{*}{$\begin{array}{l}.887 \\
.584\end{array}$} & \multirow[t]{3}{*}{1.519} & \multirow[t]{3}{*}{.220} \\
\hline & Within Groups & 32.131 & 55 & & & \\
\hline & Total & 34.792 & 58 & & & \\
\hline \multirow[t]{3}{*}{ Management by exception (Active) } & Between Groups & .288 & 3 & \multirow{3}{*}{$\begin{array}{l}.096 \\
.424\end{array}$} & \multirow[t]{3}{*}{.226} & \multirow[t]{3}{*}{.878} \\
\hline & Within Groups & 23.320 & 55 & & & \\
\hline & Total & 23.608 & 58 & & & \\
\hline \multirow[t]{3}{*}{ Management by exception (Passive) } & Between Groups & 1.340 & 3 & \multirow{3}{*}{$\begin{array}{l}.447 \\
.695\end{array}$} & .643 & .590 \\
\hline & Within Groups & 38.200 & 55 & & & \\
\hline & Total & 39.540 & 58 & & & \\
\hline *OVERALL TRANSACTIONAL & Between Groups & .358 & 3 & .119 & .569 & .638 \\
\hline & Within Groups & 11.536 & 55 & .210 & & \\
\hline & Total & 11.894 & 58 & & & \\
\hline AVOIDANCE OF LEADERSHIP & Between Groups & 6.229 & 3 & 2.076 & 2.463 & .072 \\
\hline (Laissez faire) & Within Groups & 46.358 & 55 & .843 & & \\
\hline & Total & 52.587 & 58 & & & \\
\hline
\end{tabular}

$* \mathrm{p} \leq 0.05$ 
Appendix 8:

One way ANOVA of the components of transformational, transactional and avoidance of leadership of DG middle level managers as perceived by their subordinates

\begin{tabular}{|c|c|c|c|c|c|c|}
\hline & & $\begin{array}{l}\text { SUM OF } \\
\text { SQUARES }\end{array}$ & DF & \begin{tabular}{|} 
MEAN \\
SQUARE
\end{tabular} & $\mathbf{F}$ & SIG. \\
\hline \multirow[t]{3}{*}{ Idealized Influence } & Between Groups & 4.131 & 3 & \multirow{3}{*}{$\begin{array}{r}1.377 \\
.533\end{array}$} & \multirow[t]{3}{*}{2.583} & \multirow[t]{3}{*}{.062} \\
\hline & Within Groups & 31.453 & 59 & & & \\
\hline & Total & 35.585 & 62 & & & \\
\hline \multirow[t]{3}{*}{ Inspirational motivation } & Between Groups & 5.753 & 3 & \multirow{3}{*}{$\begin{array}{r}1.918 \\
.587\end{array}$} & \multirow[t]{3}{*}{3.265} & \multirow[t]{3}{*}{$.028^{*}$} \\
\hline & Within Groups & 34.659 & 59 & & & \\
\hline & Total & 40.413 & 62 & & & \\
\hline \multirow[t]{3}{*}{ Intellectual stimulation } & Between Groups & 3.460 & 3 & \multirow{3}{*}{$\begin{array}{r}1.153 \\
.430\end{array}$} & \multirow[t]{3}{*}{2.684} & \multirow[t]{3}{*}{.055} \\
\hline & Within Groups & 25.351 & 59 & & & \\
\hline & Total & 28.812 & 62 & & & \\
\hline \multirow[t]{3}{*}{ Individualized consideration } & Between Groups & 3.248 & 3 & \multirow{3}{*}{$\begin{array}{r}1.083 \\
.780\end{array}$} & \multirow[t]{3}{*}{1.389} & \multirow[t]{3}{*}{.255} \\
\hline & Within Groups & 45.998 & 59 & & & \\
\hline & Total & 49.246 & 62 & & & \\
\hline \multirow{3}{*}{$\begin{array}{l}\text { *OVERALL } \\
\text { TRANSFORMATIONAL }\end{array}$} & Between Groups & 3.955 & 3 & \multirow{3}{*}{$\begin{array}{r}1.318 \\
.478\end{array}$} & \multirow[t]{3}{*}{2.760} & \multirow[t]{3}{*}{$.050^{*}$} \\
\hline & Within Groups & 28.185 & 59 & & & \\
\hline & Total & 32.140 & 62 & & & \\
\hline \multirow[t]{3}{*}{ Contingent Reward } & Between Groups & 3.723 & 3 & \multirow{3}{*}{$\begin{array}{r}1.241 \\
.774\end{array}$} & \multirow[t]{3}{*}{1.604} & \multirow[t]{3}{*}{.198} \\
\hline & Within Groups & 45.665 & 59 & & & \\
\hline & Total & 49.389 & 62 & & & \\
\hline \multirow{3}{*}{$\begin{array}{l}\text { Management by exception } \\
\text { (Active) }\end{array}$} & Between Groups & 1.456 & 3 & \multirow{3}{*}{$\begin{array}{l}.485 \\
.483\end{array}$} & \multirow[t]{3}{*}{1.005} & \multirow[t]{3}{*}{.397} \\
\hline & Within Groups & 28.499 & 59 & & & \\
\hline & Total & 29.954 & 62 & & & \\
\hline \multirow{3}{*}{$\begin{array}{l}\text { Management by exception } \\
\text { (Passive) }\end{array}$} & Between Groups & 2.281 & 3 & \multirow{3}{*}{$\begin{array}{l}.760 \\
.613\end{array}$} & 1.241 & .303 \\
\hline & Within Groups & 36.156 & 59 & & & \\
\hline & Total & 38.437 & 62 & & & \\
\hline *OVERALL & Between Groups & .236 & 3 & .079 & .333 & .801 \\
\hline TRANSACTIONAL & Within Groups & 13.911 & 59 & .236 & & \\
\hline & Total & 14.146 & 62 & & & \\
\hline AVOIDANCE OF & Between Groups & 10.379 & 3 & 3.460 & 5.602 & $.002 *$ \\
\hline LEADERSHIP & Within Groups & 36.439 & 59 & .618 & & \\
\hline & Total & 46.817 & 62 & & & \\
\hline
\end{tabular}

$* \mathrm{p} \leq 0.05$ 
Appendix 9:

Detailed Summary of the Transformational Leadership Qualities of the Interview Participants

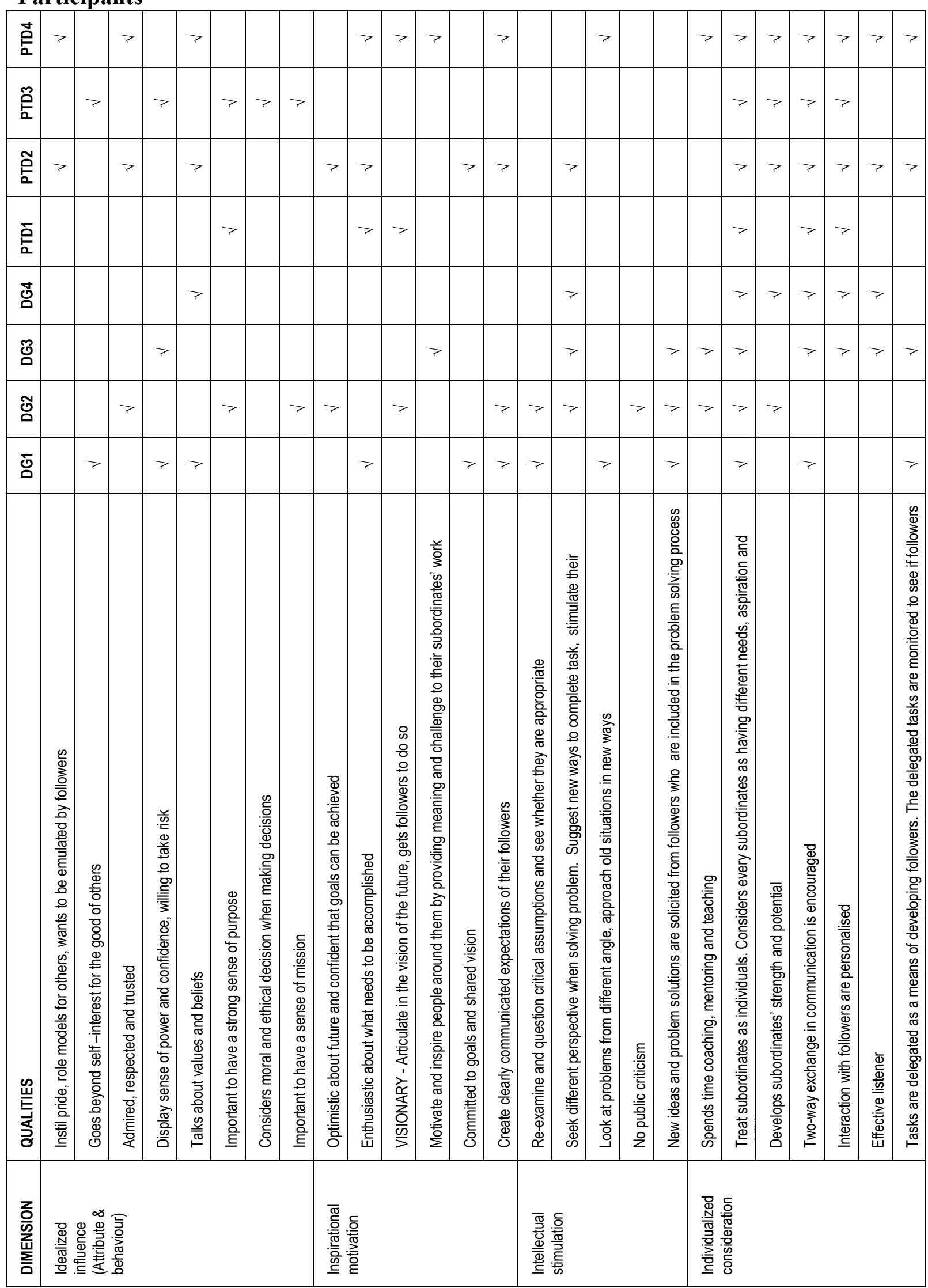


Appendix 10:

Detailed Summary of the Transactional Leadership Qualities of the Interview Participants

\begin{tabular}{|c|c|c|c|c|c|c|c|c|c|c|c|c|c|}
\hline 吉 & $>$ & & $>$ & & & & & & & & & & \\
\hline 吕 & & & $>$ & & $>$ & & & & & & & & \\
\hline 吕 & & & & & & & & & & & & & \\
\hline 亯 & & & & & & & & & & & & & \\
\hline 吉 & & & & & & & & & $>$ & & & & \\
\hline ญ్రి & & & & $>$ & & & & & & & & & \\
\hline ণั & $>$ & & $>$ & $>$ & & & & & & & & & \\
\hline ঠু & & & & & & & & & & & & & \\
\hline 岂 & 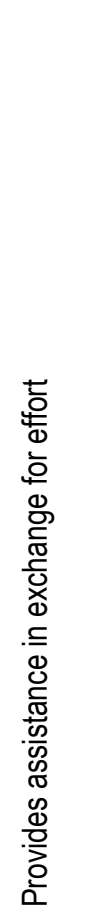 & 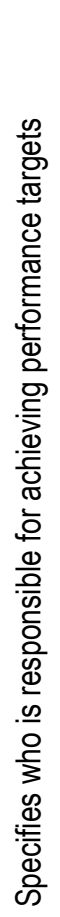 & 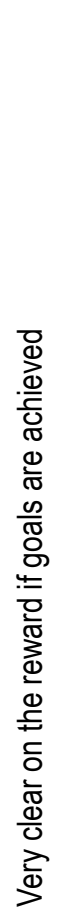 & 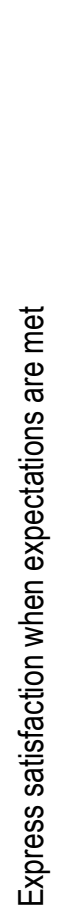 & 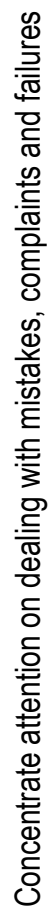 & 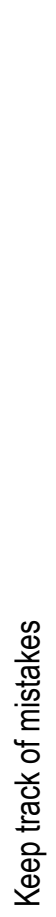 & 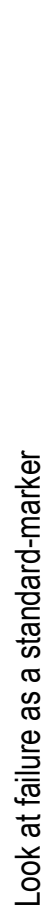 & 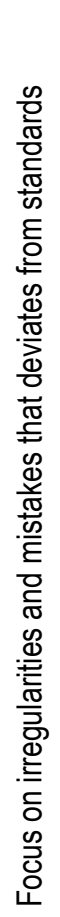 & 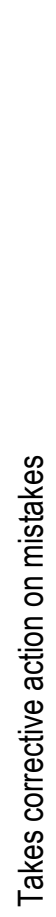 & 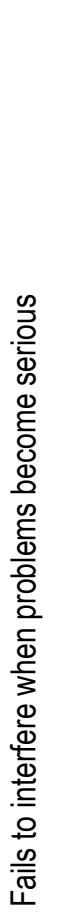 & 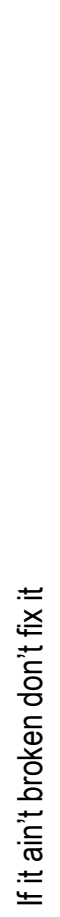 & 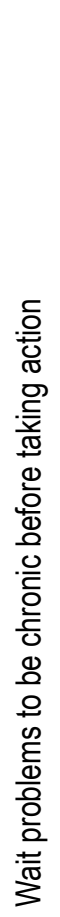 & 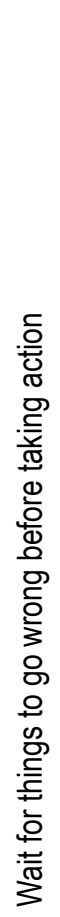 \\
\hline 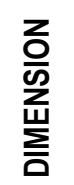 & \multicolumn{4}{|c|}{ 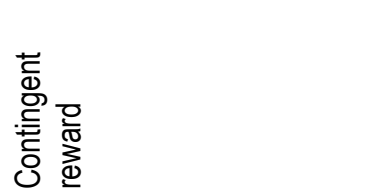 } & \multicolumn{5}{|c|}{ 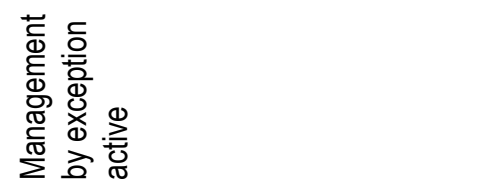 } & \multicolumn{4}{|c|}{ 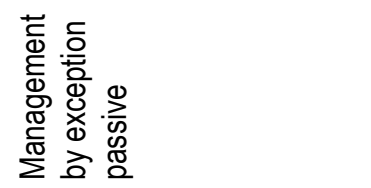 } \\
\hline
\end{tabular}




\section{References}

Adeyemi-Bello, T. (2001). The impact of leadership style on organizational growth. Work Study, 50(4), pp. 150-153.

Ahmad Sarji, A. H. (1996). Ucapan perasmian mesyuarat agong tahunan Persatuan Pegawai Tadbir dan Diplomatik 1996. Paper presented at the Mesyuarat Agong Tahunan Persatuan Pegawai Tadbir dan Diplomatik. Retrieved 4 March 2010, from http://www.pmo.gov.my/ucapan/?m=p\&p+ahmadsarji\&id+2551

Alimo-Metcalfe, B., \& Alban-Metcalfe, R. J. (2001). The development of a new transformational leadership questionnaire. Journal of Occupational and Organizational Psychology, 74, pp. 1 $-27$.

Amir, H. N. (2008, 10 December 2008). Pertubuhan guru tidak mahu PTD dalam perkhidmatan pendidikan. Berita Harian,

Andersen, J. A. (2008). Style theories. In A. Marturano \& J. Gosling (Eds.), Leadership: The Key Concepts. New York: Routledge.

Antonakis, J., Avolio, B. J., \& Sivasubramaniam, N. (2003). Context and leadership: an examination of the nine-factor full range leadership theory using the Multifactor Leadership Questionnaire. The Leadership Quarterly, 14(2003), pp. 261 - 295.

Antonakis, J., \& House, R. J. (2002). The full-range leadership theory: the way forward. In B. J. Avolio \& F. J. Yammarino (Eds.), Transformational and Charismatic Leadership: The Road Ahead. Oxford: JAI, An Imprint of Elsevier Science.

Antonakis, J., Schriesheim, C. A., Donovan, J. A., Gopalakrishna-Pillai, K., Pellegrini, E. K., \& Rossomme, J. L. (2004). Methods for studying leadership. In J. Antonakis, A. T. Cianciolo \& R. J. Stenberg (Eds.), The Nature of Leadership. Thousand Oaks, CA: SAGE Publications Ltd.

Ardichvili, A. (2001). Leadership styles and work-related values of managers and employees of manufacturing enterprises in post-communist countries. Human Resource Development Quarterly, 12(4, Winter 2001), pp. 363 -383.

Ardichvili, A., \& Gasparishvili, A. (2001). Leadership profiles of managers in post-communist countries: a comparative study. Leadership \& Organization Development Journal, 22(2), pp. $62-69$.

Ardichvili, A., \& Kuchinke, K. P. (2002). Leadership styles and cultural values among managers and subordinates: a comparative study of four countries of the former Soviet Union, Germany and the US. Human Resource Development International, 5(1), pp. 99-117.

Avolio, B. J., \& Bass, B. M. (1995). Individual consideration viewed at multiple levels of analysis: a multi level framework for examining the diffusion of transformational leadership. Leadership Quarterly, 6(2), pp. 199 - 218.

Avolio, B. J., \& Bass, B. M. (2004). Multifactor leadership questionnaire: manual and sampler set (3 ed.). Redwood City, CA: Mind Garden Inc.

Baharudin, O. (2004). Gaya kepimpinan pemimpin dan komitmen pekerja di Jabatan Agama Selangor. Unpublished Master's thesis. Northern University of Malaysia (Universiti Utara Malaysia).

Barbour, R. S. (2001). Checklist for improving rigour in qualitative research: a case of the tail wagging the dog. BMJ, 322(7294), pp. 1115 - 1117.

Baruch, Y. (1999). Response rate in academic studies - a comparative analysis. Human Relations, 52(4), pp. 421 - 438.

Bass, B. M. (1985). Leadership and performance beyond expectations. New York: Free Press.

Bass, B. M. (1996). Is there universality in the full range model of leadership. International Journal of Public Administration, 19(6), pp. 731 - 761.

Bass, B. M. (1998). Transformational leadership: Industrial, military and educational impact. New Jersey: Lawrence Erlbaum Associates, Inc. 
Bass, B. M. (1999). Two decades of research and development in transformational leadership. European Journal of Work and Organizational Psychology, 8(1), pp. 9-32.

Bass, B. M. (2008). The Bass handbook of leadership: Theory, research \& managerial applications (4th ed.). New York: Free Press.

Bass, B. M., \& Avolio, B. J. (1993). Transformational leadership: a response to critique. In M. M. Chemers \& R. Ayman (Eds.), Leadership Theory and Research: Perspectives and Directions. San Diego, CA: Academic Press Inc.

Bass, B. M., \& Avolio, B. J. (1994). Introduction. In B. M. Bass \& B. J. Avolio (Eds.), Improving organizational effectiveness through transformational leadership London: Sage Publications.

Bass, B. M., \& Riggio, R. E. (2006). Transformational Leadership (2 ed.). New Jersey: Lawrence Erlbaum Associates.

Bennis, W. G., \& Nanus, B. (1985). Leaders: the strategies for taking charge. New York: Harper \& Row.

Bergman, M. M. (2008). Introduction: whither mixed methods? In M. M. Bergman (Ed.), Advances in Mixed Methods Research. London: SAGE Publications Ltd.

BERNAMA (2007). Langkah tempatkan PTD tadbir Jabatan Pelajaran Negeri Ditangguhkan. Bernama. Retrieved 4 March 2010, from http://www.bernama.com.my/v3/news lite.php?id=269164

BERNAMA (2008). Sebanyak 26 kesatuan perguruan bantah PTD, mahu jumpa PM dan Hishammuddin. Bernama. Retrieved 4 March 2010, from http://www.bernama.com/bernama/v3/bm/news lite.php?id=325445

Berson, Y., \& Avolio, B. J. (2004). Transformational leadership and the dissemination of organizational goals: a case study of a telecommunication firm. The Leadership Quarterly, 15(2004), pp. 625 - 646.

Berson, Y., Shamir, B., Avolio, B. J., \& Popper, M. (2001). The relationship between vision, strength, leadership style and concept. The Leadership Quarterly, 12(2001), pp. 53 - 73.

Blake, R. R., \& Mouton, J. S. (1964). The managerial grid: key orientations for achieving production through people. Houston, Texas: Gulf Publishing

Bodla, M. A., \& Nawaz, M. M. (2010). Comparative study of Full Range Leadership Model among faculty members in public and private sector higher education institutes and universities. International Journal of Business and Management, 5(4), pp. 208 - 214.

Bogler, R. (2001). The influence of leadership style on teacher job satisfaction. Educational Administration Quarterly, 37(5), pp. 662 - 683.

Bolden, R., Gosling, J., Marturano, A., \& Dennison, P. (2003). A review of leadership theory and competency frameworks. Exeter: University of Exeter, UK.

Bowman, R. (2004). Teacher as leaders. Clearing House, 77(5), pp.187 - 189.

Briggs, A. R. J. (2001a). Academic middle managers in further education. Management in Education, 15(2), pp. 12 - 14.

Briggs, A. R. J. (2001b). Academic middle managers in further education: refection on leadership. Research in Post-Compulsory Education, 6(2), pp. 223 - 236.

Briggs, A. R. J. (2001c). Middle managers in further education: exploring the role. Management in Education, 15(4), pp. 12 - 15.

Bryman, A. (1992). Charisma and leadership in organization. London: SAGE.

Bryman, A. (2004). Qualitative research on leadership: a critical but appreciative review. The Leadership Quarterly, 15(2004), pp. 729 - 769.

Bryman, A. (2006). Integrating quantitative and qualitative research: how is it done? Qualitative Research, 6(1), pp. 97 - 113.

Bryman, A., Stephens, M., \& Campo, C. (1996). The importance of context: qualitative research and the study of leadership. Leadership Quarterly, 7(3), pp. 353 - 370.

Burns, J. M. (1978). Leadership. New York: Harper \& Row Publishers Inc. 
Carless, S. A., Wearing, A. J., \& Mann, L. (2000). A short measure of transformational leadership. Journal of Business and Psychology, 14(3), pp. 389 - 405.

Casimir, G. (2001). Combinative aspects of leadership style: The ordering and temporal spacing of leadership behaviours. The Leadership Quarterly, 12(2001), pp. 245 - 278.

Cohen, L., Manion, L., \& Morrison, K. (2000). Research methods in education. London: RoutledgeFalmer.

Coleman, M. (2005). Theories and practice of leadership: an introduction. In M. Coleman \& P. Earley (Eds.), Leadership and Management in Education: Culture, Change and Context. Oxford: Oxford University Press.

Creswell, J. W., \& Plano Clark, V. L. (2007). Designing and conducting mixed methods research. Thousand Oaks, CA: SAGE Publications Inc.

Creswell, J. W., Plano Clark, V. L., \& Garret, A. L. (2008). Methodological issues in conducting mixed methods research designs. In M. M. Bergman (Ed.), Advances in Mixed Methods Research. London: SAGE Publications Ltd.

Creswell, J. W., Plano Clark, V. L., Gutmann, M. L., \& Hanson, W. E. (2003). Advanced mixed methods research designs. In A. Tashakkori \& C. Teddlie (Eds.), Handbook of Mixed Methods in Social Behavioral Research. Thousand Oaks, CA: SAGE Publications Inc.

Crowther, F., \& Olsen, P. (1997). Teachers as leaders - an exploratory framework. International Journal of Educational Management, 11(1), pp.6 - 13.

Currie, G., \& Lockett, A. (2007). A critique of transformational leadership: moral, professional and contingent dimensions of leadership within public services organizations. Human Relations, 60(2), pp. 341 - 370.

Danielson, C. (2006). Teacher leadership that strengthens professional practice. Heatherton, Victoria: Hawker Bronlow Education.

Dubinsky, A. J., Yammarino, F. J., \& Jolson, M. A. (1995). An examination of linkages between personal characteristics and dimensions of transformational leadership. 9, 3, pp. 315 -335.

Dulewicz, V., \& Higgs, M. (2005). Assessing leadership styles and organisational context. Journal of Managerial Psychology, 20(2), pp. 105 - 103.

Dvir, T., Eden, D., Avolio, B. J., \& Shamir, B. (2002). Impact of transformational leadership on follower development and performance: a filed experiment. Academy of Management, 45(4), pp. $735-744$.

Eagly, A. H., \& Johannesen-Schmidt, M. C. (2001). The leadership styles of women and men. Journal of Social Issues, 57(4), pp. $781-797$.

EPRD (2001). Education in Malaysia: a journey to excellence. Kuala Lumpur: Educational Planning and Research Divison (EPRD), Ministry of Education Malaysia.

EPRD (2002). Koleksi abstrak disertasi kedoktoran mengenai pendidikan di Malaysia 1996 2002:Doctoral Dissertation Abstracts on Education in Malaysia 1996 - 2002. Kuala Lumpur: Kementerian Pendidikan Malaysia.

EPRD (2008). Koleksi abstrak disertasi kedoktoran mengenai pendidikan di Malaysia 2003 2008:Doctoral Dissertation Abstracts on Education in Malaysia 2003 - 2008. Putrajaya: Kementerian Pelajaran Malaysia.

Ercetin, S. S., \& Duzer, A. (2008). Multidimensional perceptual leadership model. World Applied Sciences Journal, 3(1), pp. 25 - 33.

Fauziah Arof (2007). Guru berstau tolak PTD. Utusan Malaysia. Retrieved 4 March 2010, from http://www.utusan.com.my/utusan/info.asp?y=2007\&dt=0402\&pub=Utusan Malaysia\&se $\mathrm{c}=$ Muka Hadapan\&pg=mh 01.htm

Fazli, I., \& Khairul Anuar, M. A. (2008). The impacts of leadership style and best practices on company performances: empirical evidence from business firms in Malaysia. Total Quality Management, 19(1-2), pp. 163 - 171. 
Fernandez, S., Yoon, J. C., \& Perry, J. L. (2010). Exploring the link between integrated leadership and public sector performance. The Leadership Quarterly, 21(2010), pp. 308 - 323.

Floyd, S. W., \& Wooldridge, B. (1990). The strategy process, middle management involvement and organizational performance. Strategic Management Journal, 11(3 March/April), pp. 231 241.

Floyd, S. W., \& Wooldridge, B. (1992). Middle management involvement in strategy and its association with strategic type: a research note. Strategic Management Journal, 13(Summer 1992 Special Issue), pp. 153 - 167.

Floyd, S. W., \& Wooldridge, B. (1994). Dinosaurs or dynamos? Recognizing middle management's strategic role. The Academy of Management Executive, 8(4 November), pp. 47 - 57.

Floyd, S. W., \& Wooldridge, B. (1997). Middle management's strategic influence and organizational performance. Journal of Management Studies, 34(3), pp. 465 - 485.

Fukushige, A., \& Spicer, D. P. (2007). Leadership preferences in Japan: an exploratory study. Leadership \& Organization Development Journal, 28(6), pp. 508 - 530.

Gibbs, G. (2007). Analyzing qualitative data. London: SAGE Publications Ltd.

Gill, R. (1998). Cross cultural comparison of the leadership styles and behaviour of managers in the UK, USA and Southeast Asia. Asian Academy of Management Journal, 3, pp. 19 - 32.

Goleman, D. (2000). Leadership that gets result. Harvard Business Review, March - April, pp. 78 - 90.

Grummell, B., Devine, D., \& Lynch, K. (2009). Appointing senior managers in education: homosociability, local logics and authenticity in the selection process. Educational Management Administration \& Leadership, 37(3), pp. 329 - 349.

Gunter, H. M. (2001). Leaders and leadership in education. London: Paul Chapman Publishing.

Hair, J. F., Black, B., Babin, B., Anderson, R. E., \& Tatham, R. L. (2006). Multivariate data analysis (6 ed.). New Jersey: Prentice Hall.

Hasnurul Mohamed (2007). PTD ke JPN: NUTP perlu positif. Utusan Malaysia. Retrieved 4 March 2010, from

http://www.utusan.com.my/utusan/info.asp?y=2007\&dt=0319\&pub=Utusan Malaysia\&se $\mathrm{c}=$ Dalam Negeri\&pg=dn 07.htm

Hellrigel, D., \& Slocum, J. W. (2007). Organizational Behaviour (11 ed.). Mason, OH: Thompson South-Western

Herman, S., \& Egri, C. P. (2002). Triangulation in action. In K. W. Parry \& J. R. Meindl (Eds.), Grounding Leadership Theory and Research: Issues and Perspectives and Methods (Vol. 1). Connecticut: Information Age Publishing.

Hewson, C. (2006). Mixed methods research. In V. Jupp (Ed.), The SAGE Dictionary of Social Research Methods. London: SAGE Publications Ltd.

Hofstede, G. (2001). Culture's consequences: comparing values, behaviours, institutions and organizations across nations ( 2 ed.). London: SAGE publications.

Hollander, E. P. (1978). Leadership dynamics: a practical guide to effective relationships. New York: The Free Press.

Hollander, E. P. (1993). Legitimacy, power and influence: a perspective on relational features of leadership. In M. M. Chemers \& R. Ayman (Eds.), Leadership Theory and Research: Perspectives and Directions. San Diego: Academic Press Inc.

Horner, M. (1997). Leadership theory: past, present and future. Team Performance Management, 3(4), pp. 270 - 287.

Ibrahim, A. B. (1995). Assessment of accountability systems in Malaysian education. International Journal of educational Research, 23(6), pp. 531 - 544.

Ibrahim, A. B. (1996). Preliminary explorations of indigenous perspectives of educational management: the evolving Malaysian experience. Journal of Educational Administration, 34(5), pp. $50-73$. 
Ibrahim, A. B., Abdul Wahab, A. G., Bakhtiar, M., Maheswari, K., Yusro, A. H., Lim, O. K., et al. (1996). Malaysian educative leadership: interim research findings. International Journal of Educational Management 10(2), pp. 21 - 26.

INTAN (2010). Administration and Diplomatic Service Retrieved 5 January, 2010, from http://www.intanbk.intan.my/cd/m ptd/ptd-en.pdf

Jabatan Perkhidmatan Awam (2010). Maklumat Skim Perkhidmatan Pada 1 Januari 2010 Available from http://www.interactive.jpa.gov.my/ezskim/Penerbitan/Buku\%20Maklumat\%20Skim\%20Per khidmatan\%201\%20Jan\%202010.pdf

Jago, A. G., \& Vroom, V. H. (1977). Hierarchical level and leadership style. Organizational Behaviour and Human Performance, 18, pp. $131-145$.

Jazmi, M. I. (2009). Gaya kepimpinan pengetua dan kepuasan kerja guru: kajian perbandingan antara SMKA dengan SMK. Unpublished Master's thesis. Universiti Utara Malaysia (Northern University of Malaysia).

Jogulu, U. D., \& Wood, G. J. (2006). The role of leadership theory in raising the profile of women Equal Opportunities International, 25(4), pp. 236 - 250.

Johnson, B., \& Christensen, L. (2008). Educational research: quantitative, qualitative and mixed approaches. Thousand Oaks, CA: SAGE Publications Inc.

Johnson, B., Onwuegbuzie, A. J., \& Turner, L. A. (2007). Toward a definition of mixed methods research. Journal of Mixed Methods Research, 1(2), pp. $112-133$.

Johnson, B., \& Turner, L. A. (2003). Data collection strategies in mixed methods research. In A. Tashakkori \& C. Teddlie (Eds.), Handbook of mixed methods in social and behavioral research. Thousand Oaks, CA: SAGE Publications Inc.

Jones, S. (2008). Leadership - evolution and tradition In J. Remme, S. Jones, B. V. D. Heijden \& S. D. Bono (Eds.), Leadership, Change and Responsibility. Oxford: Meyer \& Meyer (UK) Ltd.

Jui-Chen, C., \& Silverthone, C. (2005). Leadership effectiveness, leadership style and employee readiness. Leadership \& Organization Development Journal, 26(1), pp. 280-288.

Jung, D. I., \& Avolio, B. J. (1999). Effects of leadership style and followers' cultural orientation on performance in group and individual task conditions. Academy of Management, 42(2), pp. $208-218$.

Kahai, S. S., Sosik, J. J., \& Avolio, B. J. (2003). Effects of leadership style, anonymity, and rewards on creativity-relevant processes and outcomes in an electronic meeting system context. The Leadership Quarterly, 14(4-5), pp. 499-524.

Keegan, A. E., \& Den Hartog, D. N. (2004). Transformational leadership in a project-based environment: a comparative study of the leadership styles of project managers and line managers. International Journal of Project Management, 22(2004), pp. 609 - 617.

Kementerian Pelajaran Malaysia (2006). Pelan Induk Pembangunan Pendidikan. Putrajaya: Kementerian Pelajaran Malaysia.

Kementerian Pelajaran Malaysia (2008). Laporan tahunan 2008/2008 Annual report. Putrajaya: Kementerian Pelajaran Malaysia.

Kementerian Pelajaran Malaysia (2010). Ringkasan Perjawatan di Kementerian Pelajaran Malaysia Mengikut Skim Perkhidmatan pada 30 Jun 2007. Retrieved 14 April 2010: http://www.moe.gov.my/upload/galeri awam/penyelidikan/2007/2007 BTMK 672281 568.pdf

Kementerian Pendidikan Malaysia (2001a). Executive summary education development plan 2001 2010. Kuala Lumpur: Kementerian Pendidikan Malaysia.

Kementerian Pendidikan Malaysia (2001b). Pembangunan Pendidikan 2001 - 2010: Perancangan bersepadu penjana kecermelangan pendidikan. Kuala Lumpur: Kementerian Pendidikan Malaysia. 
Kemper, E. A., Stringfield, S., \& Teddlie, C. (2003). Mixed methods sampling strategies in social science research. In A. Tashakkori \& C. Teddlie (Eds.), Handbook of Mixed Methods in Social Behavioral Research. Thousand Oaks, CA: SAGE Publications Inc.

Kesatuan Guru Bumiputera Sarawak (2010). Cadangan untuk mengekalkan pegawai DG di semua peringkat dalam organisasi pendidikan Retrieved 4 March, 2010, from http://www.kgbsarawak.com/isu9.html

Kirby, P. C., Paradise, L. V., \& King, M. I. (1992). Extraordinary leaders in education: understanding transformational leadership. The Journal of Educational Research, 85(5), pp. $303-311$.

Kirkbride, P. (2006). Developing transformational leaders: the full range leadership model in action. Industrial and Commercial Training, 38(1), pp. 23 - 32.

Kouzes, J. M., \& Posner, B. Z. (2007). The Leadership Challenge. San Francisco, CA: Jossey-Bass.

Kuchinke, K. P. (1999). Leadership and culture: work related values and leadership styles among one company's U.S and German telecommunication employees. Human Resource Development Quarterly, 10(2), pp. 135 - 154.

Kuhnert, K. W., \& Lewis, P. (1987). Transactional and transformational leadership: a constructive development analysis. The Academy of Management Review, 12(4), pp. 648 -657.

Lee, M. (1999). Education in Malaysia: towards vision 2020. School Effectiveness and School Improvement, 10(1), pp. 86 - 98.

Lee, N. (2008). Developing and validating an instrument to assess performance of public sector organisations: a case study of Malaysian schools. Measuring Business Excellence, 12(3), pp. $56-75$.

Leech, N. L., Dellinger, A. B., Brannagan, K. B., \& Tanaka, H. (2009). Evaluating mixed research studies: a mixed methods approach. Journal of Mixed Methods Research, 4(1), pp. 17 - 31.

Leithwood, K., Begley, P. T., \& Cousins, B. J. (1994). Developing expert leadership for future schools. London: Falmer Press.

Leithwood, K., \& Janzti, D. (2000). The effects of transformational leadership on organizational conditions and student engagement with school. Journal of Educational Administration, 38(2), pp. 112 - 129.

Leithwood, K., \& Janzti, D. (2005). Transformational leadership. In B. Davies (Ed.), The Essential of School Leadership. London: Paul Chapman Publishing and Corwin Press: A SAGE Publications Company.

Leithwood, K., \& Poplin, M. S. (1992). The move toward transformational leadership. Educational Leadership, 49(5), pp. 8 - 12.

Leithwood, K., Tomlinson, D., \& Genge, M. (1996). Transformational school leadership. In K. Leithwood, J. Chapman, D. Corson, P. Hallinger \& A. Hart (Eds.), International Handbook of Educational Leadership Administration (Part 2). Dordrecht: Kluwer Academic Publishers.

Levine, K. J. (2008). Trait theory. In A. Marturano \& J. Gosling (Eds.), Leadership: The Key Concepts. New York: Routledge.

Lim, H.-H. (2007). Improving administrative performance in Malaysia: the more difficult next steps in reform. Policy and Society, 26(2), pp. 33 - 59.

Liu, W., Lepak, D. P., Takeuchi, R., \& Sims, H. P. (2003). Matching leadership styles with employment modes: strategic human resource management perspective. Human Resource Management Review, 13(1), pp. 127-152.

Lo, M.-C., Ramayah, T., \& Wei, M. H. (2009). Leadership styles and organizational commitment: a test on Malaysia manufacturing industry. African Journal of Marketing Management, 1(6), pp. 133-139.

Lok, P., \& Crawford, J. (2004). The effect of organisational culture and leadership style on job satisfaction and organisational commitment: a cross national commitment. The Journal of Management Development, 23(4), pp. 321 - 338. 
Lowe, K. B., Kroeck, K. G., \& Sivasubramaniam, N. (1996). Effectiveness correlates of transformational and transactional leadership: a meta-analytic review of the MLQ literature. Leadership Quarterly, 7(3), pp. 385 - 425.

Lunenburg, F. C., \& Ornstein, A. C. (1996). Educational Administration. California: Wadsworth Publishing Company.

Mahfooz, A. A., Zainal, A. A., \& Rehana, A. (2004). Organizational leadership in the Malaysian context. In D. Tjosvold \& L. Kwok (Eds.), Leading in High Growth Asia: Managing Relationship for Teamwork and Change (pp. 109 - 138). Singapore: World Scientific Publishing Co. Pte. Ltd.

Mays, N., \& Pope, C. (1995). Qualitative research: rigour and qualitative research. BMJ, 311(6997), pp. $109-112$.

McColl-Kennedy, J. R., \& Anderson, R. D. (2002). Impact of leadership style and emotions on subordinate performance. The Leadership Quarterly, 13(2002), pp. 454 - 559.

McColl-Kennedy, J. R., \& Anderson, R. D. (2003). Subordinate - manager gender combination and perceived leadership style influence on emotions, self-esteem and organizational commitment. Journal of Business Research, 58(2005), pp. 115 - 125.

Mengel, T. (2008). Behavioural theories of leadership. In A. Marturano \& J. Gosling (Eds.), Leadership: The Key Concepts. New York: Routledge.

Messick, D. M., \& Kramer, R. M. (2005). Introduction: new approaches to the psychology of leadership. In D. M. Messick \& R. M. Kramer (Eds.), The Psychology of Leadership: New Perspectives and Research. Mahwah, New Jersey: Lawrence Erlbaum Associates, Publishers.

Miner, J. B. (2005). Organizational behaviour: essential theories of motivation and leadership. New york: M.E. Sharpe Inc.

Ministry of Education (2001). Education Development Plan 2001-2010: generating educational excellence through collaboration planning. Kuala Lumpur: Educational Planning and Research Division, Ministry of Education Malaysia.

Ministry of Women Family and Community Development (2007). Measuring and monitoring gender equality: Malaysia's gender gap index. Kuala Lumpur: Ministry of Women, Family and Community Development in partnership with United Nations Development Programme.

MLQ International (2008). The Full Range Leadership Model Retrieved 10 August 2010, from http://www.mlq.com.au/flash frlm.asp

Morrison, M. (2007). What do mean by educational research? In A. R. J. Briggs \& M. Coleman (Eds.), Research Methods in Educational Leadership and Management. London: SAGE Publications Ltd.

Morse, J. M., \& Niehaus, L. (2009). Mixed method design: principles and procedures. Wallnut Creek, CA: Left Coast Press Inc.

Mosley, A. L. (1998). A behavioral approach to leadership: implications for diversity in today's organizations. The Journal of leadership Studies, 5(1), pp. 38 - 50.

Muijs, D. (2004). Doing quantitative research in education with SPSS. London: SAGE Publications Ltd.

Nazatul-Shima, A., Fatimah, P., Normaziah, C. M., \& Misyer, M. T. (2008). Malaysian employees' preference of their managers leadership styles. International Review of Business Research Papers, 4(5 October-November), pp. 97-108.

Nik Maheran, N. M., Filzah, M. I., Siti Norezam, O., \& Rosli, A. R. (2009). Decision making quality of higher education institutions leaders in Malaysia: leadership style, decision style, managerial process and competitive intensity relationships. Putrajaya: Kementerian Pengajian Tinggi.

NOOSR (1996). Country education Profiles: Malaysia A comparative study. Canberra: National Office of Overseas Skills Recognition.

Nor Shamsuri, H. M. (2002). Stail kepimpinan pentadbir sekolah menengah di daerah Kubang Pasu. Unpublished Master's thesis. Universiti Utara Malaysia (Northern University of Malaysia). 
Northouse, P. G. (2004). Leadership: Theory and practice (3rd ed.). California: SAGE.

Nursuhaila, G. (2007). Tahap amalan kepimpinan transformasional dalam kalangan pengetua sekolah menengah Bandar Tangkak. Unpublished Master's thesis. Universiti Teknologi Malaysia (Malaysian University of Technology).

Ogawa, R. T. (2005). Leadership as social construct. In F. W. English (Ed.), The SAGE Handbook of Educational Leadership: Advances in Theory, Research and Practice. California: SAGE.

Onwuegbuzie, A. J., \& Collins, K. M. T. (2007). A typology of mixed methods sampling designs in social science research. The Qualitative Report, 12(2), pp. 281 - 316.

Oshagbemi, T., \& Gill, R. (2004). Differences in leadership behaviour across hierarchical levels in UK organisations. The Leadership \& Organization Development Journal, 25(1), pp. 93 - 106.

Oshagbemi, T., \& Ocholi, S. A. (2005). Leadership styles and behaviour profiles of managers. Journal of Management Development, 25(8), pp. 748 - 762.

Pearson, C., \& Entrekin, L. (2001). Cross-cultural value sets of Asian managers: the comparative cases of Hong Kong, Malaysia and Singapore. Asia Pacific Journal of Human Resources, 39(1), pp. 79 - 92.

Podsakoff, P. M., MacKenzie, S. B., Moorman, R. H., \& Fetter, R. (1990). Transformational leaders behaviours and their effects on followers' trust in leader, satisfaction and organizational citizenship behaviors. Leadership Quarterly, 1(2), pp. 107 - 142.

Popper, M., \& Zakkai, E. (1994). Transactional, charismatic and transformational leadership: conditions conducive to their predominance. Leadership \& Organization Development Journal, 15(6), pp. 3 - 7.

Pounder, J. S. (2001). "New leadership" and university organisational effectiveness: exploring the relationship. Leadership \& Organization Development Journal, 22(6), pp. 281 - 290.

Price, T. L. (2008). Transformational leadership. In A. Marturano \& J. Gosling (Eds.), Leadership: The Key Concepts. New York: Routledge.

Prime Minister's Department (1999). Regulation for the Conduct of Research in Malaysia. Retrieved 20 February 2010. from

http://www.epu.gov.my/c/document library/get file?p I id=17621\&folderld=44646\&nam e=DLFE-2735.pdf.

Rad, A. M. M., \& Yarmohammadian, M. H. (2006). A study of relationship between managers' leadership style and employees' job satisfaction. Leadership in Health Services, 19(2), pp. 11-28.

Rafferty, A. E., \& Griffin, M. A. (2004). Dimensions of transformational leadership: conceptual and empirical extensions. The Leadership Quarterly, 15 (2004), pp. 329 - 354.

Riches, C. (1997). Managing for people and performance. In T. Bush \& D. Middlewood (Eds.), Managing People in Education. London: Paul Chapman Publishing Limited.

Rouleau, L., \& Balogun, J. (2008). Exploring middle managers' stretegic sensemaking role through practical knowledge. Les Cahiers De Recherche du GePS, 2(7), pp. 2 - 54.

Sandelowski, M., Voils, C. I., \& Knafl, G. (2009). On quantitizing. Journal of Mixed Methods Research, 3(3), pp. $208-222$.

Sanga, K. F., \& Walker, K. D. (2005). Apem Moa Soloman Island leadership. Wellington: He Parekereke, Institute for Research and Development in Maori and Pacific Education.

Shea, C. M. (1999). The effect of leadership style on performance improvement on a manufacturing task. The Journal of Business, 72(3), 407-422.

Singh, K. (2007). Quantitative social research methods. New Delhi: SAGE Publications Inc.

Stewart, J. (2006). Transformational Leadership: An Evolving Concept Examined through the Works of Burns, Bass, Avolio, and Leithwood Canadian Journal of Educational Administration and Policy Issue 54, pp. 1 - 29. 
Suruhanjaya Perkhidmatan Awam (2010). Position: Administrative and Diplomatic Officer Retrieved 14 May, 2010, from

http://www.spa.gov.my/portal/page? pageid=93,82227\& dad=portal\& schema=PORTAL

Swift, B. (2006). Data analysis. In R. Sapsford \& V. Jupp (Eds.), Data Collection and Analysis. London: SAGE Publication Ltd.

Tashakkori, A., \& Creswell, J. W. (2007). Exploring the nature of research questions in mixed methods research. Journal of Mixed Methods Research, 1(3), pp. 207 - 211.

Tavanti, M. (2008). Transactional leadership. In A. Marturano \& J. Gosling (Eds.), Leadership: The Key Concepts. New York: Routledge.

Teddlie, C. (2005). Methodological issues related to causal studies of leadership: a mixed methods perspective from the USA. Educational Management Administration \& Leadership, 33(2), pp. $211-227$.

Teddlie, C., \& Fen, Y. (2007). Mixed methods sampling: a typology with examples. Journal of Mixed Methods Research, 1(1), pp. 77 - 100.

Teddlie, C., \& Tashakkori, A. (2003). Major issues and controversies in the use of mixed methods in the social and behavioral sciences. In A. Tashakkori \& C. Teddlie (Eds.), Handbook of Mixed Methods in Social and Behavioral Research. Thousand Oaks, CA: SAGE Publications Ltd.

Tichy, N. M., \& Devanna, M. A. (1986). The transformational leader. New York: John Wiley \& Sons.

UTUSAN (2007). Cuepecs sokong tolak kemasukan PTD ke JPN. Utusan Malaysia. Retrieved 4 March 2010, from

http://www.utusan.com.my/utusan/info.asp?y=2007\&dt=0403\&pub=Utusan Malaysia\&se $\mathrm{c}=$ Dalam Negeri\&pg=dn 04.htm

Van Wart, M. (2003). Public-sector leadership theory: an assessment. Public Administration Review, 63(2), pp. $214-228$.

Vigoda-Gadot, E. (2007). Leadership style, organizational politics, and employees' performance: an empirical examination of two competing models. Personnel Review, 36(5), pp. 661 - 683.

Viitanen, E., \& Konu, A. (2009). Leadership style profiles of middle-level managers in social and health care. Leadership in Health Services, 22(2), pp. 108-120.

Wan Faridah Akmal, W. I., Noor Azmi, M., \& Ishak, M. S. (2002). Kepimpinan transaksi/transformasi dan ciri kerja profesional teknologi maklumat sektor awam Malaysia. Jurnal Teknologi, $37(\mathrm{E})$, pp. $57-70$.

Whitsett, G. (2007). Perceptions of leadership styles of department chairs. College Student Journal, 41(2), pp. 274-286.

Wilson, M., \& Sapsford, R. (2006). Asking questions. In R. Sapsford \& V. Jupp (Eds.), Data Collection and Analysis. London: SAGE Publications Ltd.

Winkler, I. (2010). Contemporary leadership theories: Enhancing the complexity, subjectivity and dynamic of leadership Berlin: Physica-Verlag.

Wood, G. J., \& Jogulu, U. D. (2006). Malaysian and Australian male and female middle managers: a cros-cultural comparison of workplace attitudes, aspirations for promotion and self-rated leadership styles. International Journal of Knowledge, Culture and Change Management, 6(3), pp. $109-119$.

Wooldridge, B., Schmid, T., \& Floyd, S. W. (2008). The middle management perspective on strategy process: contributions, synthesis and future research. Journal of Management, 34(6 December), pp. 1190 - 1221.

Wright, G. (2007). Leading the teaching and learning - a study of transformational leadership in secondary schools facing challenging circumstances. Unpublished Education Doctorate thesis. University of Hull.

Yahya, D. (2009). Korelasi dan pengaruh kompetensi emosi terhadap kepimpinan sekolah: perbandingan antara sekolah berkesan dengan sekolah kurang berkesan. Unpublished Doctoral thesis. Malaya University. 
Yukl, G. (1998). Leadership in organizations (4 ed.). New Jersey: Prentice hall.

Yukl, G. (1999a). An evaluation of conceptual weaknesses in transformational and charismatic leadership theories. Leadership Quarterly, 10(2), pp. 285 - 305.

Yukl, G. (1999b). An evaluative essay on current conceptions of effective leadership. European Journal of Work and Organizational Psychology, 8(1), pp. 33 - 48.

Yukl, G., \& Lepsinger, R. (2004). Flexible leadership: creating value by balancing multiple challenges and choices San Francisco: Josey-Bass An Imprint of Wiley.

Zagorsek, H., Dimovski, V., \& Skerlavaj, M. (2009). Transactional and transformational leadership impacts on organizational learning. Journal for East European Management Studies, 14(2), pp. $145-165$.

Zaidi, A. (2005). Leadership behaviours of heads of schools and departments in Australian and Pakistani Universities. Unpublished Master's thesis. University of New South Wales, Australia.

Zaleznik, A. (1990). The Leadership Gap. The Executive, 4(1), 7-22.

Zaleznik, A. (1992). Managers and leaders: are they different. Harvard Business Review, 70(2 March-April), pp. 126 - 135. 